\title{
Salt Scaling of Pervious Concrete: Optimizing A Test Method and The Effects of Different DEICERS
}

\author{
by \\ Chehong Tsang \\ B.Eng., Ryerson University, Ontario, Canada, 2014
}

\author{
A thesis \\ presented to Ryerson University \\ in partial fulfillment of the \\ requirements for the degree of \\ Master of Applied Science \\ in the Program of \\ Civil Engineering
}

Toronto, Ontario, Canada, 2016

(C)Chehong Tsang 2016 


\section{Author's Declaration}

I hereby declare that I am the sole author of this thesis. This is a true copy of the thesis, including any required final revisions, as accepted by my examiners.

I authorize Ryerson University to lend this thesis to other institutions or individuals for the purpose of scholarly research.

I further authorize Ryerson University to reproduce this thesis by photocopying or by other

means, in total or in part, at the request of other institutions or individuals for the purpose of scholarly research.

I understand that my thesis may be made electronically available to the public. 


\title{
Salt Scaling of Pervious Concrete: Optimizing a Test Method and The Effects of Different Deicers
}

\author{
Chehong Tsang \\ Master of Applied Science 2016 \\ Civil Engineering \\ Ryerson University
}

\begin{abstract}
There is currently no standard test method for evaluating the resistance of pervious concrete to salt scaling. In this study, a number of test methods were evaluated to determine an effective test method. A number of parameters were varied, including sample geometry, cycle length, level of submersion, and the effects of various deicers. The optimum cycle length was found to be 24 hours with the submersion of the bottom $10 \mathrm{~mm}$ of the pervious concrete samples made with $14 \mathrm{~mm}$ aggregate. Cylinder samples with a diameter of $100 \mathrm{~mm}$ and height of $150 \mathrm{~mm}$ are recommended as they provide consistent results. Using these samples, a mass loss failure criterion of 3 to $5 \%$ is proposed. The deicers that caused the most damage are $\mathrm{NaCl}, \mathrm{CaCl}_{2}$, and urea, followed by $\mathrm{MgCl}_{2}, \mathrm{~K}$ acetate, $\mathrm{Na}$ acetate, and CMA. More testing is needed to validate the effects of different deicers.
\end{abstract}




\section{Acknowledgements}

I would first like to thank Dr. Medhat Shehata for his support and guidance throughout my time at Ryerson University. His dedication is what motivated me to start and finish this degree. It has been a pleasure working with him on this research project and I hope I will have more opportunities to work with him in the future.

I would also like to thank my closest friend, Gregory Richards for all his help and support for this research and for putting up with me from undergrad till now.

Special thanks to our wonderful technical staff Min Yao, Domenic Valle, Robin Luong, and Nidal Jaalouk for all of their help in completing this research.

Funding of this research project was provided by the Government of Ontario through the Ontario Centre of Excellence. The authors acknowledge the financial support of the Government of Ontario and the financial and in-kind support of the industry partner Lafarge Canada. The authors acknowledge the support of Mahmoud Al-Fayez and Jimmy Xu, Graduate Students at Ryerson University, for their help with parts of the experimental program. 


\section{Table of Contents}

$\begin{array}{ll}\text { Declaration } & \text { ii }\end{array}$

$\begin{array}{ll}\text { Abstract } & \text { iii }\end{array}$

Acknowledgements $\quad$ iv

List of Tables $\quad$ viii

$\begin{array}{ll}\text { List of Figures } & \text { ix }\end{array}$

List of Appendices $\quad$ xiii

1 Introduction $\quad 1$

1.1 Research Significance . . . . . . . . . . . . . . . . . . . . . . 2

1.2 Research Objectives and Scope . . . . . . . . . . . . . . . . 2

2 Literature Review $\quad 4$

2.1 Pervious Concrete . . . . . . . . . . . . . . . . . . . 4

2.1 .1 Applications . . . . . . . . . . . . . . . . . 4

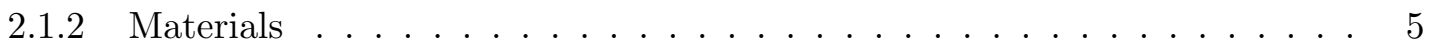

$2.1 .3 \quad$ Hardened Properties . . . . . . . . . . . . . . . . . . . 6

2.2 Frost Damage . . . . . . . . . . . . . . . . . . 7 


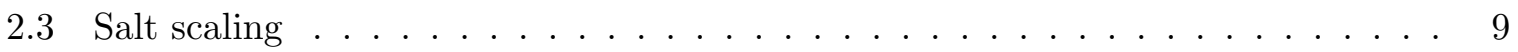

2.3 .1 Conventional Concrete . . . . . . . . . . . . . . . . . 9

2.3 .2 Pervious Concrete $\ldots \ldots \ldots \ldots \ldots \ldots \ldots \ldots$

2.3 .3 Mechanisms of Damage Due to Salt Scaling . . . . . . . . . . . . . 21

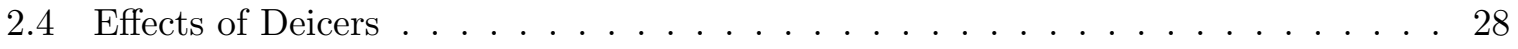

3 Materials and Experimental Methods 33

3.1 Materials . . . . . . . . . . . . . . . . . . 33

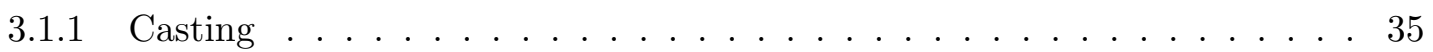

3.1 .2 Demoulding Cylinder Samples _ . . . . . . . . . . . . . 36

3.1.3 Sample Preparation Prior to Testing . . . . . . . . . . . . . . . . 37

3.2 Compressive Strength Testing . . . . . . . . . . . . . . . . . 38

3.3 Freezing/Thawing Equipment $\ldots \ldots \ldots \ldots \ldots$

3.4 Salt Scaling Test Procedures . . . . . . . . . . . . . . . . . . 40

3.4.1 12-hour Cycle Under Drained and Partially Saturated Condition . . . . . 40

3.4.2 16-hour Cycle Under Partially Saturated Condition . . . . . . . . . . . 42

3.4.3 24-hour Cycle Under Drained and Partially Saturated Condition . . . . . 44

3.4 .4 Effects of Different Deicers _. . . . . . . . . . . . . 48

3.5 Summary of Test Methods . . . . . . . . . . . . . . . . . . 49

4 Results and Analysis $\quad 51$

4.1 Statistics and Interpretation of Results . . . . . . . . . . . . . . 51

4.2 Drained 12 -hour Cycle . . . . . . . . . . . . . . . . . . 52

4.3 Partially Saturated 12 -hour Cycle . . . . . . . . . . . . . . . . . 56

4.4 Partially Saturated 16 -hour Cycle . . . . . . . . . . . . . . . . . 56

4.5 Drained and Partially Saturated 24 -hour Cycle _ . . . . . . . . . . . . . 59

4.6 Partially Saturated Automatic 24-hour Cycle _ . . . . . . . . . . . . . . 64

4.7 Influence of Deicer type $\ldots \ldots \ldots \ldots \ldots \ldots$ 
4.7 .1 Summary of Effects . . . . . . . . . . . . . . . 71

4.7 .2 Progression of Damage . . . . . . . . . . . . . . . 73

4.7 .3 Effects at Elevated Temperatures . . . . . . . . . . . . 75

5 Summary and Discussion $\quad 79$

5.1 Sample Geometry . . . . . . . . . . . . . . . . . . . . . . 79

5.2 Depth of Submersion . . . . . . . . . . . . . . . . . . 80

5.3 Automatic and Manual Cycles . . . . . . . . . . . . . . . . 81

5.4 Cycle Length . . . . . . . . . . . . . . . . . . . . . . . . . 81

5.5 Effects of Curing, Drying, and the Addition of Fibres . . . . . . . . . . 82

5.6 Different Deicers . . . . . . . . . . . . . . . . . . . 82

5.7 Failure Criteria . . . . . . . . . . . . . . . . . 85

$\begin{array}{llr}6 & \text { Conclusion } & 87\end{array}$

$\begin{array}{lr}\text { Appendices } & 89\end{array}$

$\begin{array}{ll}\text { References } & 107\end{array}$ 


\section{List of Tables}

3.1 Cementing material chemical composition. . . . . . . . . . . . . . . . . 34

3.2 General mix properties. . . . . . . . . . . . . . . . . . 34

3.3 Coarse aggregate and PVA fibre properties. . . . . . . . . . . . . . . 35

3.4 Naming of each test method. . . . . . . . . . . . . . . . . . 50

3.5 Number of samples and deicers used. . . . . . . . . . . . . . . . 50

4.1 T-test of the mass loss of all deicers compared to water after 15 cycles (24-M-10). F-test was first performed to determine if the variance of samples are equal to the variance of water. . . . . . . . . . . . . . . . 74

B.1 F-Test for $100 \mathrm{~mm}$ cubes using the 12 -A-00 method. . . . . . . . . . . . 96

B.2 t-Test for $100 \mathrm{~mm}$ cubes using the 12 -A-00 method. . . . . . . . . . . . . 96

B.3 F-Test for cylinders using the $12-\mathrm{A}-00$ method. . . . . . . . . . . . . . . 97

B.4 t-Test for cylinders using the $12-\mathrm{A}-00$ method. . . . . . . . . . . . . . 97

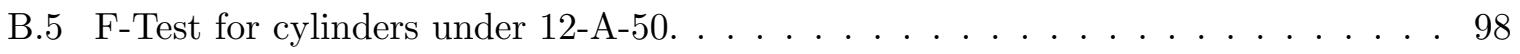

B.6 t-Test for cylinders using the $12-\mathrm{A}-50$ method. . . . . . . . . . . . . . 98

B.7 F-Test for cylinders using the 15-A-75 method. . . . . . . . . . . . . . 99

B.8 t-Test for cylinders using the 16-A-75 method. . . . . . . . . . . . . . . 99 


\section{List of Figures}

2.1 Relationship between air content and 28-day compressive strength (Meininger

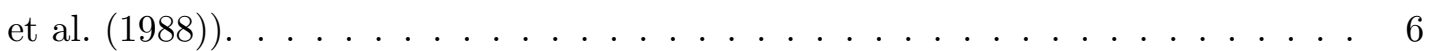

2.2 Comparison of salt scaling damage at different freezing rates and time spent at minimum temperature (Jacobsen et al. (1997)) . . . . . . . . . . . . 13

2.3 Mass loss comparison of pervious concrete samples exposed to freeze-thaw cycles in different deicers $($ Cutler et al. (2010)) . . . . . . . . . . . . . . . 19

2.4 Schematic examples of temperature changes on concrete surface with and without deicing salts (Harnik et al. (1980)) . . . . . . . . . . . . . . 22

2.5 Phase diagram for a sodium chloride solution. (Clark (2005)) . . . . . . . . 23

2.6 Graph showing the lowering point of water as the concrete pore sizes decrease (Harnik et al. (1980)). . . . . . . . . . . . . . . . . 24

2.7 A schematic representation of the glue spall mechanism. Adapted from Valenza

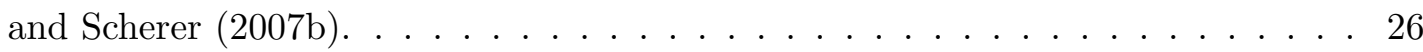

2.8 Schematic showing the penetration of ice into the concrete layer and bifurcating at a depth within the concrete (Sun and Scherer (2010)). . . . . . . . . . 27

2.9 Schematic explaining the brine rejection mechanism (Yener (2015)). . . . . . . 28

2.10 Concrete surfaces at 100 freeze thaw cycles. Left: Pretreated with $23 \% \mathrm{NaCl}$ and tested with $3 \% \mathrm{NaCl}$. Right: Pretreated with $22 \% \mathrm{CaCl}_{2}$ and tested with $4 \% \mathrm{CaCl}_{2}$. Adapted from Dam et al. (2008). . . . . . . . . . . . 31 
3.1 Grain size distribution curve of $14 \mathrm{~mm}$ limestone. . . . . . . . . . . . . . . . 34

3.2 Various sample geometries used in the different salt scaling tests. (a) $100 \mathrm{~mm}$ cube, (b) $150 \mathrm{~mm}$ cube, (c) $100 \mathrm{~mm}$ diameter by $150 \mathrm{~mm}$ height cylinder. . . . . 35

3.3 (a) Mortar disc (b) Disc placed at the bottom of cylinder mould prior to casting. 37

3.4 The three testing chamber used for all the experiments . . . . . . . . . . . 39

3.5 12-hour temperature cycle . . . . . . . . . . . . . . . . 41

3.6 Process of preparing cylinder moulds for the 16-hour partially saturated method.

(a) Sand filled mould. (b) Mould expanding due to loading. (c) Sample in completed mould. . . . . . . . . . . . . . . . . . . . . . 43

3.7 16-hour temperature cycle . . . . . . . . . . . . . . . . . 44

3.8 Typical air temperature profile of the freezer; Initial peak caused by opening of the door; Second peak is due to the defrost system of the freezer. . . . . . . . 45

3.9 Containers filled with various levels of deicing solution. . . . . . . . . . . . . 45

3.10 Typical air temperature profile of the Caron environmental chamber; peak is due to defrost system of the machine . . . . . . . . . . . . 47

4.1 Compressive strength changes under the $12-\mathrm{A}-00$ method. . . . . . . . . . . . . 54

4.2 Comparison of compressive strength variation within each set of samples under the $12-\mathrm{A}-00$ method. . . . . . . . . . . . . . . . . 54

4.3 Average mass loss for both sets of samples under 12-A-00 method. (a) A large scale is used to illustrate the relatively low levels of damage. (b) Magnification of the previous plot to illustrate the difference between the sample shapes. . . . . 55

4.4 Comparison of the variation of mass loss within each set of samples under the 12-A-00 method. . . . . . . . . . . . . . . . . . 55

4.5 Compressive strength changes under the 12-A-50 method. (a) An increase in compressive strength. (b) Box and whisker plot illustrating the variability of the

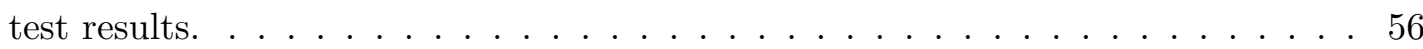


4.6 Damage to samples subjected to the 16-A-75 test. (a) Cement stripped off the surface of an aggregate. (b) A cylinder sample split in half after 54 cycles. . . . . 57

4.7 Compressive strength changes under the 16-A-75 method. (a) A reduction in compressive strength. (b) Box and whisker plot illustrating the variability of the

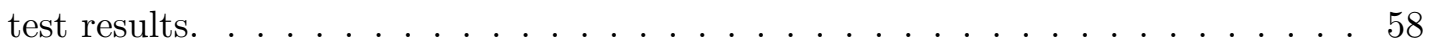

4.8 Average mass loss for cylinders under the 16-A-75 method up to 48 cycles. . . . . 58

4.9 Comparison of average mass loss for different shapes and levels of saturation under the 24-hour manual cycle using $\mathrm{CaCl}_{2}$ solution. . . . . . . . . . . . . . . 60

4.10 Mass loss comparison of samples under the 24-hour manual method with error

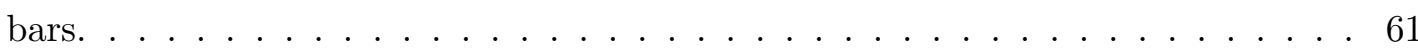

4.11 Mass loss of individual samples tested under the 24-hour manual method. . . . . 62

4.12 Box plots showing the variability of mass loss within each set of samples under the 24 -hour manual method. . . . . . . . . . . . . . . . 63

4.13 A large intact piece of pervious concrete broken off from the bulk of the sample while being tested with the $24-\mathrm{M}-50$ method. . . . . . . . . . . . . . 64

4.14 Comparison of deicing solution temperature. Temperature spike likely due to freezer defrost system. . . . . . . . . . . . . . . . 65

4.15 Comparison of average mass loss for samples exposed to different deicers using either the 24-M-10 (manual) or the 24-A-10 (auto) methods. . . . . . . . . . . 66

4.16 Comparison of mass loss of samples exposed to different deicers under either 24-M-10 (M) at 50 cycles or 24-A-10 (A) at various cycles. . . . . . . . . . 67

4.17 Effect of a drying period and the addition of fibres tested using the 24-A-10 method in $\mathrm{CaCl}_{2} \ldots \ldots \ldots \ldots \ldots \ldots \ldots$

4.18 Mass loss of comparison of samples dried for one week prior to testing and samples with the addition of fibres. . . . . . . . . . . . . . 70

4.19 Average mass loss comparison of samples exposed to different deicers under (a) the $24-\mathrm{M}-10$ method and (b) the $24-\mathrm{A}-10$ method. . . . . . . . . . . . . . 72 
4.20 Output of Tukey-Kramer analysis generated by MATLAB indicating a significant difference between the average mass loss of $\mathrm{NaCl}$ compared to the other deicers at 15 cycles (24-M-10). An overlap of the comparison intervals (horizontal lines) indicates that no significant difference exists between the two deicers. . . . . . . 74

4.21 Output of Tukey-Kramer analysis generated by MATLAB illustrating the difference between the average mass loss of different deicers at 30 cycles. An overlap indicates that no difference is present. . . . . . . . . . . 75

4.22 Box plots comparing the mass loss of samples exposed to different deicers under

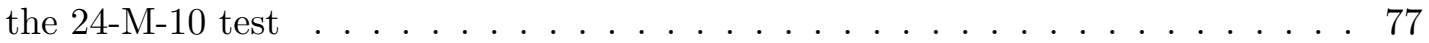

4.23 Expansion of the cement paste of pervious concrete after submerging samples in solution for 4 months at $38{ }^{\circ} \mathrm{C} \ldots \ldots \ldots \ldots \ldots$

5.1 Various levels of mass loss of different samples . . . . . . . . . . . . . . 86

A.1 24-M-10 test method in water. . . . . . . . . . . . . . . 90

A.2 24-M-10 test method in $\mathrm{CaCl}_{2}$ with $150 \mathrm{~mm}$ cube samples. . . . . . . . . . . 91

A.3 24-M-10 test method in $\mathrm{CaCl}_{2}$ with cylinder samples . . . . . . . . . . . . . 92

A.4 24-M-10 test method in urea. . . . . . . . . . . . . . . 93

A.5 24-M-10 method in $\mathrm{NaCl} . \ldots \ldots \ldots \ldots \ldots$ 


\section{List of Appendices}

$\begin{array}{lr}\text { A Salt Scaling Photos } & 89\end{array}$

$\begin{array}{ll}\text { B Statistical Analysis } & 95\end{array}$ 


\section{Chapter 1}

\section{Introduction}

As cities continue to expand and develop, the area of impervious cover increases. In developed cities, much of the land is covered by roads, parking lots, driveways, sidewalks, and other pavement surfaces. The use of conventional concrete pavements contributes to an increase in stormwater runoff, leading to potential flooding and pollution of waterways. As conventional concrete prevents the infiltration of water into the soil, the water must be diverted to a collection system. With larger cities comes an increased need for more expansive collection systems to accommodate the increased runoff.

Pervious concrete is one method of managing runoff to reduce the need for larger stormwater facilities. The use of pervious pavements mimics pre-development conditions as it allows the water to infiltrate into the ground. Pervious concrete is also able to improve the quality of water by removing contaminants such as oils and suspended solids (ACI Committee 522, 2010).

Pervious concrete in cold climates is subjected to cycles of freezing and thawing as well as exposure to deicing salts. The combination of both could lead to a phenomenon known as salt scaling that has been observed and studied for many years in conventional concrete (Verbeck and 
Klieger, 1956). As salt scaling can also occur in pervious concrete (Anderson, Dewoolkar, and Suozzo, 2013), its use in cold climates may be limited due to the limited amount of information on its long term durability.

\subsection{Research Significance}

The environmentally beneficial aspects of pervious concrete makes its use desirable. Pervious concrete used in cold climates will inevitably be exposed to deicing salts. As this will likely reduce the service life of the pavement, it is important to determine its resistance to salt scaling before it is put in place and decide on the most suitable salt to be used as a deicer. The information generated by this study can be used to aid in the development of a standard testing protocol to evaluate the salt scaling durability of pervious concrete as one currently does not exist.

\section{$1.2 \quad$ Research Objectives and Scope}

The purpose of this research was to optimize a testing method to evaluate the resistance of pervious concrete to deterioration caused by deicing salts. Currently, a standard test method exists for evaluating salt scaling in conventional concrete but not for pervious concrete.

This study evaluated a number of different test methods for salt scaling of pervious concrete. The results from each phase of the study was used in developing and refining various parameters of the subsequent test procedures.

The first parameter studied was the method of evaluating the damage caused by salt scaling. Initially, the damage was determined through the loss of compressive strength, mass loss, along with a visual inspection of the deterioration. 
Sample shape was also taken into consideration. The study aimed to determined whether there is a practical difference in results caused by a difference in sample shape or size.

The duration of each cycle, and the length of each test was also studied. The length of each cycle should be sufficiently long in order to cause measurable damage in order for it to better differentiate between different parameters (mix design, deicer type, deicer concentration). For example, too little damage would result in an inability to differentiate between a resilient concrete mix and a weak one.

The testing was also used to determine the relative levels of damage caused by different deicers at the same concentration. Finally, the effects of long term exposure to different deicers at elevated temperatures was also considered. This was done to examine the effects of salt on the concrete without the influence of freezing temperature or cycles of freezing/thawing. 


\section{Chapter 2}

\section{Literature Review}

\subsection{Pervious Concrete}

Pervious concrete is a type of concrete with a system of interconnected pores allowing water to rapidly drain through. Pervious concrete itself is made up of coarse aggregate that is coated by a thin layer of cement paste, holding the system together. While the compressive strength, void content, and permeability tend to vary depending on the mix design and preparation methods, they are generally correlated with one another.

\subsubsection{Applications}

The most obvious application of pervious concrete is in any situation where drainage is desirable. Many pavements, such as parking lots, greenhouse floors, swimming pool decks, and parks can be made using pervious concrete (ACI Committee 522, 2010). The conversion of these pavements from conventional concrete to pervious concrete will reduce the amount of stormwater runoff while also recharging groundwater as it allows the rainwater to infiltrate into 
the ground (Yang and Jiang, 2003). Additionally, pervious concrete is able to improve water quality by filtering out contaminants (ACI Committee 522, 2010).

However, due to its low strength, use of pervious concrete is usually limited to pavements subjected only to light traffic. Pervious concrete's properties are particularly sensitive to the water content, which can change drastically if it is not closely monitored (ACI Committee 522, 2010). The open structure of pervious concrete will also need to be maintained as the voids can become clogged with debris, thereby reducing its permeability (Mata and Leming, 2012).

\subsubsection{Materials}

Pervious concrete generally consists of water, admixtures, coarse aggregate, cementitious material, and little to no fine aggregate. Pervious concrete can be made with a wide range of materials that are generally also used in conventional concrete. The coarse aggregates used in pervious concrete tend to be single-sized or narrow-graded to help ensure the connectivity of the pore system (ACI Committee 522, 2010). The use of fine aggregate tends to be limited due to the effect of reducing the porosity and therefore the permeability of the pervious concrete (ACI Committee 522, 2010). Cementitious material generally consists of portland cement, but can also include other supplementary cementing materials such as slag, fly ash, and silica fume (Yang, 2011; Anderson and Dewoolkar, 2015; Kevern, Wang, and Schaefer, 2008). Water reducing admixtures are often required since the water to cement ratio is often lowered to increase the strength of the concrete. 


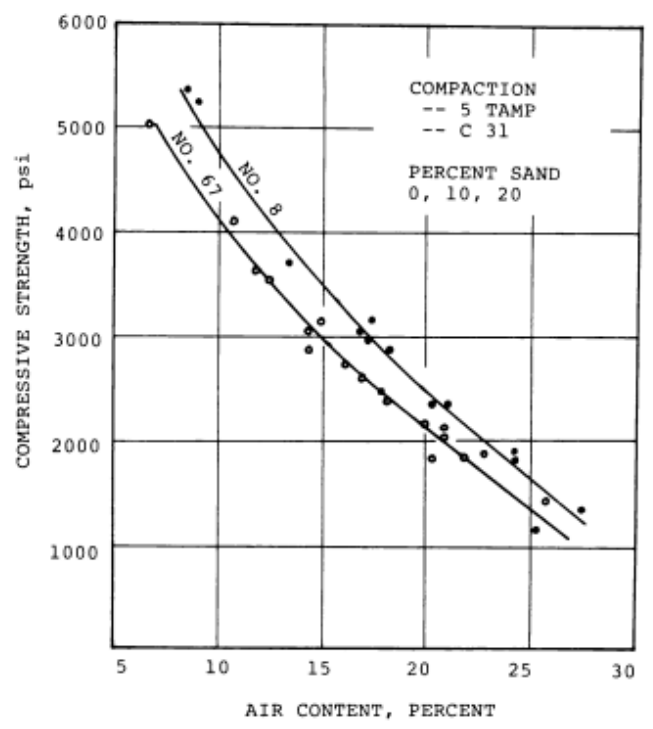

Figure 2.1: Relationship between air content and 28-day compressive strength (Meininger et al. (1988)).

\subsubsection{Hardened Properties}

\section{Compressive Strength}

The open nature of pervious concrete tends to result in compressive strengths lower than conventional concrete. The compressive strength of pervious concrete is largely dictated by the air content (Figure 2.1). The addition of fine aggregate tends to increase the compressive strength while reducing the void content (Meininger et al., 1988; Kevern et al., 2008). Typical compressive strengths can range from 2.8 to $28 \mathrm{MPa}$ (ACI Committee 522, 2010), although higher strengths are possible with continued development.

\section{Porosity and Permeability}

The permeability and porosity are highly correlated as an increased porosity will increase the probability of interconnected voids. Meininger et al. (1988) found that a minimum air void 
content of $15 \%$ is required for adequate flow. Typical percolation rates are generally in the range of 81 to $739 \mathrm{~L} / \mathrm{min} / \mathrm{m}^{2}$ (ACI Committee 522, 2010).

\subsection{Frost Damage}

Concrete pavements in cold climates will invariably be exposed to cyclic freezing and thawing. If the concrete is sufficiently saturated during these cycles, frost damage will likely occur and while it is well established that the use of entrained air is able to mitigate the damage, it is important to discuss the theories behind the mechanism of attack.

Concrete begins to suffer damage from freezing and thawing if it exceeds a critical degree of saturation (Fagerlund, 1973). This was initially explained by the crystallization pressure as ice expands upon freezing. The freezing point of water within the pores of the concrete is proportional to the size of the pores; the smaller the pore size in which the water is contained, the lower the freezing point (Harnik, Meier, and Rösli, 1980). Unfrozen water from the surrounding smaller pores would be drawn towards the growing body of ice (Fagerlund, 1993). As the body of ice continues to grow, the pressure exerted on the pore walls will be large enough to produce damage (Fagerlund, 1993).

Powers (1945) proposed the hydraulic pressure theory. The freezing of water on the concrete surface and in larger pores causes the unfrozen water to migrate further into the unsaturated regions of the concrete due to the expansion of water as it freezes. As the movement of water is impeded by the small size of the concrete pores, a hydraulic pressure in generated, subsequent freeze thaw cycles will increase the depth of the saturated region. It was observed that concrete fully saturated with water through the use of a vacuum was unable to withstand the damage caused by freezing. While a concrete that appeared to be saturated (without the use of a vacuum) did not fail on first freeze, but rather after repeated cycles of freezing and thawing. 
This is explained by the subsequent increases of saturation following each cycle. The use of entrained air would provide space for the water to flow into. Furthermore, the distance between air voids would be important as the destructive action of the proposed mechanism is due to the resistance to the movement of water (Powers, 1945). The critical spacing factor can vary depending on the concrete mix but has been reported to be 200 to $300 \mu \mathrm{m}$ (Fournier, Bérubé, and Vézina, 1987; Pigeon, Gagne, and Foy, 1987). As the spacing factor in general is proportional to the total air content, the durability of concrete against freeze thaw cycles is well correlated to the total air content (Nmai, 2006). Li, Pour-Ghaz, Castro, and Weiss (2012) note that above the critical degree of saturation, damage is inevitable even with entrained air.

To evaluate the resistance to frost damage of concrete, standard test methods such as the ASTM C666 (Standard Test Method for Resistance of Concrete to Rapid Freezing and Thawing) can be used. The method contains two procedures: procedure A, and procedure B. In procedure A, freezing and thawing is done while the samples are submerged in water. In procedure B, samples are frozen in air and thawed in water. The temperature cycles between 4 and $-18{ }^{\circ} \mathrm{C}$ taking between 2 to 5 hours to transition from one temperature to the other.

Frost damage in pervious concrete is dependent on the level of saturation of the cement paste even when procedure A is used (Yang, Brown, and Cheney, 2006). Vacuum saturated samples (with a higher degree of saturation) failed at a lower number of cycles than samples that were simply tested after curing in lime-saturated water for 28 days. This suggests that the formation of ice within the cement paste is more important than the formation of ice within the large voids of pervious concrete. However, there still appears to be a correlation between the porosity and the freeze thaw resistance (Kevern et al., 2008), meaning the bulk ice can still be responsible for damage in higher porosity, weaker pervious concrete mixes. 


\subsection{Salt scaling}

In cold climates, deicing chemicals are frequently applied to pavements in order to remove or prevent the buildup of ice. This is possible through a phenomenon known as freezing point depression. When water mixes with a deicing chemical (some frequently used deicers include $\mathrm{NaCl}$, and $\mathrm{CaCl}_{2}$ ), the freezing point of the resulting solution is lower than the freezing point of water. The extent of this lowering is dependent on the type of deicer, as well as the concentration; the higher the concentration, the lower freezing point of the solution.

While the use of deicing chemicals is beneficial, as it greatly increases the safety of roads and walkways, it can lead to a phenomenon known as salt scaling. It has been known for many years that the use of deicing chemicals can exacerbate the damage caused by freezing and thawing cycles to the surface of conventional concrete. The characteristics and proposed mechanisms of salt scaling for both conventional concrete and pervious concrete will be discussed here.

\subsubsection{Conventional Concrete}

Salt scaling damage in conventional concrete generally manifests on the top surface of the pavement. It is recognized by the progressive removal of chips or flakes of material (mainly binder) from the concrete surface, leaving behind holes resembling divots (Valenza and Scherer, 2007a). Although the loss of material itself is not a major structural concern, it can render the concrete more susceptible to the ingress of moisture (Ahani and Nokken, 2012).

As salt scaling damage in conventional concrete has been recognized for many years, there exists a number of standard testing methods for evaluating the resistance of concrete to salt scaling. One example that is used in many of the studies referenced in this section is the ASTM C672. This test replicates the conditions in field by pooling a deicing solution on the top surface of a concrete test slab. The deicing solution is maintained at a depth of $6 \mathrm{~mm}$. Each slab requires 
a surface area of at least $0.045 \mathrm{~m}^{2}$ and a depth of at least $75 \mathrm{~mm}$. Additionally, a minimum of two specimens are required for each test. While the method of curing and the type of deicer is specified, both can be changed if they are the parameters to be studied.

As previously mentioned, salt scaling can often be recognized by the removal of flakes of mortar. Generally, there is very little damage to the aggregate itself, the process is progressive, with more material breaking off with each successive freezing and thawing cycle.

While salt scaling has been studied for many years, the exact mechanism of damage is still a subject of debate. There are a number of parameters that have been studied to determine their influence on salt scaling of conventional concrete in order to help identify the underlying mechanism. The results of some of these studies are presented here as a preface to the following section which will discuss a number of theories proposed by different researchers over the years. It is important to note that these results should be interpreted with caution. The results of individual test slabs of the same mix tends to be quite variable. Additionally, even when slabs were cast by the same operator, testing at different labs showed high levels of variability (Bouzoubaa, Bilodeau, Fournier, Hooton, Gagne, and Jolin, 2008). The results can be hard to interpret at times due to the number of confounding variables including, but not limited to: curing time, curing type, compressive strength, surface strength, sorptivity, air content, and finish.

\section{Effect of Deicer Type and Concentration}

A moderate deicer concentration leads to the most severe salt scaling damage. The exact concentration varies slightly between the works of various researchers, ranging from approximately $2 \%$ to $5 \%$ by weight (Verbeck and Klieger, 1956; MacInnis and Whiting, 1979; Valenza and Scherer, 2007a; Liu and Hansen, 2016). Nonetheless, the common trend shows that the use of deicers in conjunction with freezing and thawing cycles results in more damage than freezing 
and thawing cycles alone. Additionally, the use of high concentrations of deicers, in the range of 8-10\% or more, results in a reduced amount of salt scaling. This counter intuitive property will be discussed in a later section under the mechanisms of salt scaling. Furthermore, this occurs regardless of the type of deicer that is used. Verbeck and Klieger (1956) experimented with four different deicers: $\mathrm{CaCl}_{2}, \mathrm{NaCl}$, urea, and ethyl alcohol, all with various concentrations and found that slabs exposed to solutions of 2 and $4 \%$ suffered a higher rate of scaling when compared to 0,8 , and $16 \%$.

The effects of potassium acetate on salt scaling had been studied by Wang, Nelsen, and Nixon (2006). It was found that potassium acetate had caused only minor scaling at a $13.6 \%$ concentration. By contrast, $\mathrm{NaCl}$ (at $13.3 \%$ ) and $\mathrm{CaCl}_{2}$ (at 9.5\%) exhibited more severe scaling under the same testing conditions.

\section{Effect of Air Entrainment}

The use of entrained air, already known to increase the freeze thaw durability of concrete, also helps to mitigate the damage caused by salt scaling (Verbeck and Klieger, 1956; Pigeon et al., 1996; Valenza and Scherer, 2007a). In order for air entrainment to be beneficial, the spacing factor should be less than $300 \mu \mathrm{m}$ (Fournier et al., 1987; Pigeon et al., 1987). Verbeck and Klieger (1956) compared the salt scaling on slabs with and without air entrainment and found that the damage to air entrained concrete at 200 cycles, was less than the damage to non air entrained concrete at 50 cycles. Klieger (1957) found that non air entrained concrete would suffer from severe scaling at anywhere from 5 to 83 cycles, while sufficiently cured, air entrained samples were able to withstand over 250 cycles with little to no damage. 


\section{Effect of Curing Type and Duration}

The effect of the curing method on the salt scaling resistance of concrete appears to vary significantly depending on the composition of the concrete mix. Afrani and Rogers (1994) found that curing using wet burlap covered with polyethylene improved the resistance when compared to curing in a moist room or using a curing compound. Ahani and Nokken (2012) found that curing compound decreased the salt scaling resistance of concrete mixes containing fly ash and slag, while increasing the resistance in concrete containing only portland cement. At the same time, a shortened curing period also showed varying results depending on the concrete mix. Gagné, Houehanou, Jolin, and Escaffit (2011) found that lengthening the curing time from 14 to 28 days greatly improved the salt scaling resistance, suggesting it was due to the reduced sorptivity. Klieger (1957) also noted an increase of salt scaling resistance with increased curing times. Additionally, the time required for samples to cure sufficiently (in the context of salt scaling) was reduced as the curing temperature was increased. Interestingly, curing at temperatures below freezing $\left(25^{\circ} \mathrm{F}\right)$ led to low levels of compressive strength, but samples had adequate resistance to salt scaling comparable to samples with much higher compressive (Klieger, 1957). Yang, Yang, and Zhu (2003) compared the effect of steam curing at different temperatures to samples cured in water at $20{ }^{\circ} \mathrm{C}$. Steam cured concrete was found to be less resistant to salt scaling, with decreasing resistance as the temperature increased.

\section{Effect of Cooling Rate and Duration}

At identical cooling and thawing rates, a longer time spent at the minimum temperature resulted in a greater amount of scaling (Jacobsen, Sther, and Sellevold, 1997). It is often difficult to compare only the effects of the cooling rate for freeze thaw cycles. By changing the cooling rate, the length of time spent below freezing temperatures is changed and this cannot be remedied without changing the total length of the cycle. In the study by Jacobsen et al. (1997), of 


\begin{tabular}{|c|c|c|c|c|c|c|c|}
\hline \multirow[t]{2}{*}{$\begin{array}{l}\text { No of cy. } \\
\text { pr day }\end{array}$} & $\begin{array}{c}\text { Cooling } \\
\text { rate }\end{array}$ & $\begin{array}{l}\text { Time at } \\
-18{ }^{\circ} \mathrm{C}\end{array}$ & $\begin{array}{l}\text { Time }< \\
-3{ }^{\circ} \mathrm{C}\end{array}$ & $\begin{array}{c}\text { Mix } \\
040-05\end{array}$ & $\begin{array}{c}\text { Mix } \\
040-05 \mathrm{~A}\end{array}$ & $\begin{array}{c}\text { Mix } \\
035.08\end{array}$ & $\begin{array}{c}\text { Mix } \\
037-00\end{array}$ \\
\hline & ${ }^{\circ} \mathrm{C} / \mathrm{h}$ & h & h & \multicolumn{4}{|c|}{ scaling $\left(\mathrm{kg} / \mathrm{m}^{2}\right)$} \\
\hline \multicolumn{8}{|c|}{ Reduced cooling rate, constant time at minimum temperature } \\
\hline $5^{*}$ & 12 & 0.07 & 2.39 & 0.34 & 0.17 & 0.22 & 0.30 \\
\hline $5(+7$ mths $)$ & 12 & 0.07 & 2.39 & 0.27 & 0.12 & & \\
\hline $3 \mathrm{~b}$ & 4.9 & 0.07 & 4.29 & & & 0.60 & 0.81 \\
\hline 2 & 2.8 & 0.07 & 6.69 & 1.25 & 0.13 & 0.90 & 1.20 \\
\hline \multicolumn{8}{|c|}{ Increased time at minimum temperature, constant rate of cooling } \\
\hline $5^{*}$ & 12 & 0.07 & 2.39 & 0.34 & 0.17 & 0.22 & 0.30 \\
\hline 3 a & 12 & 3.27 & 5.59 & 0.53 & 0.20 & 0.53 & 0.69 \\
\hline 1.5 & 12 & 11.27 & 13.59 & 0.83 & 0.19 & 1.14 & 0.99 \\
\hline
\end{tabular}

*: same series, reference cyle for comparing effect of coling rate and time at $-18^{\circ} \mathrm{C}$.

Figure 2.2: Comparison of salt scaling damage at different freezing rates and time spent at minimum temperature (Jacobsen et al. (1997)).

particular interest are the cycles with a total duration of eight hours. As seen in Figure 2.2, the time spent below $-3{ }^{\circ} \mathrm{C}$ and the time spent at the minimum temperature is longer for the 3a cycle where the rate of cooling is much higher than the $3 \mathrm{~b}$ cycle. Although cycle $3 \mathrm{a}$ would be expected to cause more damage based on the previous conclusion, the mass of scaled off material is higher for cycle $3 \mathrm{~b}$, suggesting that the slower cooling rate resulted in more damage.

\section{Effect of Surface Sealers}

As salt scaling damage in conventional concrete occurs on the surface, a number of researcher have evaluated the effectiveness of sealers. The use of sealers would prevent the absorption of water and prevent the subsequent damage caused by freezing and thawing. Pigeon et al. (1996) noted that the use of silanes and siloxane based sealers was not only ineffective, but rather detrimental to the concrete. Basheer and Cleland (2006) found that the use of silanes and siloxane based sealer to be quite effective when the depth of penetration of the sealer was 
high. Similar results with the use of sealers were reported by Liu and Hansen (2016).

\section{Effect of Supplementary Cementing Materials}

The influence of supplementary cementing materials on salt scaling has been tested by a number of researchers. It was found that the use of fly ash or slag would greatly increase the damage caused by salt scaling (Bouzoubaa et al., 2008, 2011; Boyd and Hooton, 2007; Nili and Zaheri, 2011; Ahani and Nokken, 2012; Gagné et al., 2011; Duos and Eggers, 1999; Afrani and Rogers, 1994; Chidiac and Panesar, 2008). The range of replacement varied from $15 \%$ up to 50\%, with higher levels replacements generally suffering more damage. However, Ahani and Nokken (2012) tested using a 35\% slag replacement, and found that the resistance to salt scaling was higher than the control. There are number of explanations for these observations offered by the different researchers. The use of slag may delay the setting time of the concrete and allow bleeding to occur after finishing had been completed (Afrani and Rogers, 1994). This explanation is feasible since the salt scaling resistance of the concrete is mainly governed by the surface properties, as the compressive strength was generally not found to be correlated with the scaling resistance (Duos and Eggers, 1999; Chidiac and Panesar, 2008; Bouzoubaa, Bilodeau, Fournier, Hooton, Gagne, and Jolin, 2011). Afrani and Rogers (1994) notes that when the bottom of the slabs were tested, they did not show any signs of scaling despite severe damage to the top surface. An alternate study by Gagné et al. (2011) suggested that sorptivity correlated well with the scaling resistance of concrete. In that study, the concrete made with fly ash or slag had a higher sorptivity and suffered more damage than the control. Steam curing concrete was also found to result in a surface of higher sorptivity (He, Long, and Xie, 2012) and a lower resistance to salt scaling (Yang et al., 2003). The use of $20 \%$ silica fume showed an increased resistance to salt scaling (Nili and Zaheri, 2011). The agrees well with Gagné et al. (2011) since the sorptivitiy of concrete containing silica fume is generally lower (Leung, Kim, Nadeem, Jaganathan, and Anwar, 2016; Turk, Karatas, and Gonen, 2013; Folagbade, 2012). 
Additionally, silica fume reduces bleeding of concrete which in turn can increase the strength of the surface layer. However, Boyd and Hooton (2007) and Seo, Jung, Kim, and Na (2016) tested the strength of the surface using the pull-off test and found no correlation between the strength and salt scaling resistance.

\section{Effect of Carbonation}

Carbonation in concrete is generally a result of exposure to carbon dioxide $\left(\mathrm{CO}_{2}\right)$ resulting in the formation of $\mathrm{CaCO}_{3}$ (Chang and Chen, 2006). Carbonation has been shown to reduce the sorptivity of ordinary Portland cement concrete (Dias, 2000), leading to an improved resistance to salt scaling (Utgenannt, 2002). However, Eguez Alava, De Belie, and De Schutter (2014) found that carbonation did not improve the salt scaling resistance of concrete.

Carbonation in concrete containing blast furnace slag results in a decrease in salt scaling resistance (Utgenannt, 2002; Eguez Alava et al., 2014). This is potentially due to the increase in porosity as a result of carbonation. $\mathrm{CO}_{2}$ normally reacts with $\mathrm{Ca}(\mathrm{OH})_{2}$ during the process of carbonation, which produces $\mathrm{CaCO}_{3}$, blocking the pores and reducing porosity of the concrete. Due to the reduced levels of $\mathrm{Ca}(\mathrm{OH})_{2}$ in concrete containing slag, other hydration products were decalcified which increases the porosity of the concrete as carbonation increases (Gruyaert, Van den Heede, and De Belie, 2013).

\subsubsection{Pervious Concrete}

Salt scaling in pervious concrete is a phenomenon that has been observed and studied by a number of researchers. However, currently there is no standard method for testing salt scaling of pervious concrete. While no standard method exists, a number of researchers adopted either their own method or used modified versions of the standard methods for conventional concrete. 
As this study compares and evaluates a number of different test methods for their effects on salt scaling of pervious concrete, the test methods used by other researchers will first be presented in this section.

\section{Salt Scaling Studies}

Cutler, Wang, Schaefer, and Kevern (2010) tested the salt scaling resistance of pervious concrete under both saturated and drained conditions. In the saturated condition, samples were completely submerged in solution during testing. In the drained test method, samples would be submerged initially, but the solution would be drained prior to freezing. The temperature varied between $10{ }^{\circ} \mathrm{C}$ and $-18{ }^{\circ} \mathrm{C}$ for both conditions. The change in temperature from the high end to the low end and vice versa took 2 hours each, without holding the temperature at either the maximum or minimum for any length of time, resulting in a total cycle length of 4 hours. Three different deicers were tested, each at a concentration of $9 \%$, along with a distilled water control. The deicers tested were calcium chloride $\left(\mathrm{CaCl}_{2}\right)$, sodium chloride $(\mathrm{NaCl})$, and calcium magnesium acetate (CMA). Two types of pervious concrete mixtures were used for this test: one with the addition of a latex polymer admixture (referred to as latex-modified) and one without latex modification but included the use of a viscosity modifying admixture (referred to as nonlatex). All samples used for this study were $100 \mathrm{~mm}$ cubes cured for 28 days in a humidity room prior to testing. The level of damage was assessed by measuring the mass loss and the compressive strength at regular intervals. The earlier tests of the present study were based on the work by Cutler et al. (2010), the experimental details will be discussed in Chapter 3.

Anderson and Dewoolkar (2015) tested a longer cycle that ranged from $25{ }^{\circ} \mathrm{C}$ for 8 hours in laboratory air to $-20{ }^{\circ} \mathrm{C}$ for 16 hours in a freezer. Samples were submerged in solution during the last hour the of thawing phase and drained prior to freezing as would be the case, according 
to the authors, for a pervious concrete pavement under service conditions. $\mathrm{NaCl}$ was the only deicer that was studied and was tested at various concentrations $(2,4,8$, and $12 \%$ by weight) as well as a set of control samples exposed only to freezing and thawing in water without $\mathrm{NaCl}$. The effect of fly ash replacement was also studied at 0, 10, 20, and 30\% replacement. All samples used were cylinders with a diameter of $102 \mathrm{~mm}$ and a height of $203 \mathrm{~mm}$ compacted with a $10 \mathrm{~mm}$ tamping rod, in two layers with 25 strokes per layer. Samples were then moist cured for 28 days at $23{ }^{\circ} \mathrm{C}$. The mass loss of each sample was measured at the end of every 10 cycles until the samples were considered to have failed at $15 \%$ mass loss or when the sample reached 100 freeze-thaw cycles.

Yang (2011) conducted a study on the freeze-thaw durability of pervious concrete, however, a number of samples were frozen in a $2 \% \mathrm{NaCl}$ solution as well. The cycle used consisted of two cycles per day with three phases: a constant temperature phase (at the thawing temperature, a freezing phase, and a thawing phase (where the temperature transitioned between high and low). Each phase had a duration of four hours, resulting in a total cycle length of 12 hours. The maximum temperature of the cycle was $15{ }^{\circ} \mathrm{C}$ with a minimum temperature of $-12{ }^{\circ} \mathrm{C}$. The samples used were rectangular beams with dimensions of 76.2 x $101.6 \times 406.4 \mathrm{~mm}$ either air cured $\left(22{ }^{\circ} \mathrm{C}, 60 \% \mathrm{RH}\right)$ or water cured in lime-saturated water (at $22{ }^{\circ} \mathrm{C}$ ) for at least 60 days. The mass loss was measured every six to seven cycles with a mass loss of $30 \%$ being defined as failure.

Mata (2008) used the freeze-thaw cycle described in ASTM C672 with a freezing period of 16-18 hours at $-18{ }^{\circ} \mathrm{C}$ and a thawing period of $6-8$ hours at $23{ }^{\circ} \mathrm{C}$. The samples used were discs with $100 \mathrm{~mm}$ diameter and a thickness of $25 \mathrm{~mm}$, with some mixtures containing fine aggregate. Since a deicing solution cannot be ponded on the top surface as described in ASTM C672, the bottom half of the discs were submerged in a $1 \%$ by weight $\mathrm{CaCl}_{2}$ solution. Damage was assessed through mass loss and change in dynamic modulus. 


\section{Effects of Deicer Type and Concentration}

As mentioned previously, the test evaluating the effect of different deicers was performed by Cutler et al. (2010). The authors concluded that $\mathrm{CaCl}_{2}$ caused the most damage, followed by $\mathrm{NaCl}$, and $\mathrm{CMA}$ was found to cause the least amount of damage for both types of exposure conditions and for both types of mixtures. They also found that the saturated test caused more damage than the drained test.

These results should be interpreted with caution for a number of reasons, the mass loss was presented in mass (grams) of material rather than as a percentage of the total sample mass. This can be misleading as the original mass of each sample will not be the same and is particularly important as the mass loss was quite low for a number of samples tested. The results are also presented as an average without any indication on the variability between individual samples of the same mix exposed to the same conditions. Compressive strength results were equally as confusing; samples of the same mix had initial compressive strengths varying from 1700 psi to 3000 psi before any exposure to freeze thaw cycles. Finally, the drained test method with the nonlatex modified samples suffered perhaps only 3 or $4 \mathrm{~g}$ of damage despite being exposed to (in the results of the authors) the most damaging deicer. Nevertheless, the study was included in order to gain some information on the relative effects of different deicers on pervious concrete (Figure 2.3).

Anderson and Dewoolkar (2015) compared the effects of different $\mathrm{NaCl}$ concentrations on salt scaling of pervious concrete. The results indicated that a salt concentration of $4 \%$ and $8 \%$ caused the most salt scaling damage, with the damage resulting mainly from the scaling of the cement paste, with little damage to the aggregate. A pessimum concentration of $2-5 \%$ by weight, where this concentration causes more damage than any other concentration, has been reported in literature for salt scaling in conventional concrete (Verbeck and Klieger, 1956). It was also shown that the damage originated at the bottom of the sample where the level 


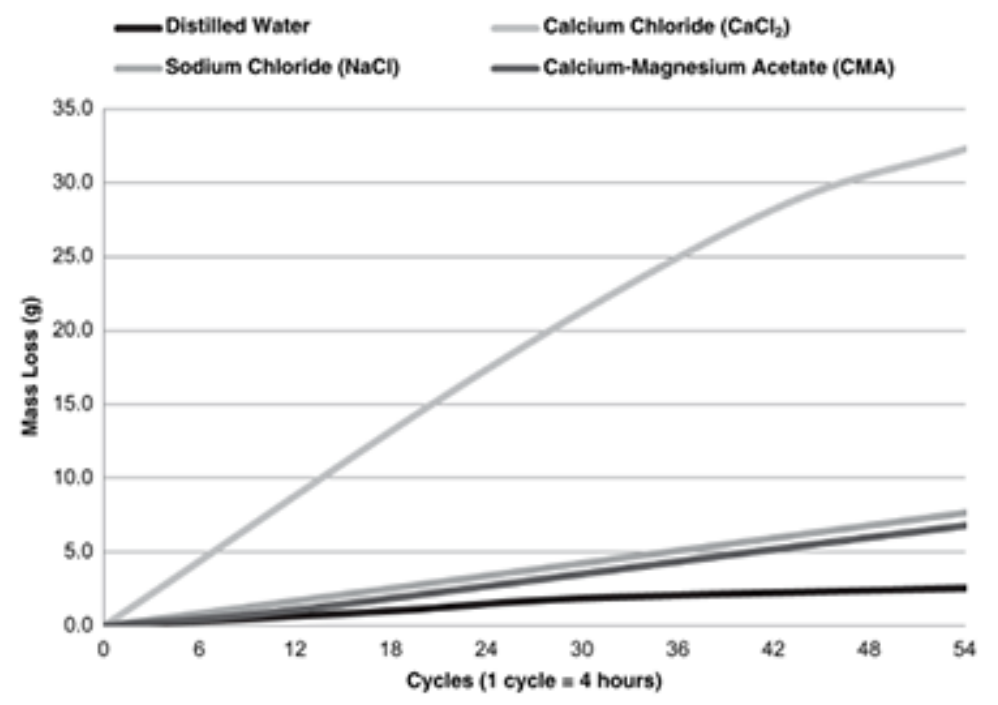

Figure 2.3: Mass loss comparison of pervious concrete samples exposed to freeze-thaw cycles in different deicers (Cutler et al. (2010)).

of saturation would be highest due to the draining of the solution. The solution would pull towards the bottom of the sample as it drains and would likely freeze before leaving the sample completely. At lower concentrations, and at $12 \% \mathrm{NaCl}$, very little damage was observed. It is likely that at high concentrations, the solution may take longer to freeze completely resulting in a reduced amount of time in a frozen state and allowing more of the solution to drain (Anderson and Dewoolkar, 2015).

\section{Effects of Supplementary Cementing Materials, Fine Aggregate, Air Entrainment, and Fibres}

Yang (2011) studied the effects of adding silica fume as well as the addition of fibres into a pervious concrete mix. With respect to salt scaling in pervious concrete, the addition of $5 \%$ silica fume found to increase the salt scaling resistance of water cured pervious concrete, particularly with mixtures with higher cement contents. Samples that were cured in air did not see this benefit. The use of $1.78 \mathrm{~kg} / \mathrm{m}^{3}$ of $38.1 \mathrm{~mm}$ polypropylene fibres also increased the 
number of cycles to failure for both air cured and water cured samples. A combination of both silica fume and fibres also appeared to increase the resistance in both air cured and water cured samples. An increased resistance from the addition of silica fume is attributed to the reduced permeability of the cement paste (Yang, 2011).

Mata (2008) had used pervious concrete mixtures with and without fine aggregate. Mixtures that did not contain any fine aggregate failed after eight cycles, even with high dosages of air entraining admixture. The mixtures containing fine aggregate had an average of $91 \%$ and $96 \%$ mass remaining, and an average of $81 \%$ and $85 \%$ remaining dynamic modulus after 40 cycles for the two mixture types containing fine aggregate. The second mixture contained twice the dosage of air entraining admixture as the first one. A higher dosage of air entraining admixture, along with a proportion of fine aggregate will allow samples to undergo a higher number of freeze-thaw cycles (Mata, 2008). However, it was noted that even with the higher dosage, microscopic analysis found that the quantity of air bubbles was below the recommended levels for conventional concrete. This was also reported by Vancura, MacDonald, and Khazanovich (2011) after surveying 29 in service pervious concrete pavements. Microscopic analysis of the cement paste in samples taken from these pavements found very little entrained air bubbles, despite the addition of air entraining admixtures to all the mixes.

Anderson and Dewoolkar (2015) tested the effect of fly ash replacement. It was found that pervious concrete samples with 10 and $20 \%$ fly ash replacement suffered less damage at the end of the test when compared to samples with 0 and $30 \%$ replacement. Compressive strength of the samples at 28 days appeared to decrease with an increase in fly ash content. While the void content and hydraulic conductivity were similar for all four mixtures. This conflicts with the literature in conventional concrete where the addition of fly ash was found to increase the severity of salt scaling. 


\subsubsection{Mechanisms of Damage Due to Salt Scaling}

The mechanisms of salt scaling are still not yet fully understood. In this section, a number of theories proposed by various researchers are presented. While many of the theories provide a reasonable explanation for the observed effects of different parameters, they are not able to explain all of them. It is also important to note that it is possible these mechanisms may work in conjunction with one another.

\section{Thermal Shock}

The mechanism of thermal or temperature shock is proposed by Harnik et al. (1980). As the melting of ice requires heat, it is argued that this heat is withdrawn from the surface of the concrete when deicers are used. This situation occurs when ice (frozen without deicers) is melted by the application of deicers, there is a sudden drop in temperature that does not occur in the absence of a deicer or when a frozen deicer solution melts (Figure 2.4). As the reduction in temperature occurs on the surface of the concrete, a temperature gradient develops causing tensile stresses. Harnik et al. (1980) argues that an ice sheet of sufficient thickness, with higher levels of deicer application, can cause the tensile stresses to exceed the tensile strength of the concrete. Valenza and Scherer (2007b) offer a dissenting opinion, contesting that the stresses will never exceed the tensile strength of the concrete under normal field conditions. This mechanism is unlikely for two reasons. First, the standard ASTM C672 test for salt scaling involves freezing and thawing of a deicer solution on the concrete surface. As stated by Harnik et al. (1980), the thermal shock does not occur unless the deicer is applied after ice formation. Furthermore, Verbeck and Klieger (1956) tested the scenario where thermal shock would occur. A comparison was made between freezing and thawing of a deicer solution on the concrete surface, and freezing water on the surface followed by melting of the ice through the application of a deicer. The latter would, in theory, produce the thermal shock as described 


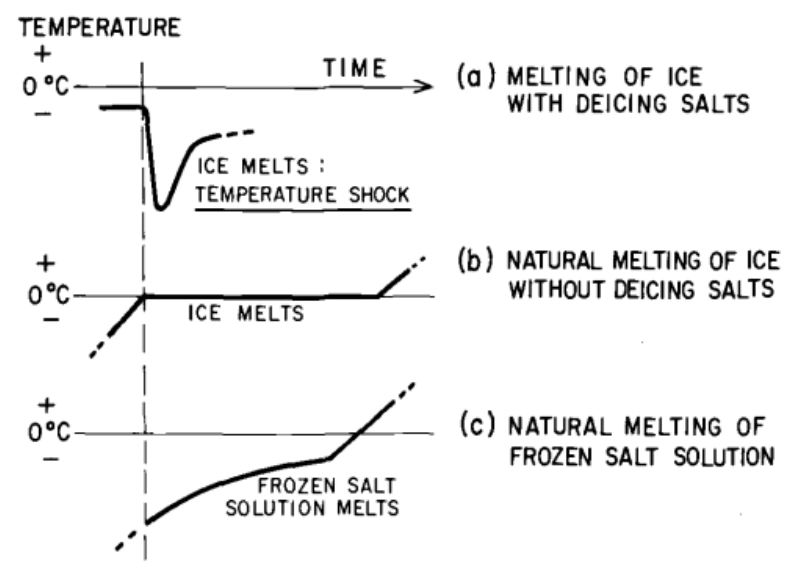

Figure 2.4: Schematic examples of temperature changes on concrete surface with and without deicing salts (Harnik et al. (1980)).

by Harnik et al. (1980). However, Verbeck and Klieger (1956) concluded that freezing and thawing the deicing solution while it is pooled on the concrete surface led to much more damage. Secondly, as mentioned previously, increasing the concentration past a certain point reduces the salt scaling damage. The mechanism of thermal shock would increase the damage to concrete as the concentration increases. While this mechanism does not explain salt scaling as it occurs in the standard tests, it may contribute to damage in field. Deicers are often applied correctively (to melt the ice or snow) and as shown by Harnik et al. (1980), a thermal shock does occur on the concrete surface.

\section{Precipitation and Growth of Salt}

The precipitation and growth of salt is thought to cause damage due to the pressures generated (Harnik et al., 1980). The precipitation of salt out of a solution can occur when the concentration of the solution is greater than the maximum saturation allowed at a certain temperature (Knöfel, Hoffmann, and Snethlage, 1987). This can occur in one of two ways, reducing the temperature of a salt solution or through the evaporation of water. As the temperature decreases, the maximum allowable salt saturation decreases. As water evaporates from a solution, it be- 


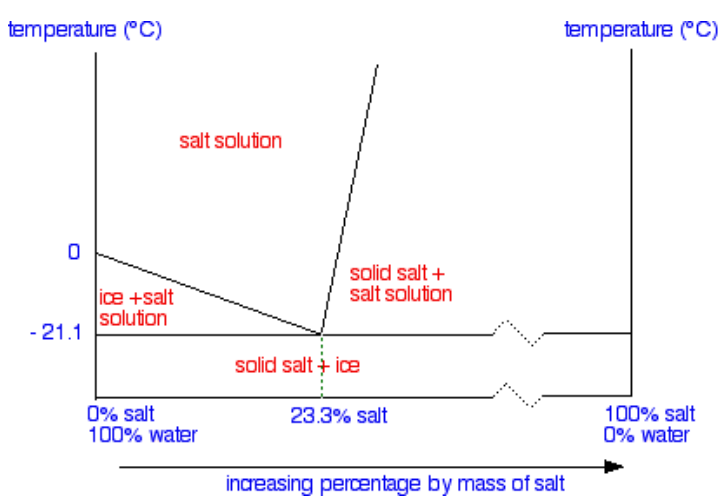

Figure 2.5: Phase diagram for a sodium chloride solution. (Clark (2005))

comes more concentrated. In either case, the solution can become supersaturated, resulting in the precipitation of salt. The growth of salt occurs within the pores of the cement matrix thus exerting pressure on the pore walls (Harnik et al., 1980).

Figure 2.5 shows the phase diagram of sodium chloride. The eutectic point of a $\mathrm{NaCl}$ solution is $-21.1{ }^{\circ} \mathrm{C}$. Below this temperature, regardless of the concentration, solid $\mathrm{NaCl}$ will precipitate out of solution as all of the water is frozen. Above this point, solid $\mathrm{NaCl}$ will only exist in the solution if the concentration is above $23.3 \%$ by weight.

The conditions for precipitation of salt do not exist in the standard test methods for salt scaling. As the standard methods use either 3 or $4 \%$ solutions, salt will not precipitate out unless the temperature reaches below $-21.1{ }^{\circ} \mathrm{C}$. The minimum temperature for the experiments is $-18{ }^{\circ} \mathrm{C}$, above the eutectic point of $\mathrm{NaCl}$. Additionally, under this mechanism, an increase of salt concentration should also increase the damage due to salt growth as it is more likely to precipitate at higher concentrations. However, precipitation of salt can occur in field due to higher levels of salt application and drying of the pavement thus potentially contributing to the damage of in-service concrete pavements. 


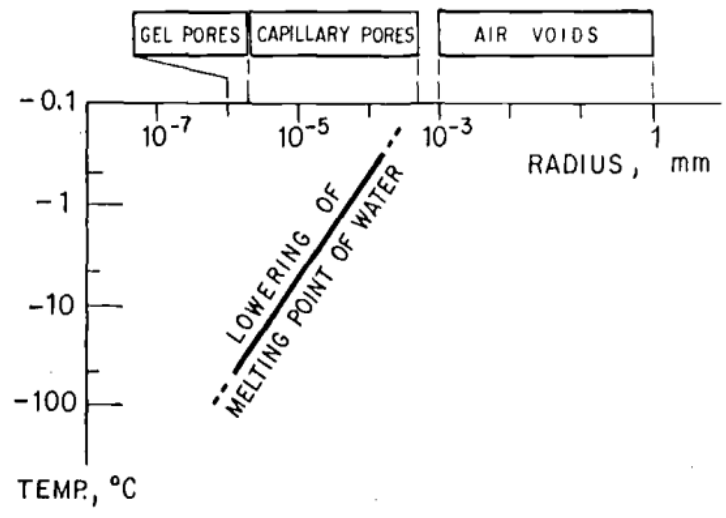

Figure 2.6: Graph showing the lowering point of water as the concrete pore sizes decrease (Harnik et al. (1980)).

\section{Osmotic Pressure}

Osmosis is the process in which water diffuses from an area of low concentration to an area of high concentration. As ice forms in a salt solution, the salt ions are not incorporated into the ice matrix, which raises the concentration of the remaining solution (Valenza and Scherer, 2007b). As seen in Figure 2.6, the melting point of water in the pores of concrete decreases as the pore sizes decrease. The water inside of the these pores begin to migrate towards the remaining solution to balance out the concentration, as the volume of the solution increases, it imposes stresses on the concrete. Additionally, the water dilutes the remaining solution, increasing its freezing point and allows more ice to form (Cruz Jr., 2008).

\section{Increased Degree of Saturation}

Following the mechanism of frost damage in concrete proposed by Powers (1945), the degree of saturation of concrete increases with each freeze-thaw cycle. This would eventually lead to damage in concrete as it exceeds the critical degree of saturation. MacInnis and Whiting (1979) noted that effect of different $\mathrm{NaCl}$ concentrations on the level of saturation of concrete. 
It was found that when exposed to the same levels of humidity, samples saturated with salt solutions with higher concentrations retained more moisture at equilibrium. Harnik et al. (1980) explains this behaviour by stating that the vapour pressure of the solution decreases as the salt concentration increases. This would reduce the amount of evaporation of the solution under a given temperature and humidity as shown by MacInnis and Whiting (1979). A minimum level of saturation is also suggested by Verbeck and Klieger (1956), as samples that were not air dried prior to testing suffered more damage. Another consequence of the increased concentration is the decreased freezing point of the salt solution, reducing the amount of ice formed. These opposing effects could explain the pessimum effect (Liu and Hansen, 2015).

\section{Glue Spalling}

Glue spalling is a technique used for chipping glass in order to manufacture decorative ornamenal glass (Gulati and Hagy, 1982). The glue spalling technique consists of three stages: (1) sandblasting the glass surface, (2) applying a layer of epoxy to the surface and allowing it to dry, and (3) curing the epoxy by heating it in an oven then allowing it to cool (Gulati and Hagy, 1982). The generated stresses are a result of the mismatch in the coefficients of thermal expansion of the glass and the epoxy as it cools. Gulati and Hagy (1982) estimate that the difference in coefficient of thermal expansion to be in the order of 13 or 14 times. The sandblasted surface allows the epoxy to adhere strongly to the glass surface. As the epoxy cools, it contracts at a higher rate than the underlying glass surface. The resulting tensile stress running parallel to the surface cause chips in the glass (Figure 2.7). 


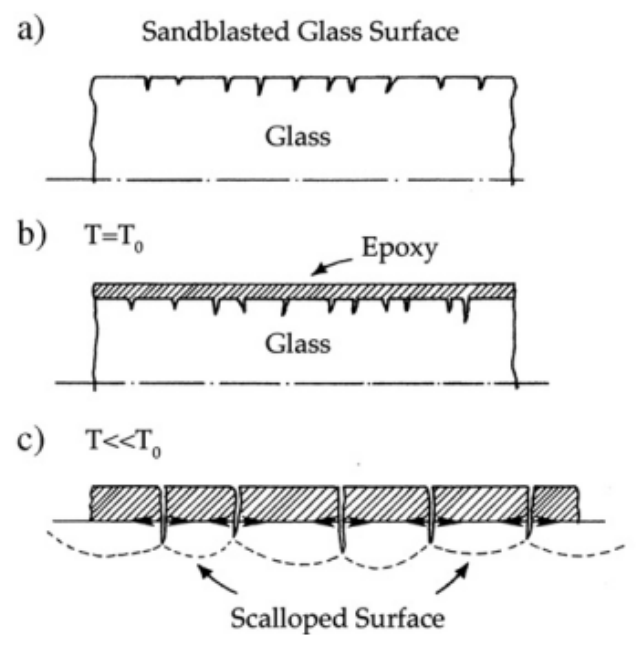

Figure 2.7: A schematic representation of the glue spall mechanism. Adapted from Valenza and Scherer (2007b).

The mechanism of glue spalling as it relates to salt scaling is proposed by Valenza and Scherer (2007b). Analogies are drawn between the glue spalling process in glass and in salt scaling. The salt solution acts as the epoxy as it is applied to the concrete surface. As the salt solution freezes, it acts analogous to the cooling of the brittle epoxy, the rough concrete surface is similar to the sandblasted surface of the glass. As the ice freezes and bonds to the surface, further cooling causes the ice to contract. The ice, with a coefficient of thermal expansion approximately five times greater than that of concrete (Sun and Scherer, 2010), contracts at a much faster rate than the concrete surface. Leading to the fracture mechanism as described in the glue spalling process, in turn leading to the removal of flakes as seen in concrete suffering salt scaling damage.

The physical properties of the ice formed with solutions of difference concetrations are used to explain the pessimum (Valenza and Scherer, 2007b). It is argued that ice from pure water will not crack while at higher salt concentrations the ice formed will not gain sufficient strength. This is supported by $\mathrm{Li}$ and Zhou (2012) where the stress-strain curved of $\mathrm{NaCl}$ and $\mathrm{CaCl}_{2}$ at different concentrations were compared. For both deicers, the modulus of elasticity of the brine 


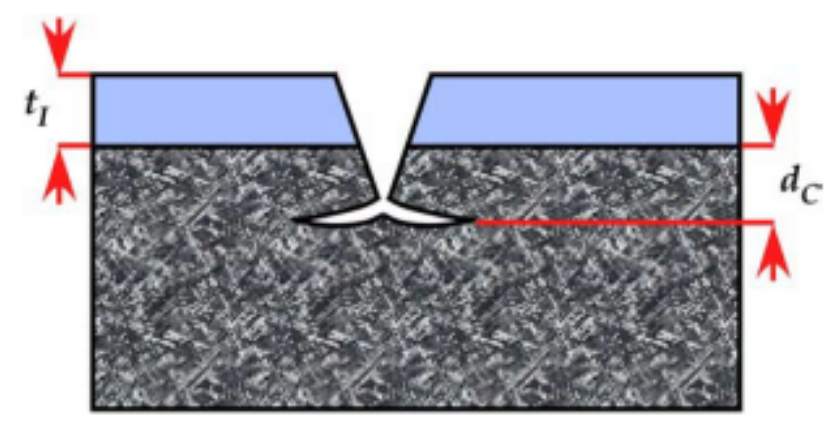

Figure 2.8: Schematic showing the penetration of ice into the concrete layer and bifurcating at a depth within the concrete (Sun and Scherer (2010)).

ice was lower as the concentration increased, with the modulus for $\mathrm{CaCl}_{2}$ being lower than that of $\mathrm{NaCl}$ at the same concentration. The cracks in the ice are expected to continue and penetrate into the concrete surface, bifurcate (Figure 2.8), and propagate parallel to the surface, resulting in the removal of material Valenza and Scherer (2007b). As this mechanism would not be possible without a layer of continuous layer of ice, it agrees well with the observations of Verbeck and Klieger (1956) where samples that were frozen without the pool of solution suffered very little damage. For that test, it should be noted that the salt solutions were pooled on the surface during the thawing phase of that test and drained prior to the freezing period. Lindmark (1998) noted that lower minimum temperatures in general caused more damage. As the temperature decreases further, the difference in contraction between the concrete and ice will be more pronounced. This would lead to more damage as suggested by the glue spalling mechanism.

\section{Brine Rejection}

An alternative mechanism is proposed by Yener (2015) where pockets of brine are forced into the voids of the concrete surface by the expanding ice. Once the pores become fully saturated, the brine will push back against the ice. The ice will be pushed away from the concrete surface, taking material with it (Figure 2.9). The pessimum effect is explained as brine pockets would 
not be present in the absence of deicers. Additionally, higher concentrations would reduce the volume of ice formed at a given temperature and would result in a weaker layer of ice. This mechanism can also explain the increase in damage seen in concrete with higher sorptivity values and the saturation would be much quicker. The use of entrained air would delay the saturation of the pores, leading to more resistant concrete.
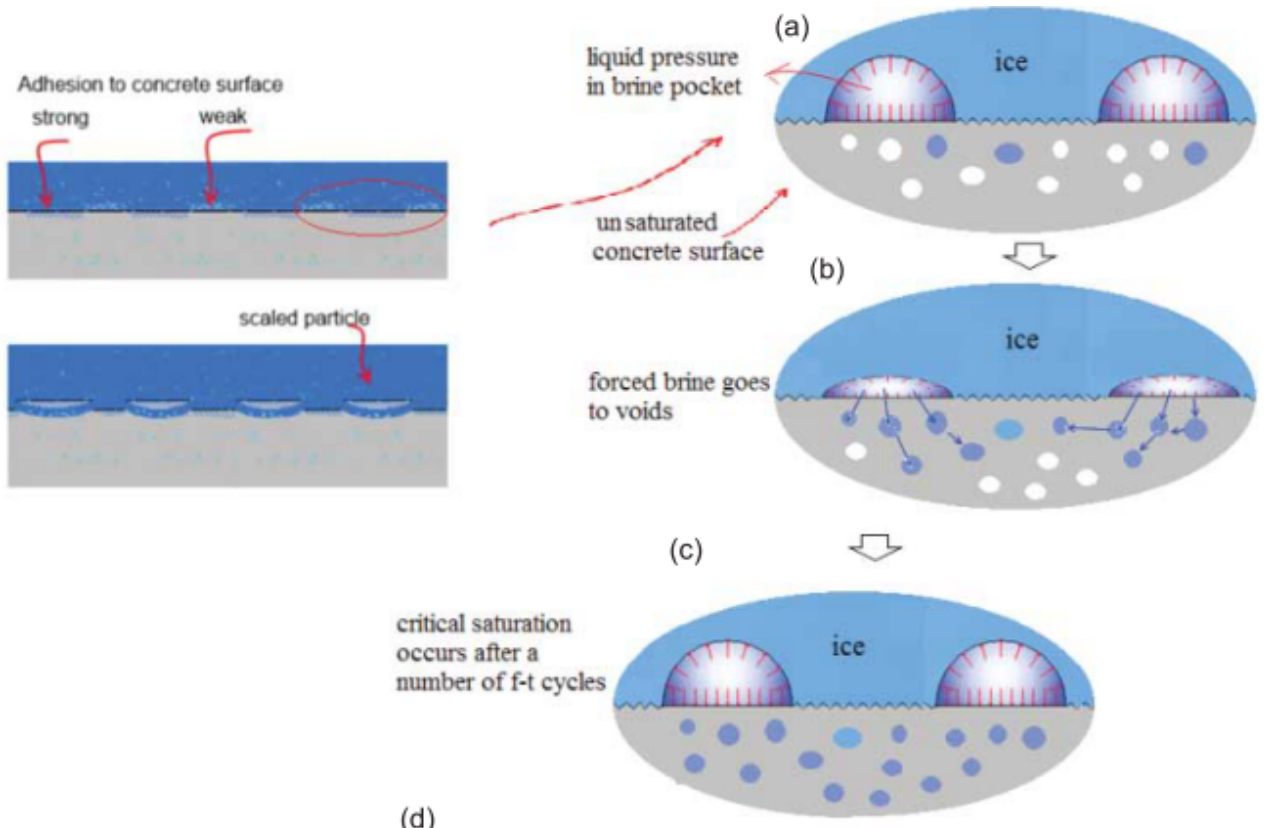

(d)
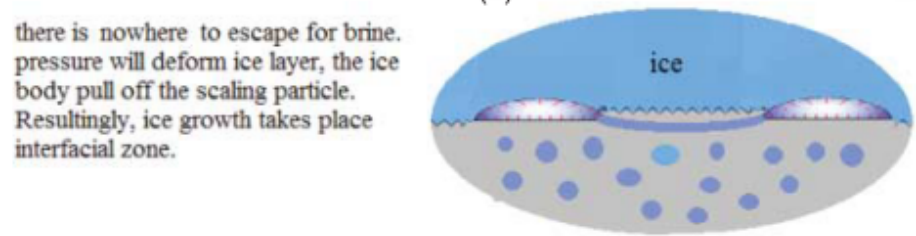

Figure 2.9: Schematic explaining the brine rejection mechanism (Yener (2015)).

\subsection{Effects of Deicers}

While the effects of different deicers on salt scaling has been mentioned in the previous section, it is important to review the detrimental effects of these deicers on concrete at different concentrations, temperatures, and exposure conditions. 
Darwin, Browning, Gong, and Hughes (2008) exposed concrete to weekly cycles of wetting and drying in a number of deicers at high and low concentration to measure the levels of deterioration. Concrete specimens were submerged in solution at $23{ }^{\circ} \mathrm{C}$ for 4 days, and dried at $38^{\circ} \mathrm{C}$ for 3 days. The level of damage was assessed by visual inspection and by measuring the dynamic modulus. It was found that both $\mathrm{MgCl}_{2}$ and CMA caused severe damage, particularly at higher concentrations (6.04 molal ion concentration). The impact of $\mathrm{NaCl}$ and $\mathrm{CaCl}_{2}$ at low concentrations (1.06 molal ion concentration) was rather small, while $\mathrm{CaCl}_{2}$ caused severe damage at higher concentrations. Damage due to continuous exposure to $\mathrm{CaCl}_{2}$ and $\mathrm{MgCl}_{2}$ solutions was also reported by Sutter, Dam, Peterson, and Johnston (2006a). Expansion and cracks began to appear after 56 days of exposure to a solution of $17 \% \mathrm{CaCl}_{2}$, with severe deterioration reported by 84 days. Damage caused by long term exposure to CMA at high concentrations was also reported by Santagata and Collepardi (2000). The deterioration was observed through visual inspection, mass loss, and loss of compressive strength of concrete samples. The use of slag cement in the concrete mix was able to mitigate some of the damage. The damage caused by CMA may be due to the formation of calcium acetate hydrate identified through petrographic analysis (Dam, Hooton, Julio-Betancourt, Peterson, Smith, and Sutter, 2008).

While the damage from $\mathrm{NaCl}$ appeared minimal in the testing program by Darwin et al. (2008), continuous exposure caused a reduction in compressive strength on the same level as $\mathrm{MgCl}_{2}$ (Shi, Fay, Peterson, Berry, and Mooney, 2011). It was suggested that this was due to the leaching of $\mathrm{Ca}^{2+}$ and $\mathrm{SO}_{4}{ }^{2-}$ from AFm or AFt phases (Shi et al., 2011). Additionally, $\mathrm{NaCl}$ can potentially initiate or accelerate ASR by increasing the alkalinity according to equation (2.1) (Shi et al., 2009). However, it is noted that this process was found to be quite slow. It can also be possible for the application of $\mathrm{NaCl}$ to form calcium oxychloride $\left(3 \mathrm{CaO} \cdot \mathrm{CaCl}_{2} \cdot 15 \mathrm{H}_{2} \mathrm{O}\right)$ due 
to the resulting formation of $\mathrm{CaCl}_{2}$.

$$
2 \mathrm{NaCl}+\mathrm{Ca}(\mathrm{OH})_{2} \leftrightarrow \mathrm{CaCl}_{2}+2 \mathrm{NaOH}
$$

The damaging effect of $\mathrm{CaCl}_{2}$ is often attributed to the formation of calcium oxychloride (Sutter, Peterson, Touton, Van Dam, and Johnston., 2006b; Shi et al., 2011.) The reaction for the formation of calcium oxychloride is provided by equation (2.2). While calcium oxychloride is reported to form fastest between $4{ }^{\circ} \mathrm{C}$ and $10{ }^{\circ} \mathrm{C}$, damage still occurred through wetting/drying cycles at higher temperatures (Darwin et al., 2008). Concrete mixes containing supplementary cementing materials were also exposed to $\mathrm{CaCl}_{2}$ and $\mathrm{MgCl}_{2}$ solutions. The mixes containing slag and fly ash suffered fewer cracks than concrete specimen without any supplementary cementing materials Dam et al. (2008). This is likely due to the consumption of calcium hydroxide by slag and fly ash that is required for the formation of calcium oxychloride. Examination of the concrete surface of mixes containing only portland cement revealed a lack of calcium hydroxide, while the inner regions showed abundant levels of calcium hydroxide (Dam et al., 2008). Calcium hydroxide was the least abundant in the mixes containing slag, which suffered the least amount of damage.

$$
3 \mathrm{Ca}(\mathrm{OH})_{2}+\mathrm{CaCl}_{2}+12 \mathrm{H}_{2} \mathrm{O} \rightarrow 3 \mathrm{CaO} \cdot \mathrm{CaCl}_{2} \cdot 15 \mathrm{H}_{2} \mathrm{O}
$$

Dam et al. (2008) exposed the surface of concrete slabs to a $22 \% \mathrm{CaCl}_{2}$ for one year prior to running salt scaling test with a $4 \% \mathrm{CaCl}_{2}$. This resulted in severe damage to the surface of the slab, with most of the damage resulting from deterioration of the cement matrix, leaving the aggregate intact (Figure 2.10). The exposure to $23 \%$ solution $\mathrm{NaCl}$ and testing at $3 \% \mathrm{NaCl}$ did not produce as much damage. 

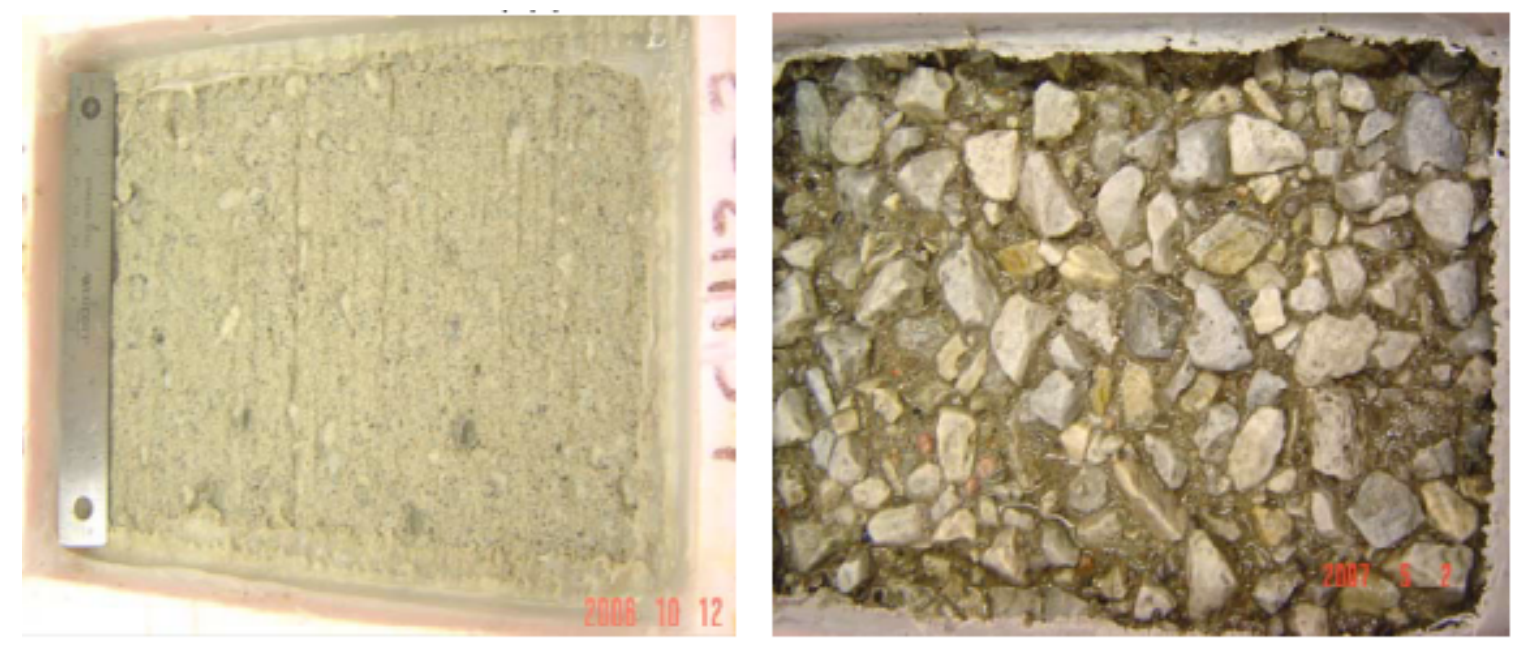

Figure 2.10: Concrete surfaces at 100 freeze thaw cycles. Left: Pretreated with $23 \% \mathrm{NaCl}$ and tested with $3 \% \mathrm{NaCl}$. Right: Pretreated with $22 \% \mathrm{CaCl}_{2}$ and tested with $4 \% \mathrm{CaCl}_{2}$. Adapted from Dam et al. (2008).

The damage observed through continuous exposure to $\mathrm{MgCl}_{2}$ was similar the damage through exposure to $\mathrm{CaCl}_{2}$ (Darwin et al., 2008; Dam et al., 2008). The main mechanisms of attack are given by equations (2.3) and (2.4). The formation of magnesium silicate hydrates (MSH) increases the porosity of the paste as it causes the decalcification of the calcium silicate hydrate (CSH) (Sutter et al., 2006a). Both brucite $\left(\mathrm{Mg}(\mathrm{OH})_{2}\right)$ and $\mathrm{MSH}$ are not cementitious materials, this results in the reduction of strength of the concrete (Shi et al., 2011). In addition to the damage caused by these two reactions, the reactions produce $\mathrm{CaCl}_{2}$, potentially leading to the formation of calcium oxychloride according to equation (2.2) (Sutter et al., 2006b).

$$
\begin{gathered}
\mathrm{Ca}(\mathrm{OH})_{2}+\mathrm{MgCl}_{2} \rightarrow \mathrm{CaCl}_{2}+\mathrm{Mg}(\mathrm{OH})_{2} \\
\mathrm{CSH}+\mathrm{MgCl}_{2} \rightarrow \mathrm{CaCl}_{2}+\mathrm{MSH}
\end{gathered}
$$

Acetates are often used as an alternative to conventional deicing salts as the chloride-based 
deicers can cause corrosive damage to reinforcing steel. However, the use of acetate based deicers can accelerate alkali silica reactions (ASR) if reactive aggregates are used by raising the pH of the pore solution (Giebson, Seyfarth, and Stark, 2010). In addition, concretes made with aggregates with a high proportion of microfines and later exposed to potassium acetate suffered deterioration of the paste through the formation of potassium sulphate products through the extraction of sulphate from ettringite, monosulphate, or microfines (Silva, Cramer, Anderson, Tejedor, and Muñoz, 2014). The formation of these products occurred even when non reactive aggregates were used.

Urea is used as a deicer as it does not result in the corrosion of reinforcing steel in concrete (Sadegzadeh, Page, and Vassie, 1993). Urea can form carbonic acid when it reacts with water (Mwaluwinga, Ayano, and Sakata, 1997), potentially increasing the carbonation of concrete when used as a deicer. However, the use of urea in a concrete mix decreases the depth of carbonation (Mwaluwinga et al., 1997). 


\section{Chapter 3}

\section{Materials and Experimental}

\section{Methods}

\subsection{Materials}

General Use (GU) Portland cement along with Granular Ground Blast Furnace Slag (GGBFS) was used in the production of pervious concrete samples for all experiments (Table 3.1). The mixture also contained natural limestone coarse aggregate without any additional fine aggregate. The gradation for the $14 \mathrm{~mm}$ limestone aggregate is provided in Figure 3.1. One main mix design was used with varying sample geometry for various tests; the three sample geometries used were: (1) $100 \mathrm{~mm}$ cubes, (2) $150 \mathrm{~mm}$ cubes, (3) $100 \mathrm{~mm}$ diameter by $150 \mathrm{~mm}$ height cylinders (Figure 3.2). General mix design parameters are provided in Table 3.2. A second mix was identical to the first but included the addition of $0.2 \%$ by volume of $8 \mathrm{~mm}$-long polyvinyl alcohol (PVA) fibres. The properties of the coarse aggregate and PVA fibre are provided in Table 3.3. 


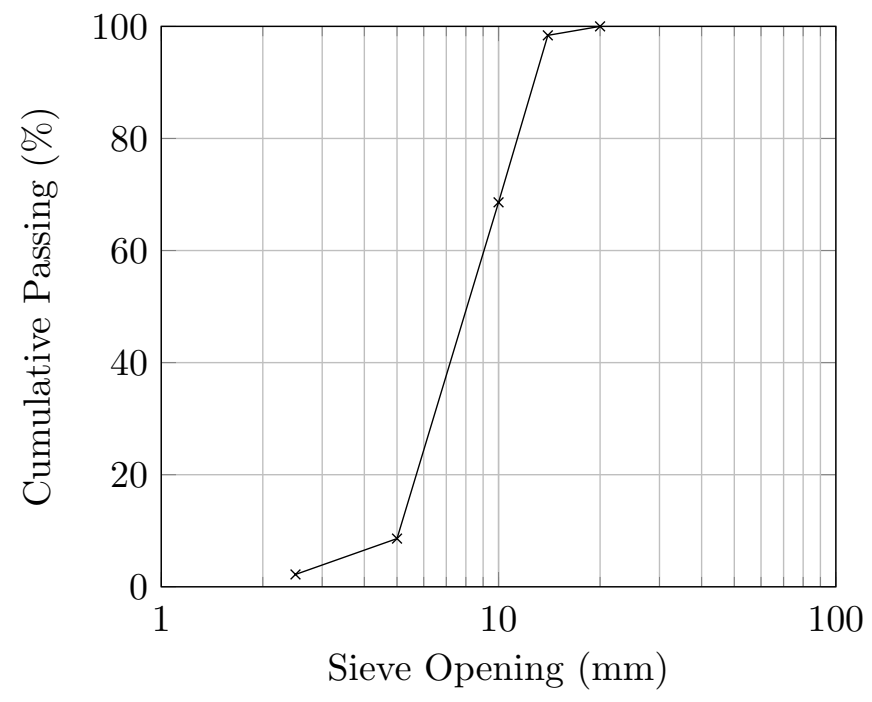

Figure 3.1: Grain size distribution curve of $14 \mathrm{~mm}$ limestone.

Table 3.1: Cementing material chemical composition.

\begin{tabular}{cccccccccc}
\hline $\begin{array}{c}\text { Cementing } \\
\text { Material }\end{array}$ & $\begin{array}{c}\mathrm{SiO}_{2} \\
(\%)\end{array}$ & $\begin{array}{c}\mathrm{Al}_{2} \mathrm{O}_{3} \\
(\%)\end{array}$ & $\begin{array}{c}\mathrm{Fe}_{2} \mathrm{O}_{3} \\
(\%)\end{array}$ & $\begin{array}{c}\mathrm{TiO}_{2} \\
(\%)\end{array}$ & $\begin{array}{c}\mathrm{CaO} \\
(\%)\end{array}$ & $\begin{array}{c}\mathrm{MgO} \\
(\%)\end{array}$ & $\begin{array}{c}\mathrm{SO}_{3} \\
(\%)\end{array}$ & $\begin{array}{c}\mathrm{S}^{2-} \\
(\%)\end{array}$ & $\begin{array}{c}\mathrm{LOI} \\
(\%)\end{array}$ \\
\hline GU & 19.6 & 4.9 & 3.1 & - & 61.4 & 3 & 3.6 & - & 2.3 \\
GGBFS & 38.4 & 10.61 & 0.79 & 0.71 & 34.2 & 6.94 & 0.2 & 1.1 & 3.09 \\
\hline
\end{tabular}

Table 3.2: General mix properties.

\begin{tabular}{|c|c|c|c|c|c|}
\hline $\begin{array}{l}\mathrm{w} / \mathrm{cm} \\
\text { ratio }\end{array}$ & $\begin{array}{c}\text { Cement } \\
\text { type }\end{array}$ & $\begin{array}{c}\text { GGBFS } \\
\text { replacement } \\
(\%)\end{array}$ & $\begin{array}{c}\text { Coarse } \\
\text { aggregate }\end{array}$ & $\begin{array}{c}\text { Coarse } \\
\text { aggregate } \\
\text { fraction }\end{array}$ & $\begin{array}{c}\text { Fine } \\
\text { aggregate } \\
\text { fraction }\end{array}$ \\
\hline 0.3 & $\mathrm{GU}$ & 15 & $\begin{array}{l}\text { CSA certified } \\
14 \mathrm{~mm} \text { crushed } \\
\text { limestone }\end{array}$ & 1 & 0 \\
\hline
\end{tabular}




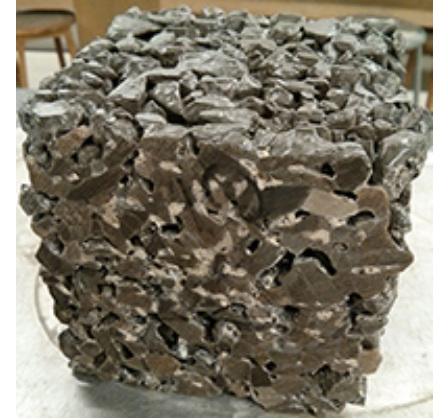

(a)

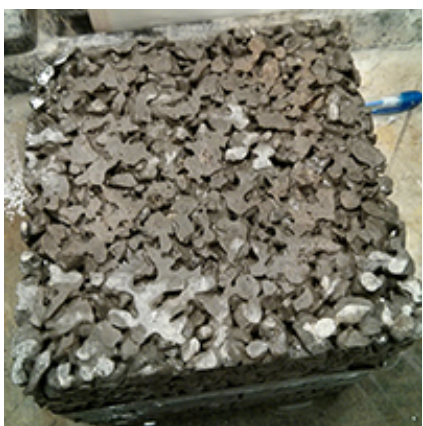

(b)

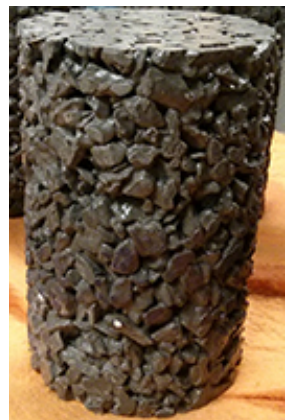

(c)

Figure 3.2: Various sample geometries used in the different salt scaling tests. (a) $100 \mathrm{~mm}$ cube, (b) $150 \mathrm{~mm}$ cube, (c) $100 \mathrm{~mm}$ diameter by $150 \mathrm{~mm}$ height cylinder.

Table 3.3: Coarse aggregate and PVA fibre properties.

\begin{tabular}{llllll}
\hline Coarse aggregate & \multicolumn{3}{l}{ Fibres } \\
\cline { 1 - 2 } Test & $\begin{array}{l}14 \mathrm{~mm} \\
\text { limestone }\end{array}$ & & Property & PVA Fibres \\
\cline { 1 - 2 } \cline { 5 - 6 } Wash loss $(75 \mu \mathrm{m}$ sieve) & $1.3 \%$ & & Filament Diameter & $38 \mu \mathrm{m}$ \\
Rodded Unit Weight & $1621 \mathrm{~kg} / \mathrm{m}^{3}$ & & Fibre Length & $8 \mathrm{~mm}$ \\
Absorption & $0.96 \%$ & & Specific Gravity & 1.3 \\
Specific Gravity $\left(\mathrm{G}_{\mathrm{sb} \text { dry }}\right)$ & 2.724 & & Tensile Strength & $1600 \mathrm{MPa}$ \\
Crushed Particles & $100 \%$ & & Flexural Strength & $40 \mathrm{GPa}$ \\
Micro-deval loss & $7.3 \%$ & & Absorption & $1 \%$ \\
\hline
\end{tabular}

\subsubsection{Casting}

The $100 \mathrm{~mm}$ cube pervious concrete samples were made by first casting a large beam (100 $\mathrm{x}$ $100 \times 300 \mathrm{~mm}$ ) and saw cut into three cubes. $150 \mathrm{~mm}$ cube samples were prepared in individual steel moulds. The cylinder samples were cast in individual plastic cylinder moulds (100 mm diameter, $200 \mathrm{~mm}$ height). All samples were then cured in a humidity room at $>95 \% \mathrm{RH}$ for 28 days prior to testing. 


\subsubsection{Demoulding Cylinder Samples}

Due to the porous nature of pervious concrete, it cannot be demoulded from cylinder moulds the same way as conventional concrete. In conventional concrete, a small hole is made in the bottom of the mould and is demoulded using compressed air. An appropriate seal at the bottom of the mould is required in order for the air pressure to build up and extrude the sample. This cannot be done in pervious concrete because the pressure is released by passing through the voids of concrete itself.

As it would not be economical to use each mould only once and creating a large amount of waste, a new method of demould was devised. This was done by first casting discs of mortar using the bottom of the mould (Figure 3.3a). The mortar was a standard mortar mix composed of 1 part cement to 2.75 parts of graded sand measured by mass with a water cement ratio of 0.485 .

The bottom of the mould was filled to approximately $10 \mathrm{~mm}$ in depth with the mortar. The moulds were then covered and the discs demoulded after 24 hours and placed in the curing room at $100 \% \mathrm{RH}$. The top surface of the discs were lightly polished using concrete polishing pads.

The discs were inserted into each cylinder mould prior to casting pervious concrete (Figure 3.3b). As the dimension of the disc fits the mould exactly, it forms a seal that allows the sample to be extracted using compressed air. This method of casting the discs in individual moulds is necessary since the diameter of the top of the mould is slightly larger than the bottom. The discs cannot be made by cutting a single concrete cylinder into smaller discs. Forcing a disc from the top portion of the cylinder would result in the deformation of the mould. 


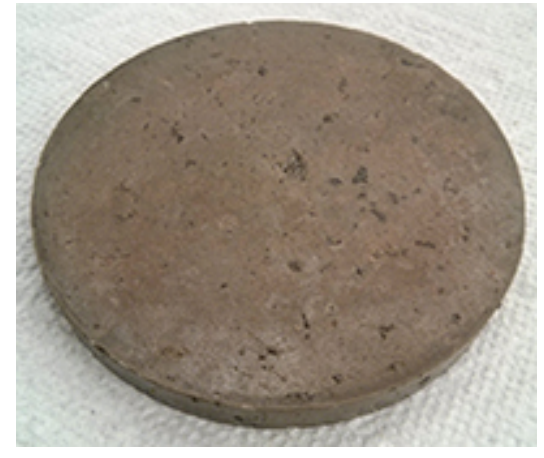

(a)

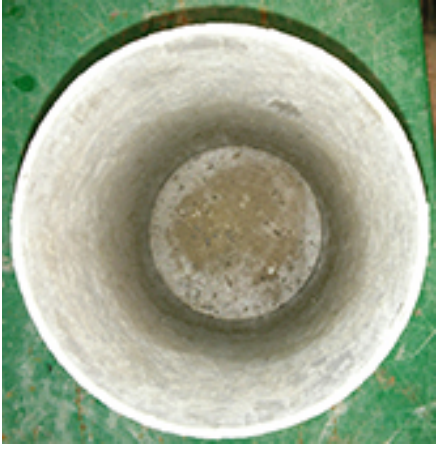

(b)

Figure 3.3: (a) Mortar disc (b) Disc placed at the bottom of cylinder mould prior to casting.

\subsubsection{Sample Preparation Prior to Testing}

After the cylinder samples were cured for 28 days, they were prepared for testing. The bottom of the samples were ground flat using an end grinder in preparation for compressive strength testing. The top of the samples were then cut off, leaving the cylinder height at approximately $152 \mathrm{~mm}$. Finally, the top of the samples were ground flat, resulting in a final dimension of $150 \mathrm{~mm}$. The reduction of the sample size was done for a number of reasons. The irregular nature of pervious concrete can cause the top surface and the total sample height to be variable. The method of demoulding the samples, as discussed previously, will result in a sample that is shorter than the height of the mould of $200 \mathrm{~mm}$. By defining a specific height for each of the samples to conform to, the samples will be more consistent. The sample height of $150 \mathrm{~mm}$ was chosen to ensure that all samples would be greater than this height initially after casting. This would allow a sufficient excess to be saw cut down to the desired height. The height to diameter ratio is $1.5: 1$, which is the minimum ratio acceptable to provide consistent compressive strength results (Anderson et al., 2013). The top of the sample was deemed to be less important than the bottom of the sample as much of the testing was focused on the bottom of the sample since a deicing solution cannot be ponded on top.

The ends of the $100 \mathrm{~mm}$ cube samples were simply ground flat. No special preparation proce- 
dures were used for the $150 \mathrm{~mm}$ cubes, as they were tested only for mass loss and not compressive strength.

\subsection{Compressive Strength Testing}

Compressive strength tests were performed on $100 \mathrm{~mm}$ cubes and on cylinders. As there is currently no standard test method for determining the compressive strength of pervious concrete, testing was done in accordance with ASTM C39. However, the cross sectional area of the tested samples was treated as a solid cross section for the purposes of calculating the compressive strength.

\subsection{Freezing/Thawing Equipment}

\section{Cincinnati SubZero}

The Cincinnati Sub-Zero (CSZ) Z-Plus environmental chamber was used for a number of tests. The model used had a capacity of $8 \mathrm{cu}$. ft $(2 \times 2 \times 2 \mathrm{ft})$ with a single shelf (Figure $3.4 \mathrm{a})$. While the chamber is capable of temperature ranges from $-34{ }^{\circ} \mathrm{C}$ to $190{ }^{\circ} \mathrm{C}$, the actual range used for this study was between $-18{ }^{\circ} \mathrm{C}$ and $15{ }^{\circ} \mathrm{C}$. A programmable controller allows an automated temperature cycle to be set.

\section{Caron Environmental Chamber}

The Caron Freeze/Thaw Chamber model 6221, is a large environmental chamber with $25 \mathrm{cu}$. ft $(32 \times 27 \times 53$ in.) of interior work space with four shelves (Figure 3.4b). This model has a 
temperature range of $-25{ }^{\circ} \mathrm{C}$ to $70{ }^{\circ} \mathrm{C}$. The temperature range used for this study was between $-18^{\circ} \mathrm{C}$ and $21^{\circ} \mathrm{C}$. The temperature was automatically cycled using the programmable controller.

\section{Industrial Freezer}

The True Freezer model T49 is a high capacity industrial freezer (Figure 3.4c). As it does not feature a programmable thermostat, this freezer was used only in the manual freeze thaw tests that will be described in the following section. The unit was set to maintain the temperature at $-18{ }^{\circ} \mathrm{C}$.

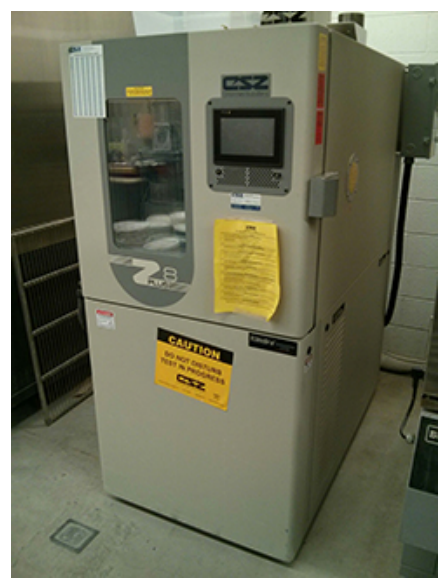

(a) Cincinnati Sub-Zero envi- (b) ronmental chamber

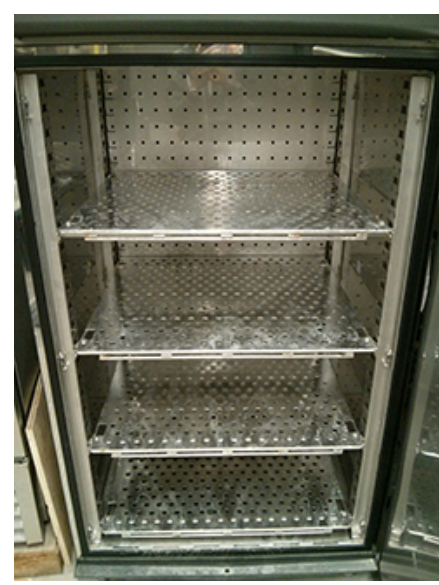

(b) Caron environmental chamber

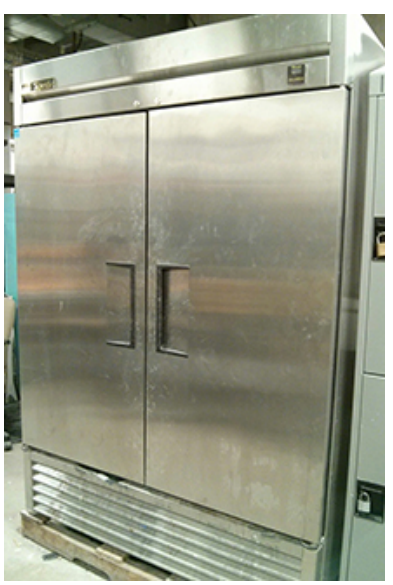

(c) Commerical freezer

Figure 3.4: The three testing chamber used for all the experiments 


\subsection{Salt Scaling Test Procedures}

\subsubsection{2-hour Cycle Under Drained and Partially Saturated Condition}

\section{Drained Condition}

The drained condition would be representative of a properly functioning pervious concrete pavement under ideal conditions where water does not stay within the voids of the concrete. For all tests, a calcium chloride solution at $4 \%$ concentration by weight was used. Eighteen 100 $\mathrm{mm}$ cubes and nine cylinders were used in this test. Before the start of each cycle, samples were placed in the $\mathrm{CaCl}_{2}$ solution. Prior to placing the samples into the container, the solution was stirred to ensure proper mixing and distribution of the deicer. The total volume of solution prepared in each container was approximately five litres. This amount of solution was sufficient to completely submerge each of the samples after placing them in the container. The containers of solution were replaced every 12 cycles and covered to minimize evaporation between replacements. This helps maintain the concentration at the desired level. The samples were then left to soak in the solution for 30 minutes before being removed and transferred to a testing container. The samples were placed on a plastic grid placed on the bottom of the container in order to minimize the area of contact between the container and the bottom of the samples. The grid also allowed the solution to drain out of the sample without pooling at the bottom. Each container was covered with a plastic wrap in order to minimize evaporation. The top rim of each container was wiped and dried prior to being covered with plastic wrap to help ensure adhesion of the wrap to the container. The containers were then placed into the Cinncinati SubZero environmental chamber where testing can begin. The temperature cycle for this initial phase has a total duration of 12 hours where the temperature range varied from $10{ }^{\circ} \mathrm{C}$ to $-18{ }^{\circ} \mathrm{C}$ as shown in Figure 3.5. This test is similar to the one used by Cutler et al. (2010), however the longer temperature cycle was selected to help ensure complete freezing and 


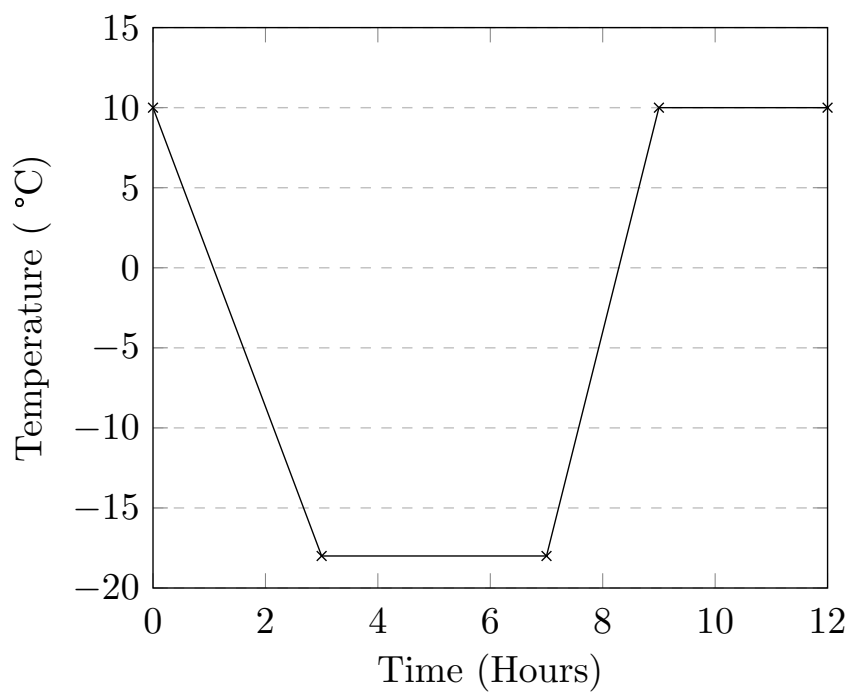

Figure 3.5: 12-hour temperature cycle

thawing of the samples.

After every 4 cycles, during the last two hours of the thawing period, the samples were removed from the environmental chamber and removed from the testing containers. After the samples were removed, the containers were flipped upside down in order drain off any excess solution that had accumulated on the bottom. Each sample was then washed under a gentle stream of water to help remove any scaled off material trapped within the sample. Each sample is washed for 30 to 60 seconds depending on the level of scaling. The scaled off material can often been seen in the stream of water that flows out of the sample. Following the wash, samples were placed on an absorbent cloth and left to dry for 30 minutes at room temperature. After the first 10 minutes of draining, the samples were transferred to a dry absorbent cloth to minimize any ponding of water near the bottom of the sample. After a total of 30 minutes of drying time, the mass of the sample was determined and recorded. The weighing of each sample was done in the same order as their washing, approximately 30 minutes after the particular sample had completed the washing cycle. The scale was tared after each sample since a small quantity of water remained once the sample was removed. Once the mass of each sample was determined, 
the samples were again submerged in the solution, drained (as described above), and the cycle was repeated. In addition to determining the mass of the samples, compressive strength was carried out at the end of 16,32 , and 52 cycles on six cubes and three cylinders. The testing was concluded at the end of 52 cycles.

\section{Partially Saturated Condition}

The partially saturated condition is representative of a more severe condition that the pervious concrete pavement can experience. It can become saturated in local areas if the voids become clogged with debris or snow, allowing the salt solution to remain long enough to freeze. Nine cylinder samples were used for this test where the samples were saturated in $50 \mathrm{~mm}$ of the $\mathrm{CaCl}_{2}$ solution. The solution was prepared as described previously, using approximately four litres to sufficiently submerge each set of samples. The solution would be replaced every 12 cycles to help maintain the concentration at the desired level. As with the previous test, the bottom of the containers were lined with a plastic grate to minimize contact with the samples. The temperature cycles and washing procedure are the same as in the previous test. The same Cincinatti subzero environmental chamber was also used. However, the samples were frozen while submerged in the solution rather than being drained prior to freezing. Three cylinders were removed for compressive strength testing at the end of 16, 32, and 52 cycles with testing concluding at the end of 52 cycles.

\subsubsection{6-hour Cycle Under Partially Saturated Condition}

For this test, cylinder samples were partially saturated by placing them into individual cylinder moulds with a diameter of approximately $100 \mathrm{~mm}$ and a height of $75 \mathrm{~mm}$ (Figure 3.6c). As the mould's original diameter matches the cylinder sample's diameter, the mould first needed to be expanded. This was done by filling approximately $3 / 4$ of a mould with sand and placing it 
in an oven at $70{ }^{\circ} \mathrm{C}$ for several hours in order to soften the plastic. Immediately after heating, a normal concrete cylinder was placed in the remaining top portion of the mould in contact with the sand. The mould was then placed in the compression testing machine and loaded. As the sand was loaded, it expanded horizontally, stretching the cylinder and increasing the mould diameter (Figure 3.6b). Once the cylinder expanded sufficiently, it was unloaded and allowed to cool. The cylinder was then cut to the final height using a mitre saw.

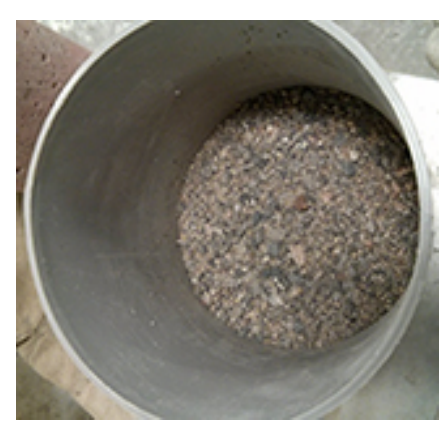

(a)

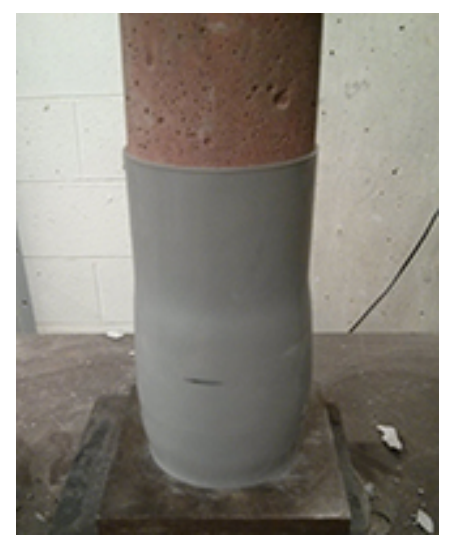

(b)

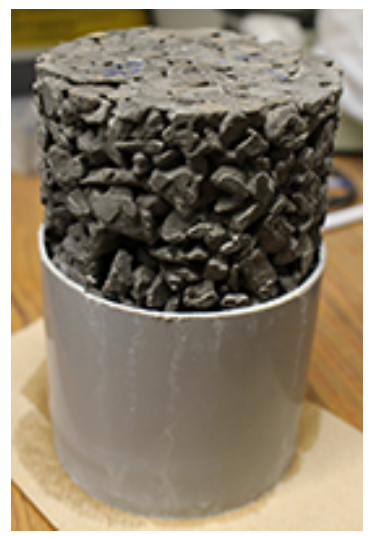

(c)

Figure 3.6: Process of preparing cylinder moulds for the 16-hour partially saturated method. (a) Sand filled mould. (b) Mould expanding due to loading. (c) Sample in completed mould.

A total of nine cylinder samples were used for this test. After the sample is placed in the mould, $\mathrm{CaCl}_{2}$ solution was poured in from the top of the sample until it overflows out the top of the mould. Each mould was tapped gently to dislodge any remaining air bubbles and the solution was topped off once more and allowed to overflow. The use of the moulds minimized the amount of solution required to submerge the samples to ensure complete freezing and thawing of the solution. The samples were then placed in containers and the top of the container was covered with a plastic wrap prior to being placed in an environmental chamber. The cycle duration was 16 hours with a temperature range that varied from $15{ }^{\circ} \mathrm{C}$ to $-18{ }^{\circ} \mathrm{C}$ with the cycle as shown in Figure 3.7.

The samples were removed every 6 cycles for mass measurements using the same procedure 


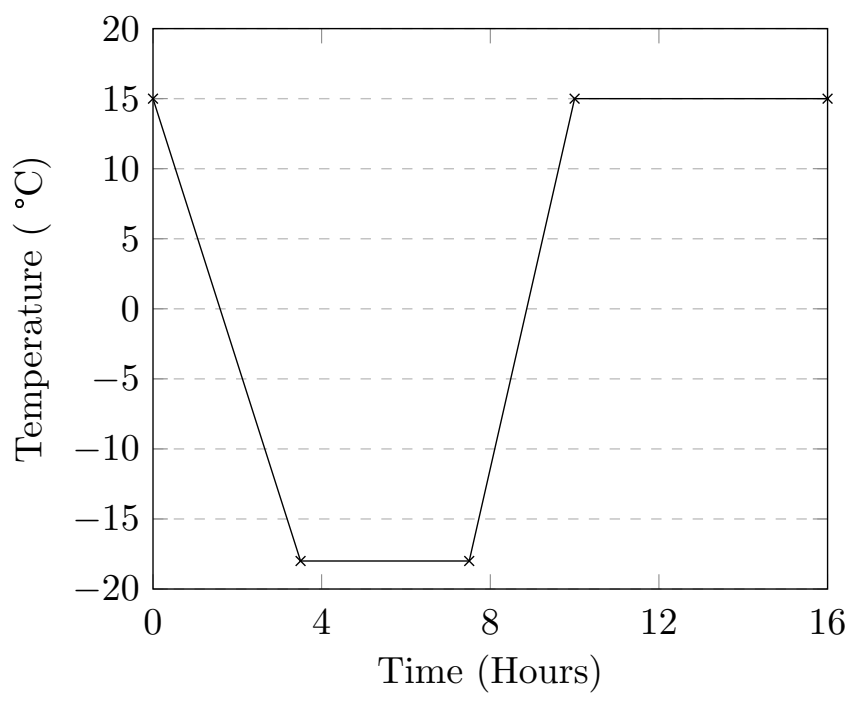

Figure 3.7: 16-hour temperature cycle

as discussed previously, and to replace the solution. As a number of moulds fit rather tightly around the samples, they were loosened by allowing a stream of hot water to run along the outside of the mould, with care taken to ensure that the hot water does not touch the sample directly. The mould should be loosened sufficiently so that the sample can be removed with little to no effort. At the end 18, 36, and 54 cycles, three samples were tested for compressive strength.

\subsubsection{4-hour Cycle Under Drained and Partially Saturated Condition}

\section{Partially Saturated Condition}

Based on the limited amount of damage observed in the previous two cycles, this 24-hour cycle was adopted. The cycle consisted of 12 hours of freezing at $-18{ }^{\circ} \mathrm{C}$, and 12 hours thawing at 21 ${ }^{\circ} \mathrm{C}$. The cycles were performed with no control of the heating or cooling rate; containers were removed from the freezer for thawing and placed back in for freezing. As the cooling rates were not controlled, the temperature was monitored with loggers placed inside the freezer. A typical 
plot from the temperature logger is shown by Figure 3.8. Samples were left in the freezer at $-18{ }^{\circ} \mathrm{C}$ over the weekends, resulting in a total of 5 completed cycles per week.

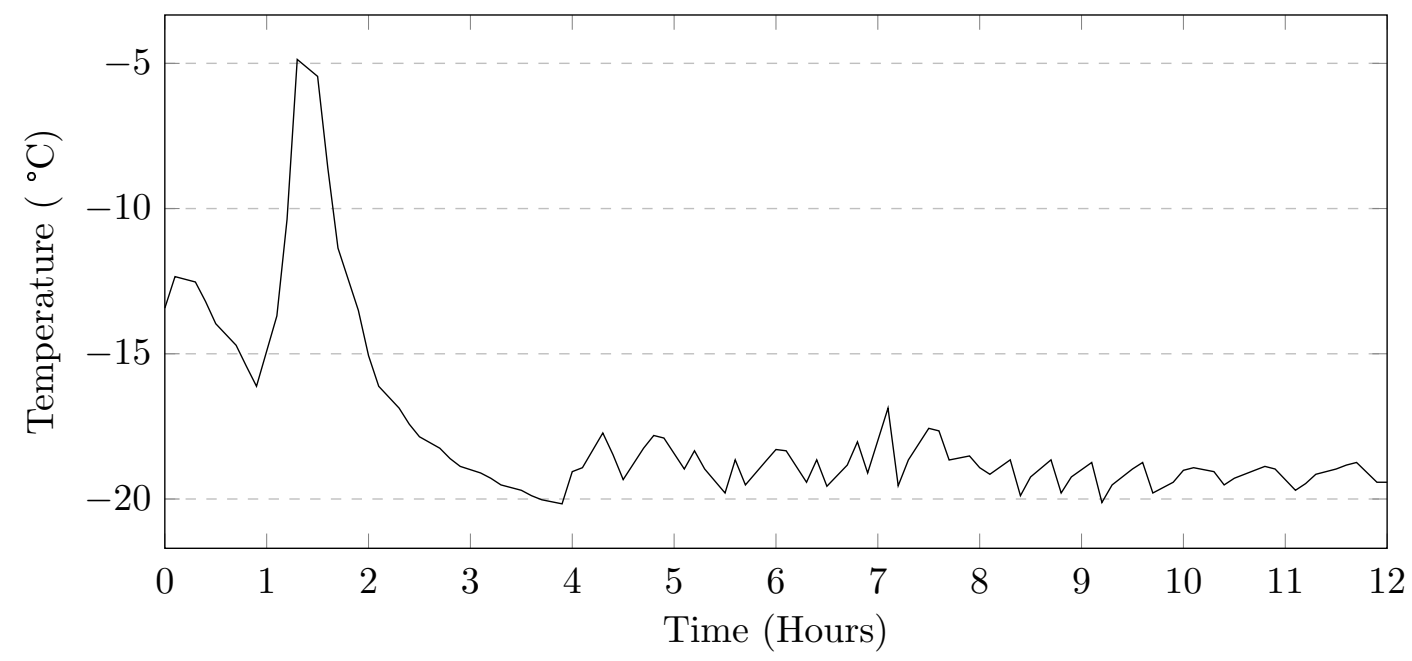

Figure 3.8: Typical air temperature profile of the freezer; Initial peak caused by opening of the door; Second peak is due to the defrost system of the freezer.

The samples were tested in a semi-saturated condition where the bottom of the samples were saturated in $10 \mathrm{~mm}$ or $50 \mathrm{~mm}$ of solution (Figure 3.9). In order to maintain those levels, approximately 1.3 litres were used for $10 \mathrm{~mm}$ of saturation, and 4 litres were used for $50 \mathrm{~mm}$ of saturation. Twelve $150 \mathrm{~mm}$ cube samples and twelve cylinder samples were tested with $10 \mathrm{~mm}$ of solution, and another twelve cylinders were tested with $50 \mathrm{~mm}$ of solution. All containers were covered with plastic wrap during freezing and thawing to minimize evaporation.

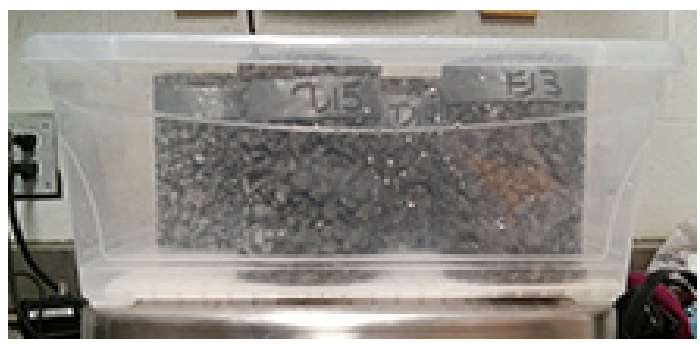

(a) $10 \mathrm{~mm}$

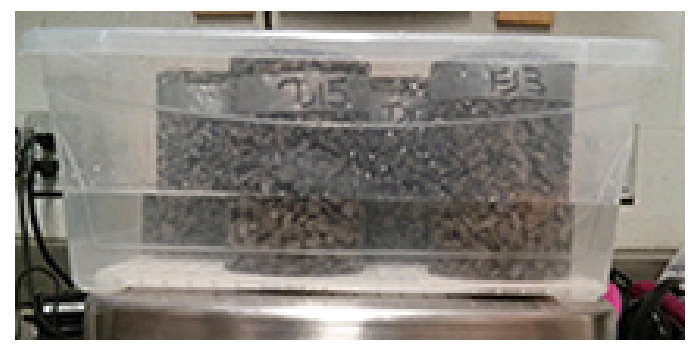

(b) $50 \mathrm{~mm}$

Figure 3.9: Containers filled with various levels of deicing solution. 
After every 5 cycles, the samples were removed from their containers at approximately 8 hours into the thawing cycle. This allowed the solution to thaw sufficiently so that no ice remained and also left enough time to complete the measurements before the freezing phase began. The samples were washed under a stream of water for at least 60 seconds, more for the larger cube samples, and brushed lightly to dislodge any scaled off material. Once a container has had all samples removed, a photograph was taken in order to get a general idea of the level of damage and mass of scaled off material. Due to the number of samples being tested at once, the total length of time for the washing procedure was over an hour. As the samples that were washed first would dry significantly during this time, each sample was placed on a cart in the curing room at $100 \%$ humidity as its washing cycle was completed. This would prevent inconsistent drying of the samples in laboratory air. After all the samples have been washed and placed in the curing room, the cart holding the samples would be tipped slightly in order to drained off the water that had accumulated. The cart was then moved to a controlled environment at 23 ${ }^{\circ} \mathrm{C}$ and $50 \% \mathrm{RH}$ for one hour to allow the samples to dry. During this time, an absorbent cloth was used to remove much of the excess water that still remained on the cart. Following this drying period, the mass of the samples were determined to $0.1 \mathrm{~g}$ in the same order they were washed. As the mass of each was taken, a photograph of the bottom of each sample was taken in order to assess the progression of damage.

The mass loss is calculated and presented as a percentage of the original mass of the samples. The deicing solutions were then replaced and the samples returned to their containers before the start of the next freezing cycle. At the end of 15, 30, and 50 cycles, four cylinder samples were to be tested for compressive strength.

In addition to the above testing condition, a partially saturated test was carried out using the large Caron programmable environmental chamber. The air temperature inside the chamber varied between $21{ }^{\circ} \mathrm{C}$ to $-18{ }^{\circ} \mathrm{C}$. The chamber required approximately 12 hours to lower the temperature down to $-18{ }^{\circ} \mathrm{C}$ and approximately 2 hours to raise the temperature up to $21{ }^{\circ} \mathrm{C}$. 
CHAPTER 3. MATERIALS AND EXPERIMENTAL METHODS

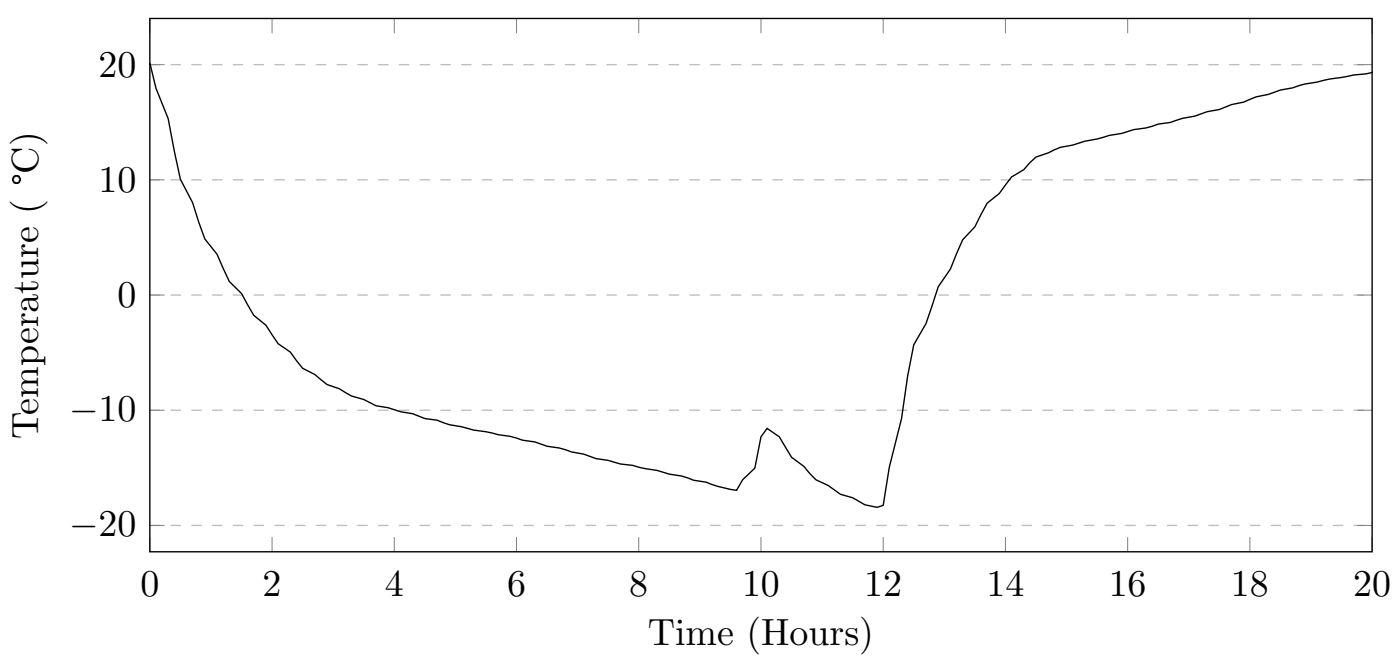

Figure 3.10: Typical air temperature profile of the Caron environmental chamber; peak is due to defrost system of the machine

The temperature change would begin every 12 hours, therefore one cycle would require 24 hours to complete. The cooling and heating rates were due to the limitations of the machine itself; due to the size of the chamber and the number of samples, the machine was unable to reduce the temperature at a faster rate. As with the freezer in the manual method, temperature loggers were placed in the machine in order to monitor the rate of temperature change. A typical plot of the output of the logger is shown in Figure 3.10. In this test, the bottom of the twelve cylinder samples were saturated in $10 \mathrm{~mm}$ of solution. Mass measurements were made every 7 cycles as the automation allows cycles to occur over the weekends as well. At the end of 14, 35, and 56 cycles, four cylinder samples were to be tested for compressive strength.

The influence of fibres and drying the samples was also tested using this method. One set (six samples) of the regular mix of pervious concrete was dried for one week at $50 \% \mathrm{RH}$ and $23^{\circ} \mathrm{C}$ following the 28 days of curing. Pervious concrete with the addition of fibres was cured for 28 days with one set dried for one week to determine the influence of both fibres and drying. Fewer samples were used for this test as there were no plans to test the compressive strength. 


\section{Drained Condition}

Another set of twelve cylinder samples followed the same procedure as above using the manual cycle but were thawed in a $\mathrm{CaCl}_{2}$ solution at room temperature. At the end of the freezing period, samples were removed from their containers and placed in prepared containers of $\mathrm{CaCl}_{2}$ solution and covered. The containers of solution were covered with plastic wrap for the majority of the test. The plastic wrap would be removed to place the samples in or to remove the samples from the containers. In order to maintain the desired concentration, the solution was replaced every 5 cycles. However, due to some losses, mainly from the solution adhering to the samples, additional solution would occasionally be added in order to ensure that the samples are completely submerged. Near the end of the thawing period, samples were removed from solution and placed on a grate to allow the excess liquid to drain. Once the dripping had stopped, samples were placed back in their original containers and covered before being placed back into the freezer. While the samples remain in solution for 12 hours on most days, they were removed after eight hours after every 5 cycles to be washed and weighed. For the last hour of the thawing cycle, they were placed back in the deicing solution before being drained as described above.

\subsubsection{Effects of Different Deicers}

The effects of different deicers were investigated using the salt scaling test and the paste study, as will be explained in this subsection.

\section{Salt Scaling}

The effects of different deicers on pervious concrete was evaluated using the manual 24 hour cycle partially saturated test. The test procedure was repeated as described above substituting 
the $\mathrm{CaCl}_{2}$ solution for the deicer of interest. The level of deicing solution was maintained at 10 mm only. In this study, the additional deicers include $\mathrm{NaCl}, \mathrm{MgCl}_{2}$, urea, potassium acetate, sodium acetate and CMA. All deicing solutions were kept at a concentration of $4 \%$ by weight and were replaced every 5 cycles.

Additionally, the effects of a smaller number of deicers was tested with the 24 hour cycle using the Caron environmental chamber, once again maintaining only $10 \mathrm{~mm}$ of saturation. The deicers tested under these conditions include $\mathrm{CaCl}_{2}, \mathrm{NaCl}, \mathrm{MgCl}_{2}$, and $\mathrm{CMA}$.

\section{Salt Exposure Without Freezing}

A number of samples that were tested for salt scaling using $\mathrm{MgCl}_{2}$ and $\mathrm{CMA}$ were submerged in their respective deicers once the salt scaling test had concluded. The samples were submerged to a depth of $50 \mathrm{~mm}$ in a $4 \%$ concentration solution and kept at $38{ }^{\circ} \mathrm{C}$. The solution was replaced every month to help ensure the desired concentration. This test was done in order to determine if any form of severe deterioration would occur from the exposure to these deicers at higher temperatures.

\subsection{Summary of Test Methods}

The methods will be defined by the total length of one cycle in hours, whether or not a programmable environmental chamber was used, and the level of submersion while samples are frozen. The use of a programmable environmental chamber will be termed "auto", while the use of a freezer will be termed "manual". A submersion level of $0 \mathrm{~mm}$ refers to a drained condition. Table 3.4 summarizes the naming convention used when referencing each test. The number of samples and the deicers used for each test are shown in table 3.5. 
Table 3.4: Naming of each test method.

\begin{tabular}{lllll}
\hline Method & $\begin{array}{l}\text { Cycle } \\
\text { length }\end{array}$ & $\begin{array}{l}\text { Auto or } \\
\text { manual }\end{array}$ & $\begin{array}{l}\text { Submersion } \\
\text { level }(\mathrm{mm})\end{array}$ & Name \\
\hline 1 & 12 & Auto & 0 & $12-\mathrm{A}-00$ \\
2 & 12 & Auto & 50 & $12-\mathrm{A}-50$ \\
3 & 16 & Auto & 75 & $16-\mathrm{A}-75$ \\
4 & 24 & Manual & 10 & $24-\mathrm{M}-10$ \\
5 & 24 & Manual & 50 & $24-\mathrm{M}-50$ \\
6 & 24 & Manual & 0 & $24-\mathrm{M}-00$ \\
7 & 24 & Auto & 10 & $24-\mathrm{A}-10$ \\
\hline
\end{tabular}

Table 3.5: Number of samples and deicers used.

\begin{tabular}{|c|c|c|c|c|}
\hline \multirow[b]{2}{*}{ Test } & \multicolumn{3}{|c|}{ Number of samples per set } & \multirow[b]{2}{*}{ Deicers used } \\
\hline & $\begin{array}{l}100 \mathrm{~mm} \\
\text { cubes }\end{array}$ & $\begin{array}{l}150 \mathrm{~mm} \\
\text { cubes }\end{array}$ & Cylinders & \\
\hline $12-\mathrm{A}-00$ & 18 & 0 & 9 & $\mathrm{CaCl}_{2}$ \\
\hline $12-\mathrm{A}-50$ & 0 & 0 & 9 & $\mathrm{CaCl}_{2}$ \\
\hline $16-\mathrm{A}-75$ & 0 & 0 & 9 & $\mathrm{CaCl}_{2}$ \\
\hline 24-M-10 & 0 & 12 & 12 & $\mathrm{CaCl}_{2}$, all (for cylinders) \\
\hline 24-M-50 & 0 & 0 & 12 & $\mathrm{CaCl}_{2}$ \\
\hline 24-M-00 & 0 & 0 & 12 & $\mathrm{CaCl}_{2}$ \\
\hline $24-\mathrm{A}-10$ & 0 & 0 & 12 & $\mathrm{CaCl}_{2}, \mathrm{NaCl}, \mathrm{MgCl}_{2}, \mathrm{CMA}$ \\
\hline
\end{tabular}




\section{Chapter 4}

\section{Results and Analysis}

\subsection{Statistics and Interpretation of Results}

Due to the small number of samples and the variability of test results, some statistical analysis was used in interpreting the significance of the results. Where shown, error bars extend $\pm \sigma$ (standard deviation) from the average to illustrate the variability of the results. Where applicable, a one-tailed t-test with a 95\% confidence interval was selected to detect any significant reduction in compressive strength or increase in mass loss. An F-test would first be used to determine if the variances of the two sets were equal prior to conducting the t-test. Box and whisker plots are also used to illustrate the variability between samples within the same set. A one-way ANOVA analysis was first performed to determine if any significant difference exists between the damage caused by different deicers. The Tukey-Kramer test (again with a 95\% confidence interval) was then performed using the built in function in MATLAB to determine where the significant differences between the damage caused by different deicers lie. The results of which are illustrated by graphs where the average was plotted with horizontal lines representing the comparison intervals between the different deicers. A horizontal overlap of these 
intervals would indicate that a significant difference does not exist between the two deicers. This statistical analysis method was selected due to the resulting difference in sample sizes, particularly in the later stages of testing as some samples were removed to determine compressive strength. The results from the statistical analysis do not provide a definitive answer but rather serves as a guide in interpreting the results.

\subsection{Drained 12-hour Cycle}

Both the cylinder and the $100 \mathrm{~mm}$ cube samples exposed to the $\mathrm{CaCl}_{2}$ solution showed minimal amounts of mass loss. An average of $0.45 \%$ for the cubes and $0.86 \%$ for the cylinders after 52 cycles. The mass loss is mainly a result of the removal of small pieces of cement. The 100 mm cube samples did not show any loss of compressive strength (Figure 4.1a), however the large variance between samples makes the results inconclusive. The cylinder samples showed a statistically significant reduction in compressive strength of only $0.5 \mathrm{MPa}$ after 52 cycles (Figure 4.1b). A comparison between the two compressive strength plots reveals a larger variability between for the $100 \mathrm{~mm}$ cubes when compared to the cylinders (Figure 4.2). Despite the results of the statistical analysis, a loss of compressive strength can be assumed due to the loss of cementitious material. While the average mass loss seems to be higher in the cylinder samples compared to the cubes, it is difficult to draw a real conclusion due to the variability within each set of samples. Figure 4.4 illustrates the variability between the mass loss within each set of samples. Although a slight difference is present, the overall low mass loss for both types of samples (Figure 4.3) makes the readings quite sensitive to slight variations in mass. The apparent mass gain is likely due to the water content of each sample. As the samples are left to dry in an uncontrolled environment for a set amount of time, the level of evaporation will be different depending on the temperature and humidity of the room. In order for the test to be less sensitive to minor variations in mass changes (from water content), a method resulting 
in more damage needs to be selected. The consistency of the compressive strength results of the cylinders makes it more suitable for detecting damage to the samples when only a small amount of mass loss occurs. As a relatively small number of samples are used for compressive strength testing, it would be beneficial to select samples that minimize the variability in order to obtain more precise results.

While this method seems more representative of field conditions where a properly functioning pervious concrete pavement is expected to drain water, the minimal levels of damage will make it difficult to differentiate between the resistance of different pervious concrete mixes to salt scaling. As the samples were only removed and submerged once every 4 cycles (48 hours), it is possible the samples dried out during the third and fourth cycles. This would result in little damage as the level of damage tends to increase with the degree of saturation of the cement paste. If the samples were removed and saturated more often, it would likely have increased the level of damage.

Overall there does not appear to be any practical difference between the mass loss results of the cubes compared to the cylinders. However, the consistency of the compressive strength results are much more favourable for the cylinders. Based on this result, cylinders were used for most of the remaining parts of the study to evaluate salt scaling in terms of both mass loss and strength reduction. 


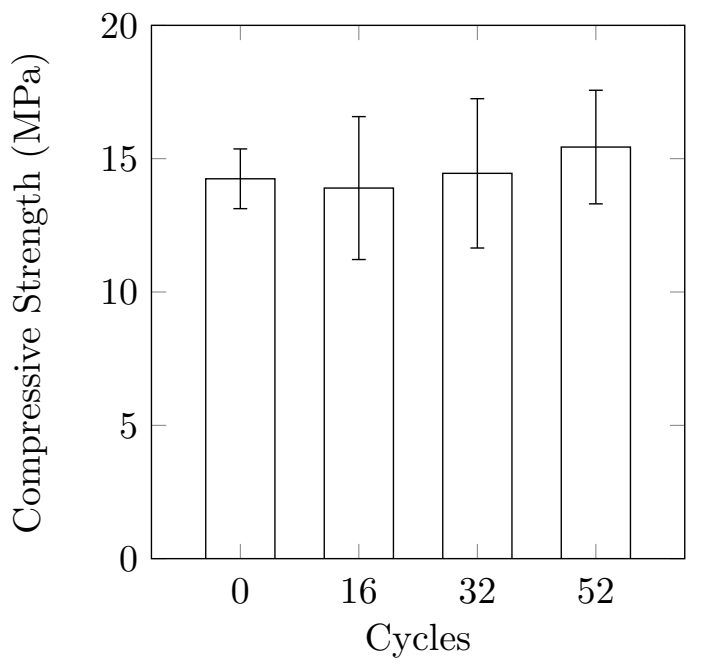

(a) $100 \mathrm{~mm}$ cubes

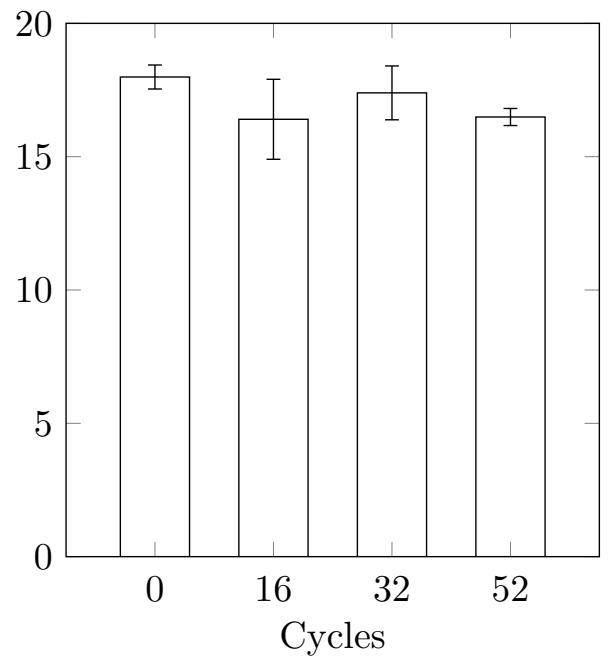

(b) Cylinders

Figure 4.1: Compressive strength changes under the 12-A-00 method.

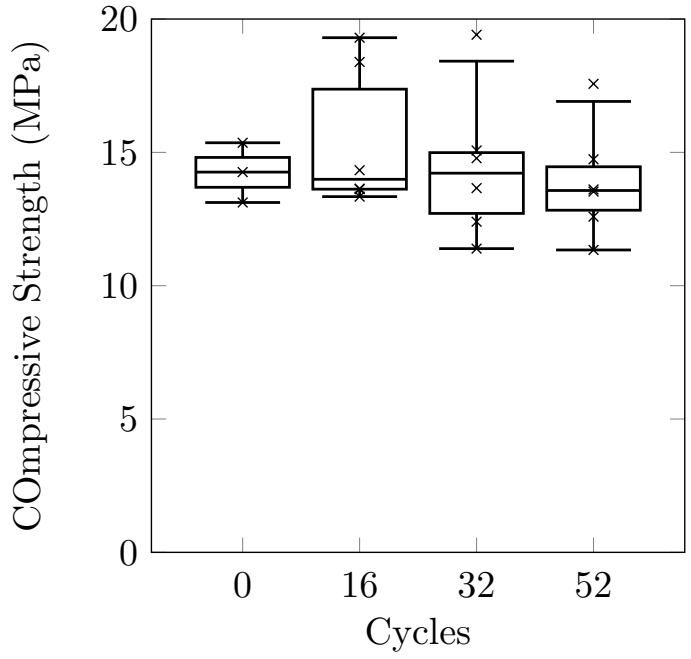

(a) $100 \mathrm{~mm}$ cubes

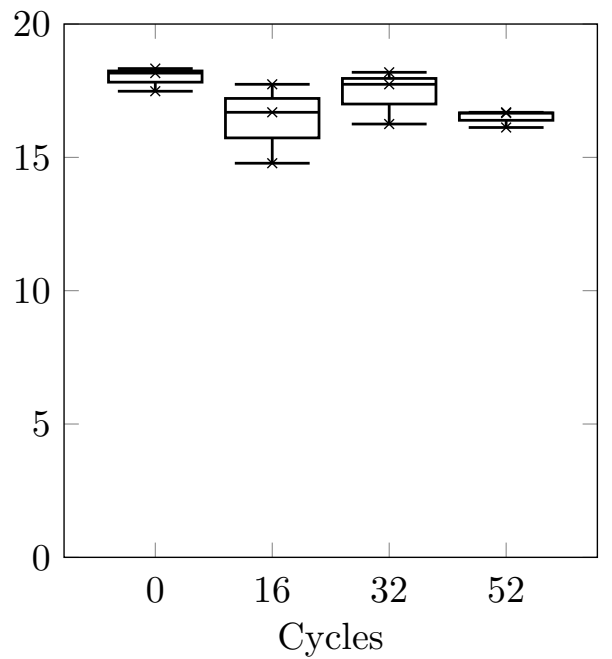

(b) Cylinders

Figure 4.2: Comparison of compressive strength variation within each set of samples under the 12-A-00 method. 


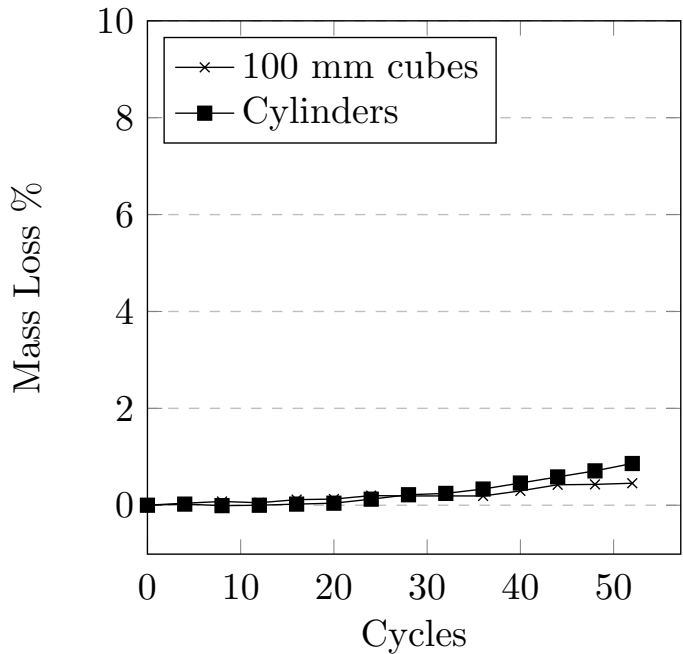

(a) Large scale

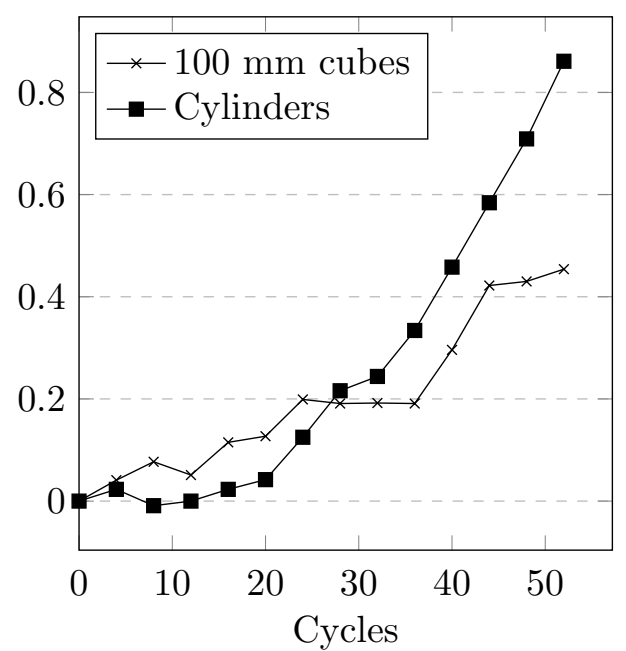

(b) Magnified scale

Figure 4.3: Average mass loss for both sets of samples under 12-A-00 method. (a) A large scale is used to illustrate the relatively low levels of damage. (b) Magnification of the previous plot to illustrate the difference between the sample shapes.

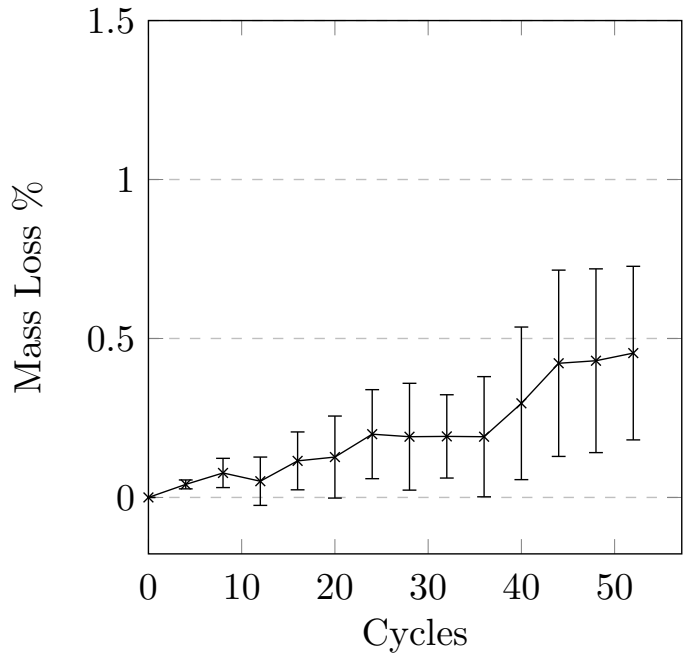

(a) $100 \mathrm{~mm}$ cubes

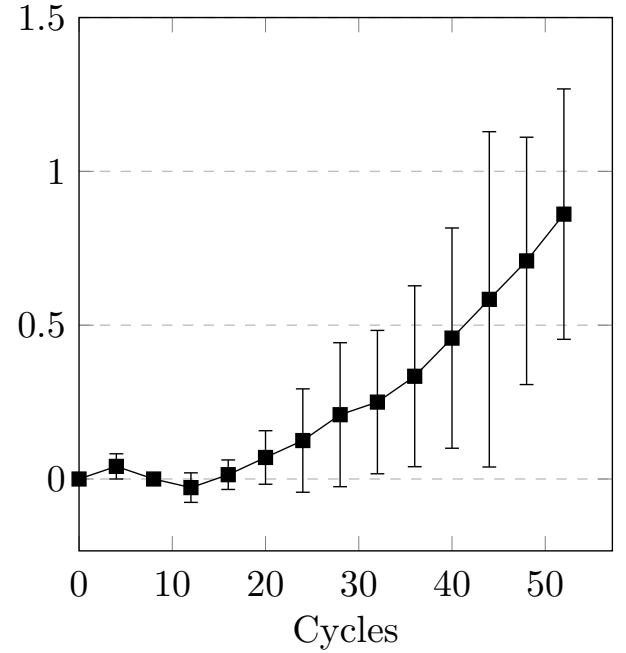

(b) Cylinders

Figure 4.4: Comparison of the variation of mass loss within each set of samples under the 12-A-00 method. 


\subsection{Partially Saturated 12-hour Cycle}

The cylinders had an average mass loss of $0.45 \%$ after 52 cycles, which is less than the average mass loss of the cylinders from the previous test. The samples also did not show any reduction in compressive strength after 52 cycles (Figure 4.5). On average it appears that there is an increase in compressive strength, however, the variability leads to fairly inconclusive results. As a large volume of solution was required to maintain the level at $50 \mathrm{~mm}$, the duration of the thawing phase was not sufficient to completely thaw the entire container. As a result, the samples did not undergo complete freezing and thawing cycles, resulting in less damage.

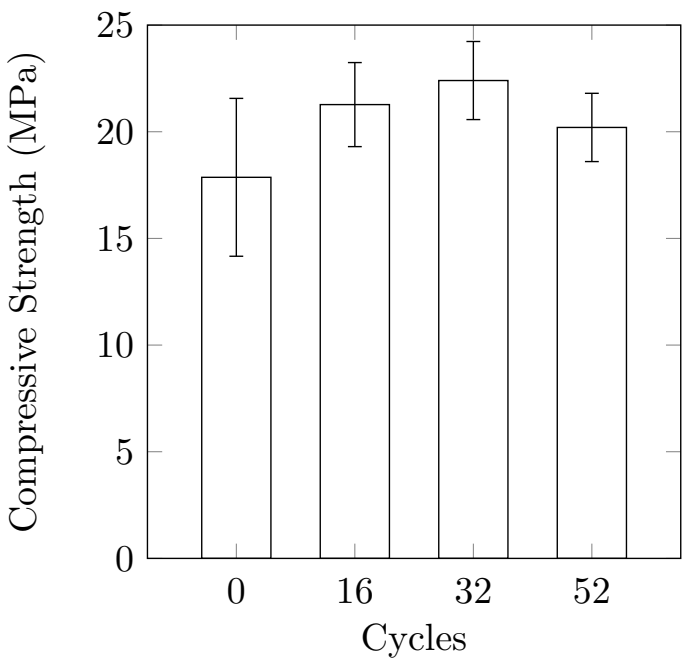

(a)

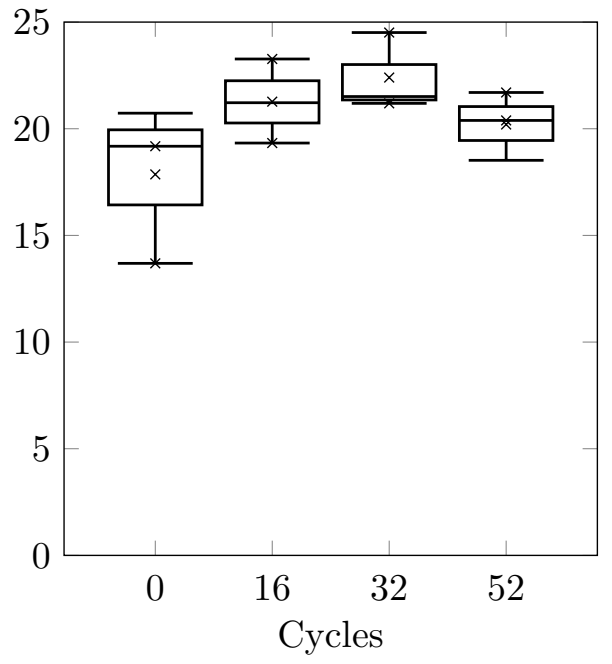

(b)

Figure 4.5: Compressive strength changes under the 12-A-50 method. (a) An increase in compressive strength. (b) Box and whisker plot illustrating the variability of the test results.

\subsection{Partially Saturated 16-hour Cycle}

This method was selected to ensure complete freezing and thawing of the solution based on the 12-hour cycle results. This was achieved by: (a) using cylinder moulds to minimize the amount of $\mathrm{CaCl}_{2}$ solution needed to submerge the samples, and (b) lengthening the thawing period. 
The mass loss was again in the form of small pieces of cement scaling off of the sample. In Figure 4.6a, an exposed aggregate can be seen as the cement has scaled off from the surface. While it appeared that the mass loss was minimal after 48 cycles (average of $0.67 \%$ ) (Figure 4.8), the three remaining samples split in half after 54 cycles (Figure 4.6b). It appears as though the damage was concentrated near the mid-height of the sample, which was also the height of the mould and $\mathrm{CaCl}_{2}$ solution. This is likely due to stress concentration at the middle of the cylinders. It is believed that the formation of ice put both lateral compression and axial tension on the sample at the interface between solution at air, and this could have caused the damage. Sudden failure of the samples is not ideal as it becomes difficult to gauge the level of damage. The simultaneous splitting of the three samples could possibly have been due to chance. The low apparent mass loss makes the results quite volatile as it is possible that certain samples may undergo significantly more cycles if it is slightly more resilient to salt scaling.

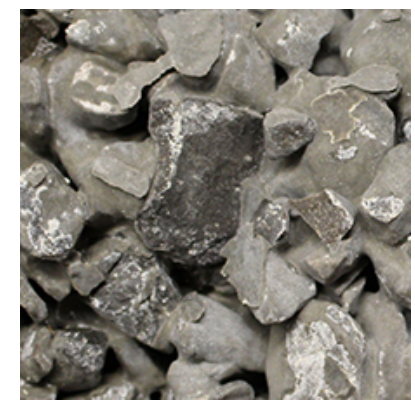

(a)

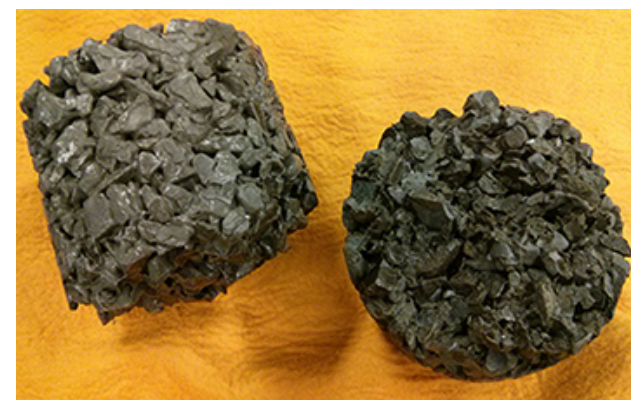

(b)

Figure 4.6: Damage to samples subjected to the 16-A-75 test. (a) Cement stripped off the surface of an aggregate. (b) A cylinder sample split in half after 54 cycles.

The compressive strength of these samples could not be tested after 54 cycles for obvious reasons. There appears to be a statistically significant reduction in compressive strength after 36 cycles (Figure 4.7). 


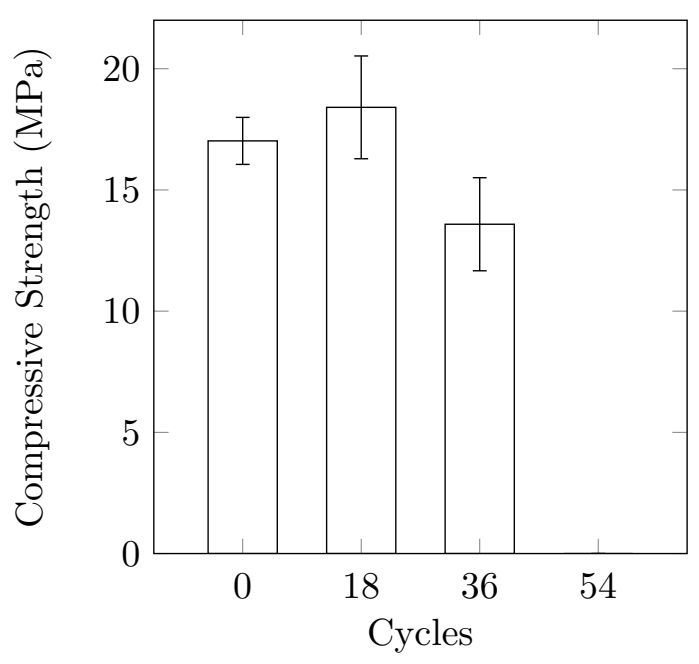

(a)

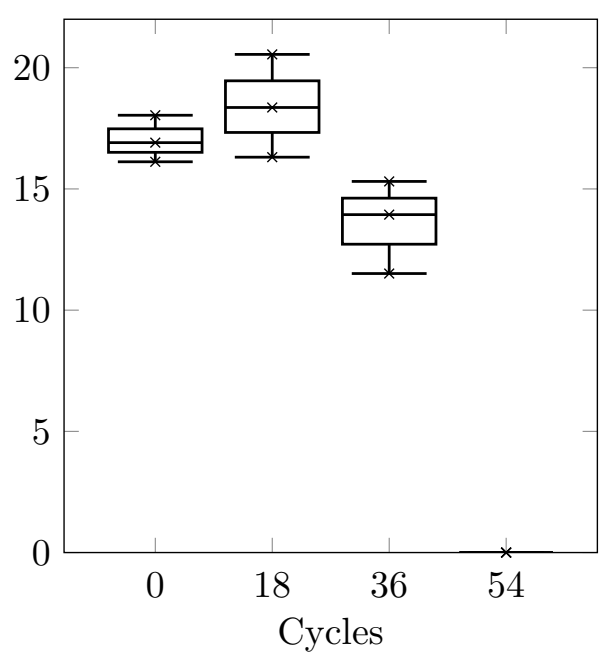

(b)

Figure 4.7: Compressive strength changes under the 16-A-75 method. (a) A reduction in compressive strength. (b) Box and whisker plot illustrating the variability of the test results.

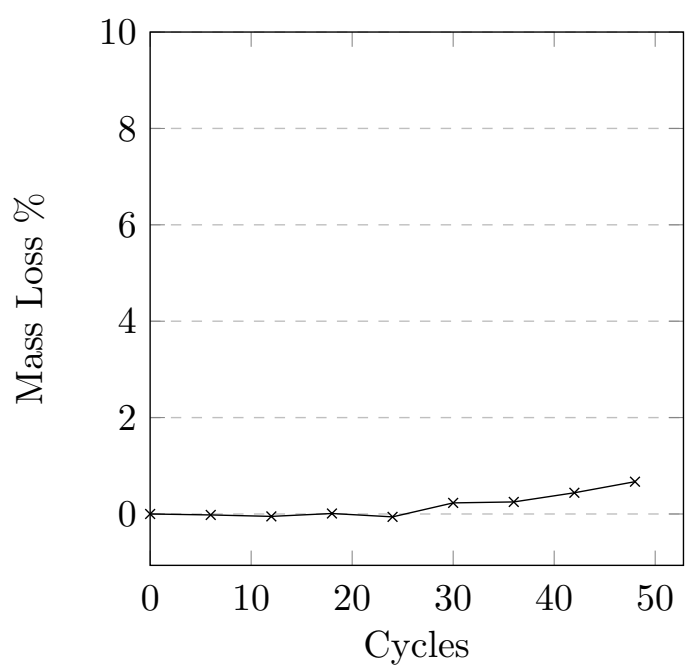

(a) Large scale

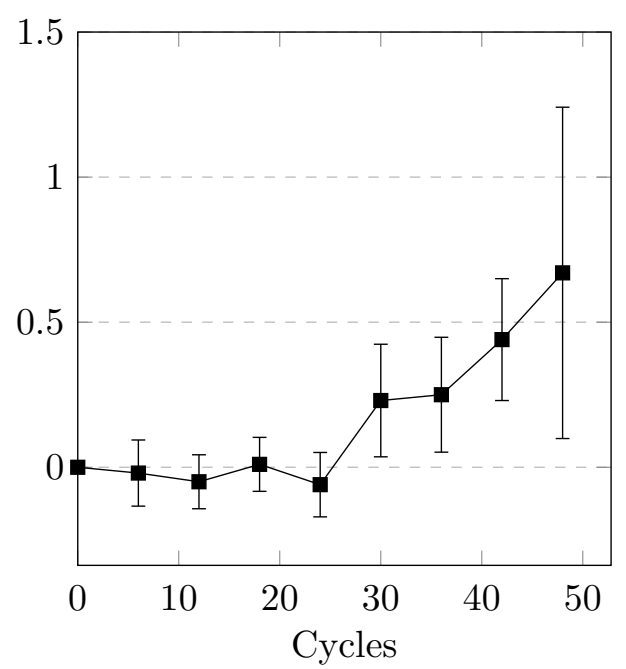

(b) Magnified scale

Figure 4.8: Average mass loss for cylinders under the 16-A-75 method up to 48 cycles. 


\subsection{Drained and Partially Saturated 24-hour Cycle}

\section{Level of Saturation and Sample Geometry}

This test method was employed in order to make sure that complete freezing and thawing took place in the samples to obtain measurable damage. The initial mass loss was similar to the previous tests where the small cement flakes would scale off. However, as the test progressed, it was apparent that the quantity of mass loss was much higher. As the pervious concrete samples loss the thin layer of cement, individual aggregates would break off from each sample. This resulted in much higher mass loss when compared to earlier tests as the samples suffered a more significant loss of cement and a subsequent loss of aggregates. Some damage to the aggregates themselves can also be seen.

The compressive strength for many samples could not be tested due to significant mass loss. Comparing the mass loss of $150 \mathrm{~mm}$ cubes and the cylinders shows that the general trend between the two types of samples are similar while the trends between various levels of saturation are quite different (Figure 4.9). Figures 4.10 to 4.12 show the variation of mass loss for the samples within each testing condition. It is apparent that under the drained and $50 \mathrm{~mm}$ conditions large variations between samples exist in the later stages of the test. At 35 cycles, both the drained and $50 \mathrm{~mm}$ conditions appeared to be more consistent than both the cubes and cylinders under the $10 \mathrm{~mm}$ conditions. For both the cubes and cylinders under $10 \mathrm{~mm}$ of solution, the variation was much lower and the mass loss was more gradual in the later cycles.

While gradual at first, the samples tested under $50 \mathrm{~mm}$ of solution showed jumps in mass loss due to large pieces breaking off (Figure 4.13). This is similar to the results of the 16-A-75 test where the damage was concentrated near the top of the height of the solution. The level of damage from the samples tested under the drained condition appeared to be quite low initially. However, as was the case with the samples exposed to $50 \mathrm{~mm}$ of solution, large sections would 


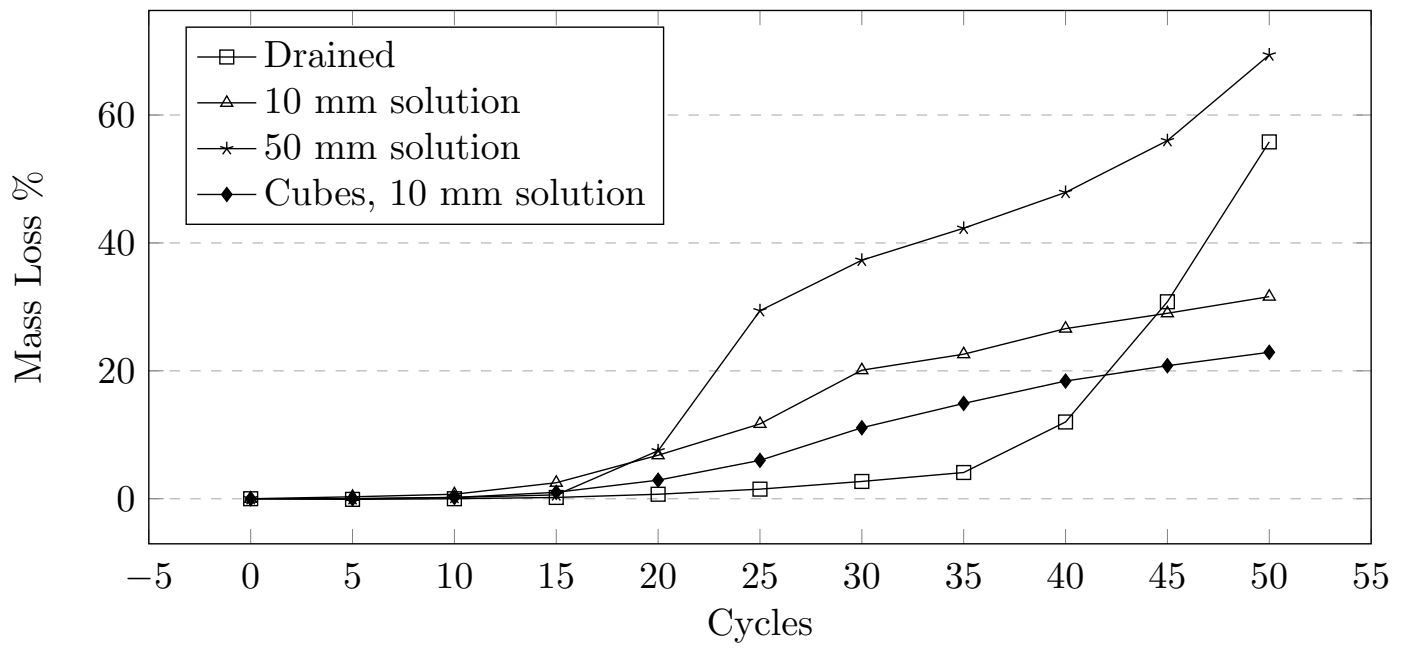

Figure 4.9: Comparison of average mass loss for different shapes and levels of saturation under the 24-hour manual cycle using $\mathrm{CaCl}_{2}$ solution.

break off, leading to a sudden increase in mass loss. This again suggests that the loss of cement was concentrated in one area. The samples were placed in the freezer immediately after the excess solution is allowed to drain. As the solution continues to drain, the bottom portions of the samples will be more saturated than the top, developing a sort of saturation gradient. As the samples were drained the same way for each cycle, the gradient will be quite similar each time. The region with the critical level of saturation will suffer the most damage. Although the very bottom of the sample would be expected to have suffered the most damage, this was not the case as the bottom piece was still intact when it had broken off. This is possibly due to some segregation of the cement paste when the samples were cast, making the bottom portion of the samples stronger due to an increased amount of paste. It is also possible that past a certain level of saturation, it acts as if it were submerged. As seen in the 16-A-75 and $50 \mathrm{~mm}$ case, the damage was concentrated near the top of the solution, rather than at the bottom.

After 50 cycles, on average, samples exposed to $50 \mathrm{~mm}$ of solution exhibited the highest levels of mass loss, followed by the drained condition, while the samples exposed to only $10 \mathrm{~mm}$ had the lowest levels of mass loss. In contrast to the earlier drained test method (12-A-00), where 


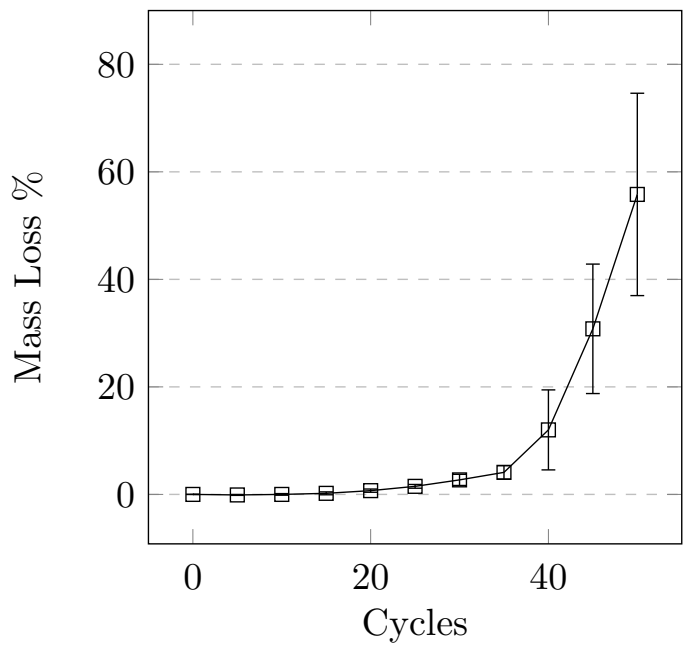

(a) Drained

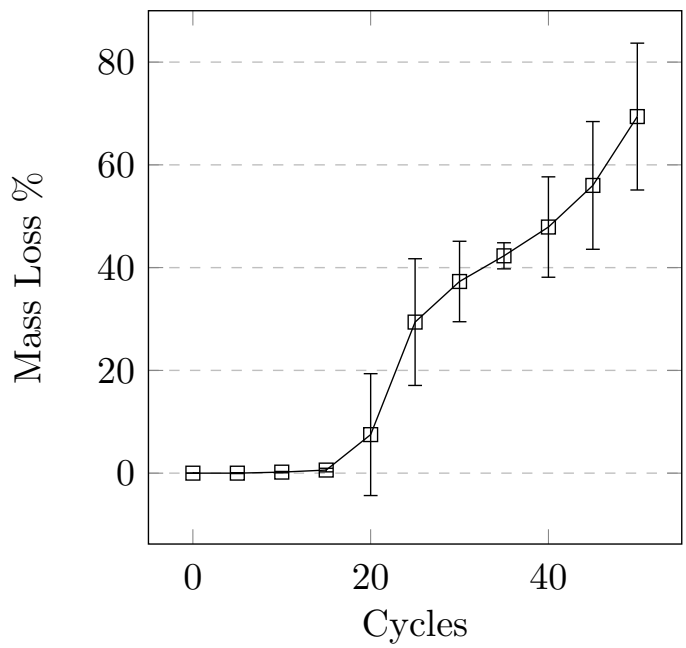

(c) $50 \mathrm{~mm}$ solution

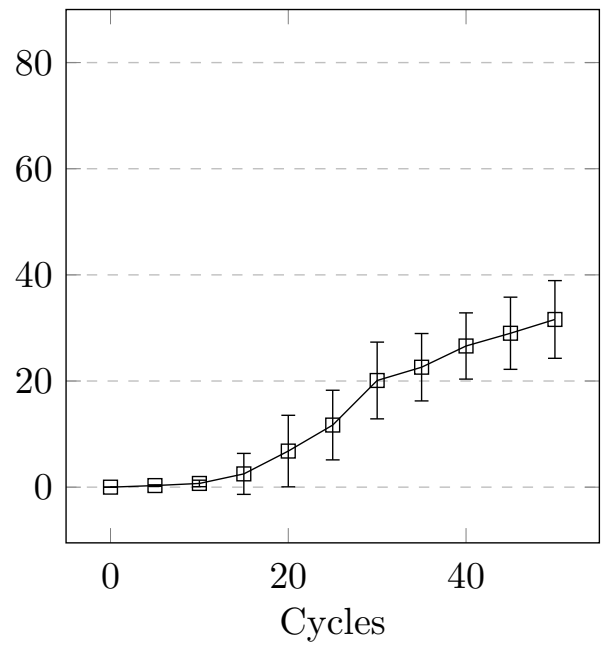

(b) $10 \mathrm{~mm}$ solution

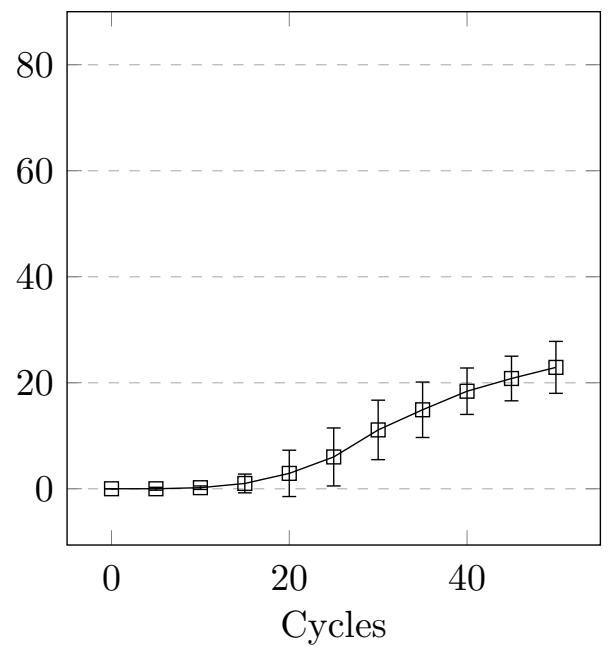

(d) Cubes, $10 \mathrm{~mm}$ solution

Figure 4.10: Mass loss comparison of samples under the 24-hour manual method with error bars. 


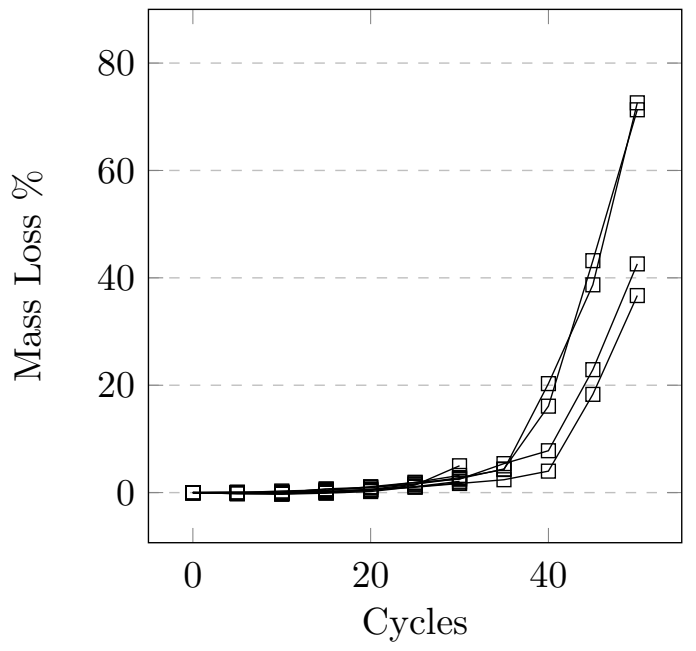

(a) Drained

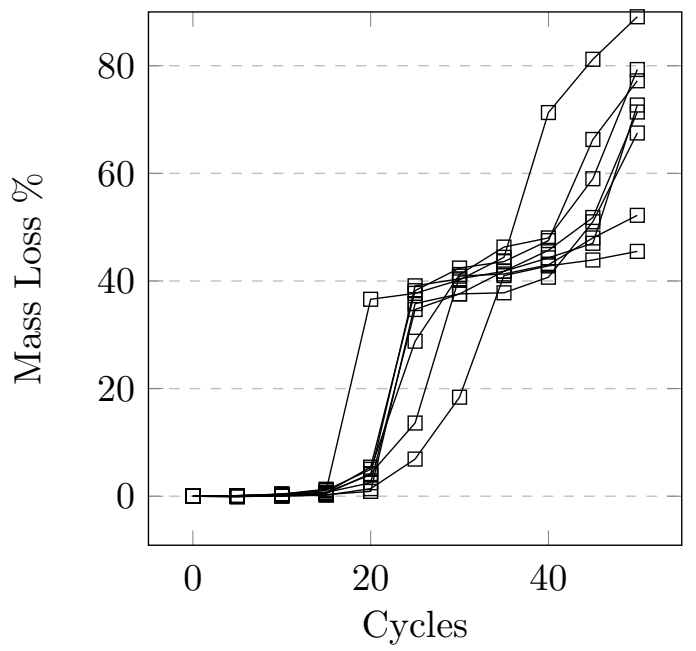

(c) $50 \mathrm{~mm}$ solution

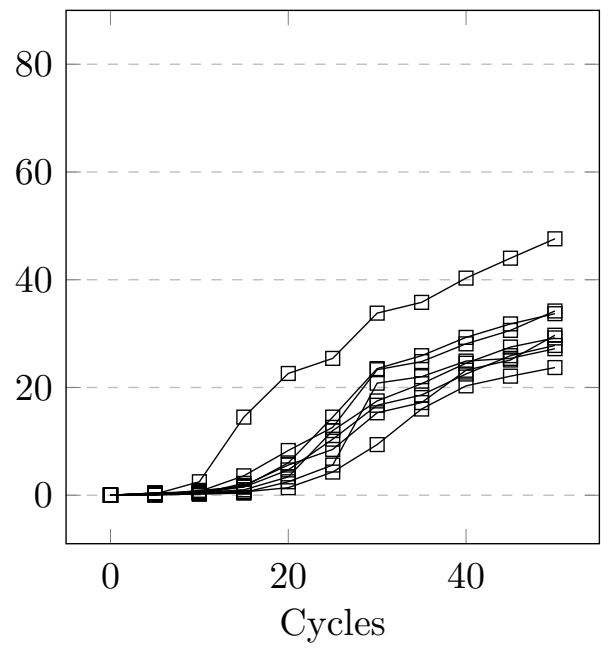

(b) $10 \mathrm{~mm}$ solution

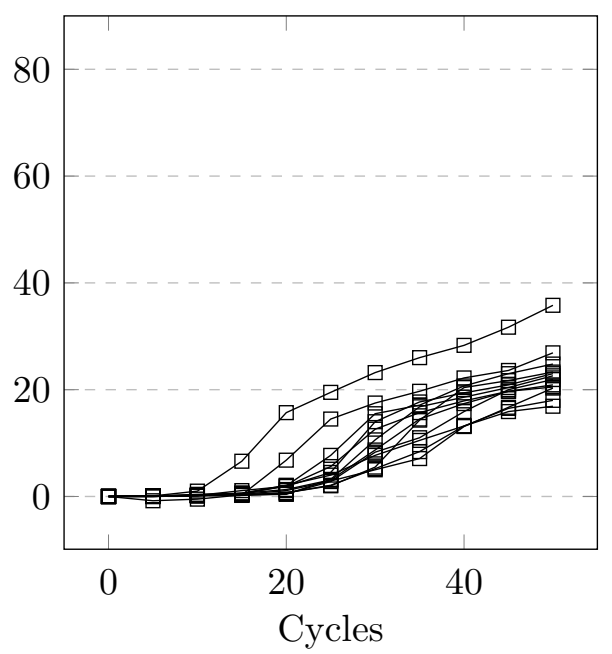

(d) Cubes, $10 \mathrm{~mm}$ solution

Figure 4.11: Mass loss of individual samples tested under the 24-hour manual method. 


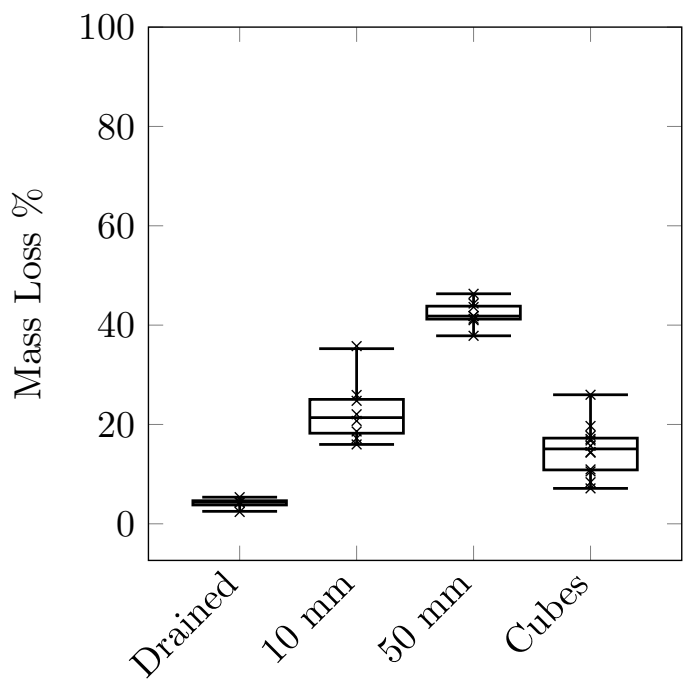

(a) 35 Cycles

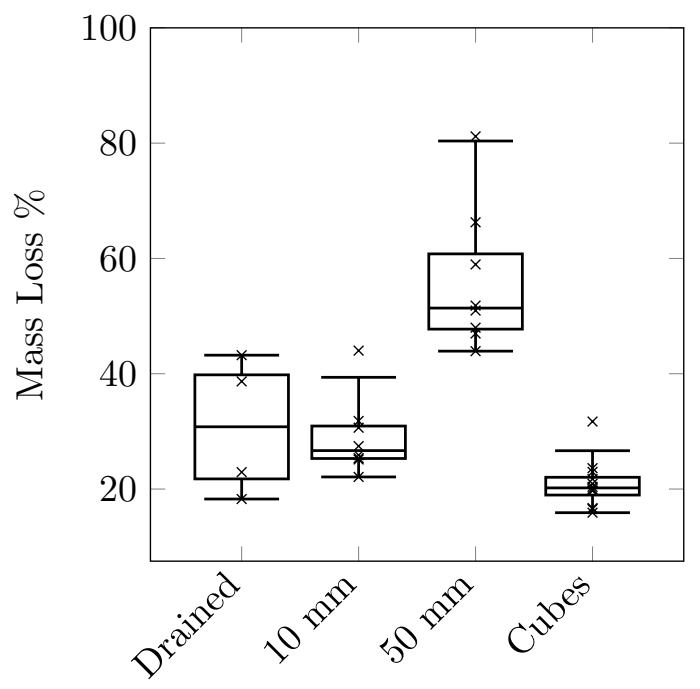

(c) 45 Cycles

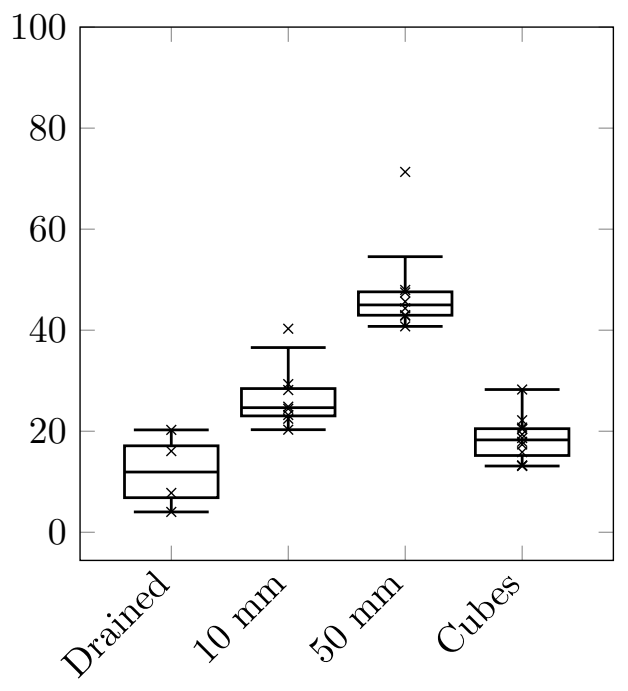

(b) 40 Cycles

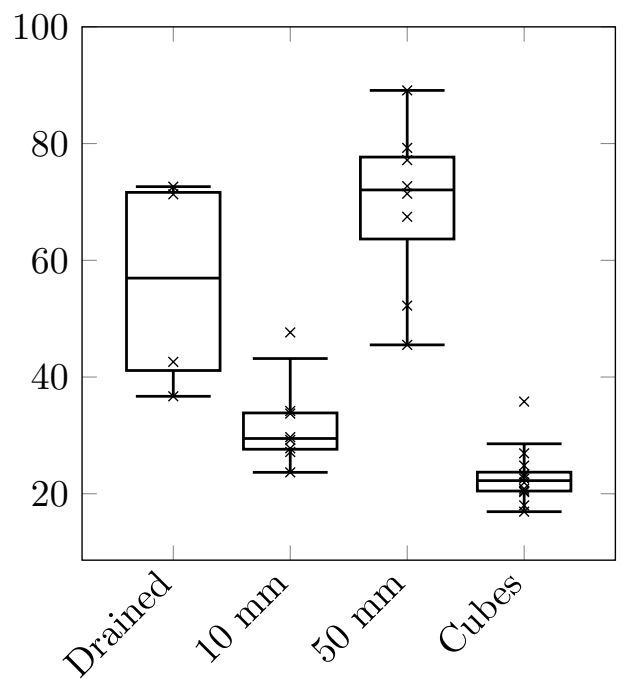

(d) 50 Cycles

Figure 4.12: Box plots showing the variability of mass loss within each set of samples under the 24-hour manual method. 


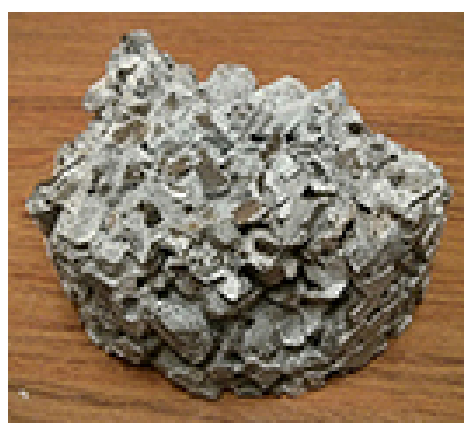

Figure 4.13: A large intact piece of pervious concrete broken off from the bulk of the sample while being tested with the 24-M-50 method.

samples were saturated only once every four cycles, the samples in the 24-M-00 method were far less likely to dry out completely since they were submerged after every cycle for the entirety of the thawing period.

In subsequent tests, a partial saturation level of $10 \mathrm{~mm}$ with the use of the cylinder samples was selected largely due to convenience. While the consistency of the $150 \mathrm{~mm}$ cubes appeared to be slightly higher, the large size made them more difficult to handle. In addition, the ease of casting of cylinders allowed a larger number of cylinders to be made and tested at once.

\subsection{Partially Saturated Automatic 24-hour Cycle}

\section{Comparison to Manual 24-hour Cycle}

The average mass loss of the samples in the $\mathrm{CaCl}_{2}$ solution after 49 and 56 cycles was $5.26 \%$ and $7.86 \%$ respectively. This is much lower than the $31.64 \%$ mass loss after 50 cycles shown by the previous test (24-M-10) where the samples were moved manually. A similar trend can be seen with the other deicers used (Figure 4.15). In both methods, there appears to be an increase in variability of samples within the same set as the level of damage increases. At first it was thought that the increase in damage was due to the rapid change in temperature in 
the manual method causing the higher levels of damage as the environmental chamber takes more time to ramp the temperature up and down. As the length of time required to bring the temperature down was quite long, the length of time where the samples were frozen may also have been reduced. Thermocouples monitoring the temperature of the solution showed that typically, the rate of cooling and the minimum temperature reached for both sets of samples were quite similar (Figure 4.14).

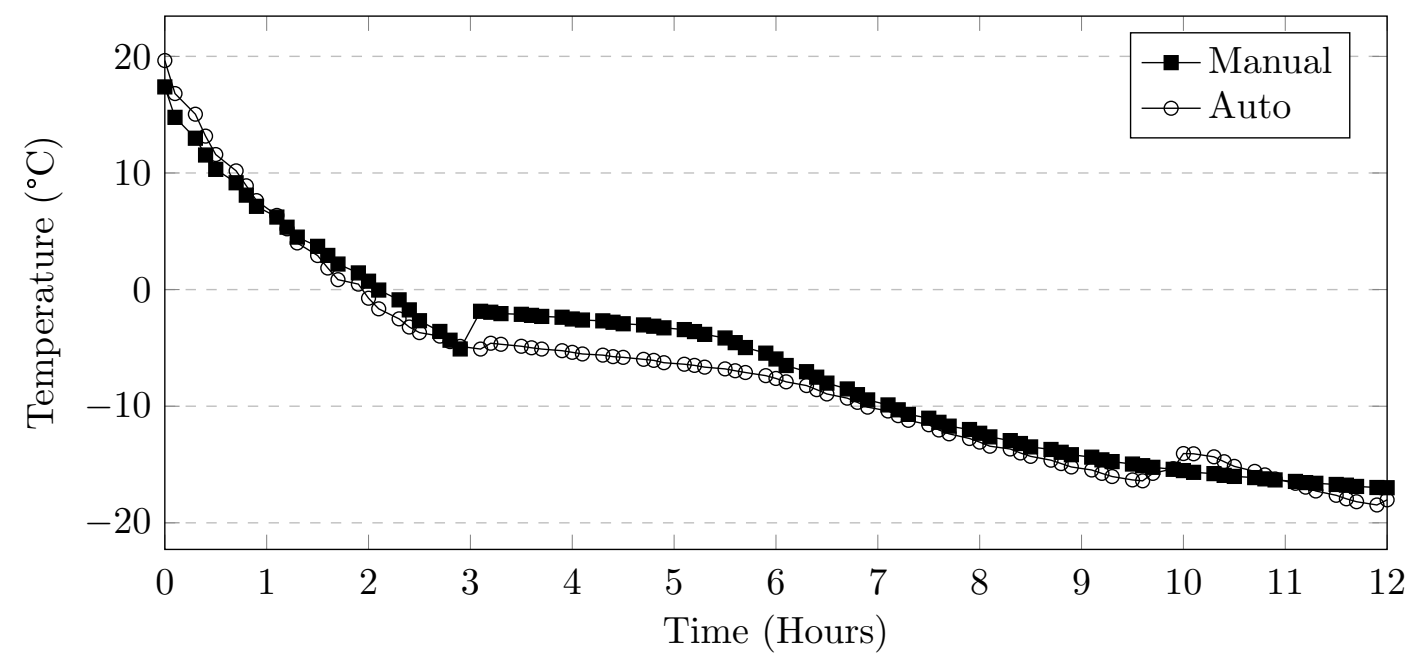

Figure 4.14: Comparison of deicing solution temperature. Temperature spike likely due to freezer defrost system.

Another probable cause could be due to the way samples were handled in each case. As damage accumulates, broken pieces (whether cement or aggregate) remain loosely attached to the remaining bulk of the sample. Since the damage occurs in the portion of the sample submerged in the solution, the broken aggregate may act as a platform separating the remaining sample from the solution, preventing further damage. In the manual method, the containers are moved daily (with the exception of weekends), causing these "platforms" to break apart and potentially knocking the samples over. The loss of the platform causes the samples to once again be submerged in the solution, allowing more damage to occur. This is supported by the fact that at times a significant amount of material detaches from the bulk of the sample during the wash. Daily movement of the samples increases the probability of this occurring in 


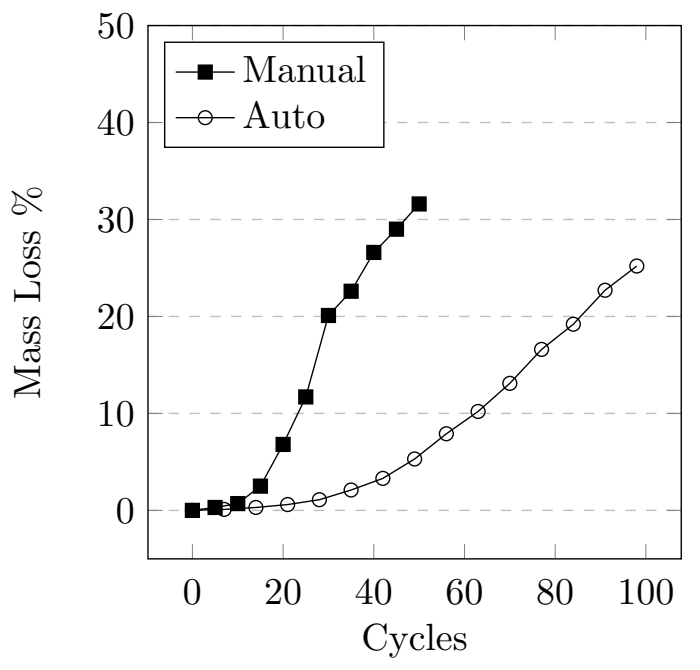

(a) $\mathrm{CaCl}_{2}$

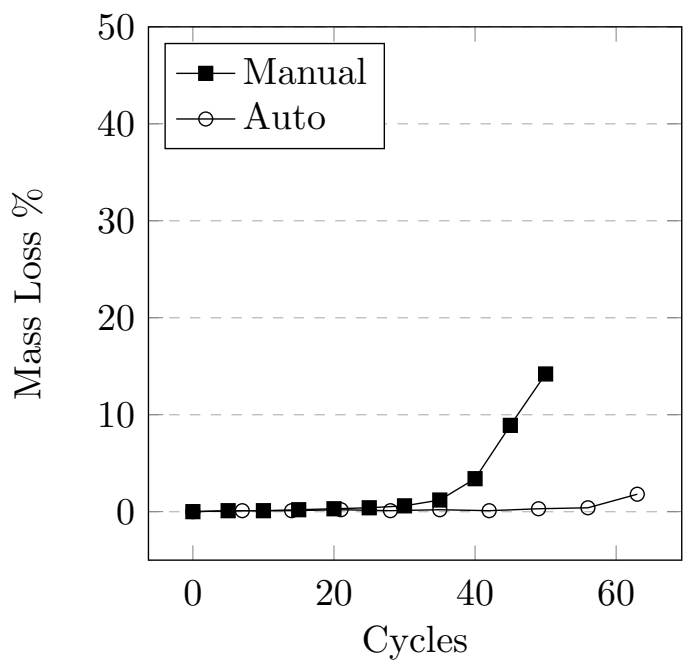

(c) $\mathrm{MgCl}_{2}$

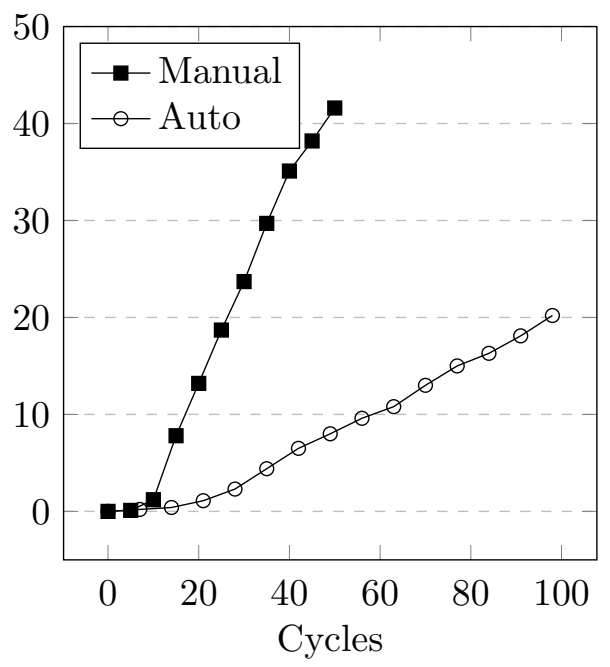

(b) $\mathrm{NaCl}$

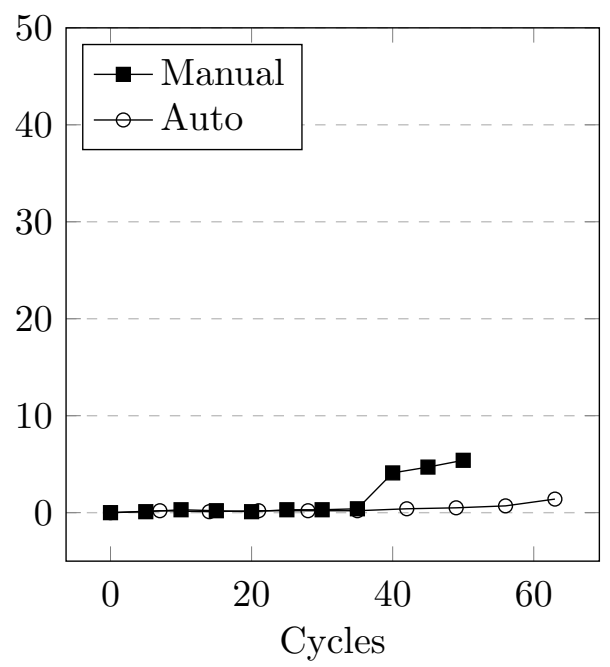

(d) CMA

Figure 4.15: Comparison of average mass loss for samples exposed to different deicers using either the 24-M-10 (manual) or the 24-A-10 (auto) methods. 


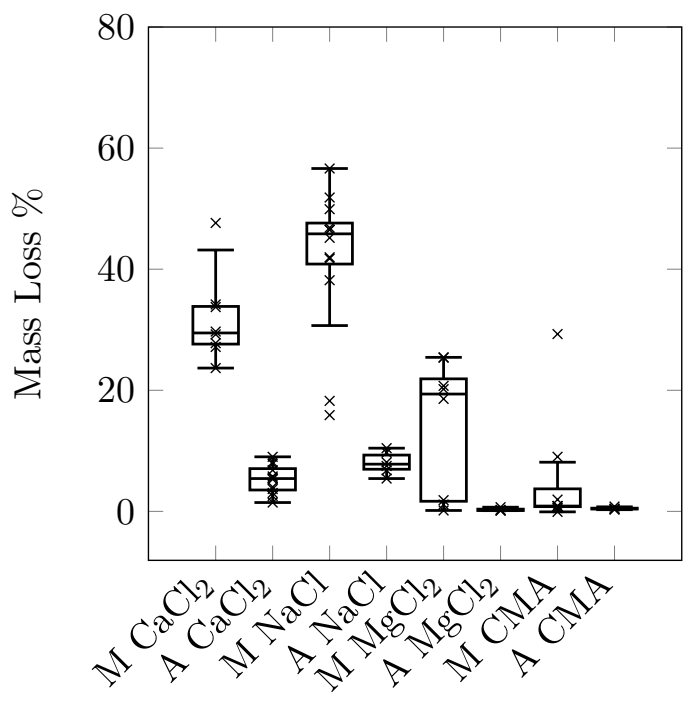

(a) M 50 cycles, A 49 cycles

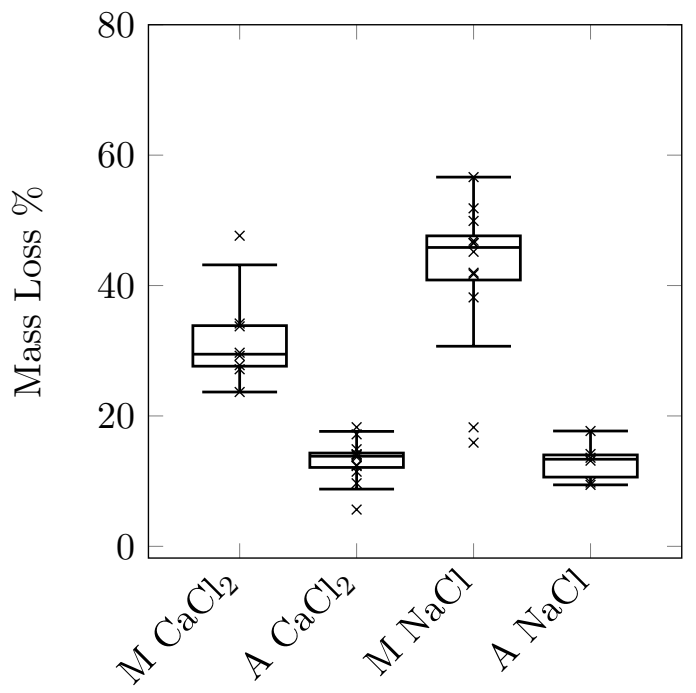

(c) M 50 cycles, A 70 cycles

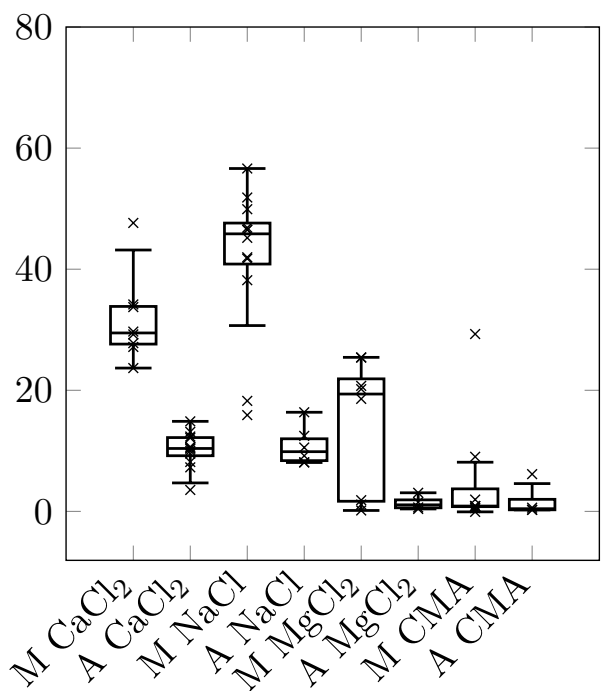

(b) M 50 cycles, A 63 cycles

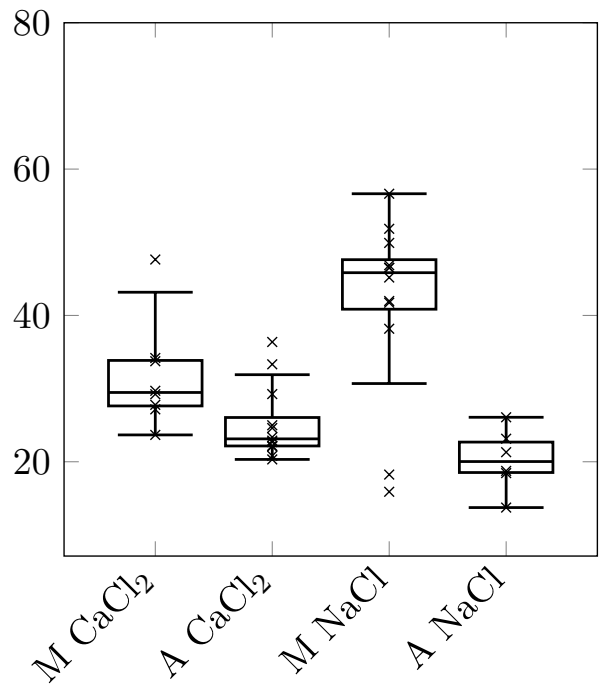

(d) M 50 cycles, A 98 cycles

Figure 4.16: Comparison of mass loss of samples exposed to different deicers under either 24-M-10 (M) at 50 cycles or 24-A-10 (A) at various cycles. 
the container between washouts. That is of course an extreme case, however, the damage is generally seen to begin around the circular perimeter of the bottom of the samples. Pieces that have broken off and remain undisturbed may protect the remaining sample as if it were still attached to the perimeter, perhaps by confining the sample. Additionally, washing is done only once every 7 cycles for the automatic method whereas it is done every 5 cycles for the manual method. At a given number of cycles, the manual method would have done more washouts when compared with the automatic method, thus removing material from the samples and containers more frequently.

One way to test this discrepancy would be to reduce the movement of the containers by turning off the freezer and allowing the samples to thaw inside. The freezer doors should be opened to allow the temperature to increase more rapidly since the freezer will be well insulated. A programmable environmental chamber could be made to complete only 5 cycles per week by leaving the samples frozen over the weekends. If possible, the freezing and thawing rate of the freezer should be matched by the environmental chamber.

\section{Influence of Drying and Fibres}

Samples that were allowed to dry for a week at $23^{\circ} \mathrm{C}$ and $50 \% \mathrm{RH}$ after curing for 28 days did not show any improved resistance to salt scaling. Drying (after curing samples under $>95 \%$ $\mathrm{RH}$ ) is thought to improve salt scaling resistance due to the reduced level of saturation. It is possible that the thin layer of cement paste saturates rather quickly while submerged in the deicing solution.

Samples with the addition of fibres also did not show any improve resistance to salt scaling. The thin layer of paste and lack of fine aggregate may be unable to adequately bond to the fibres. 


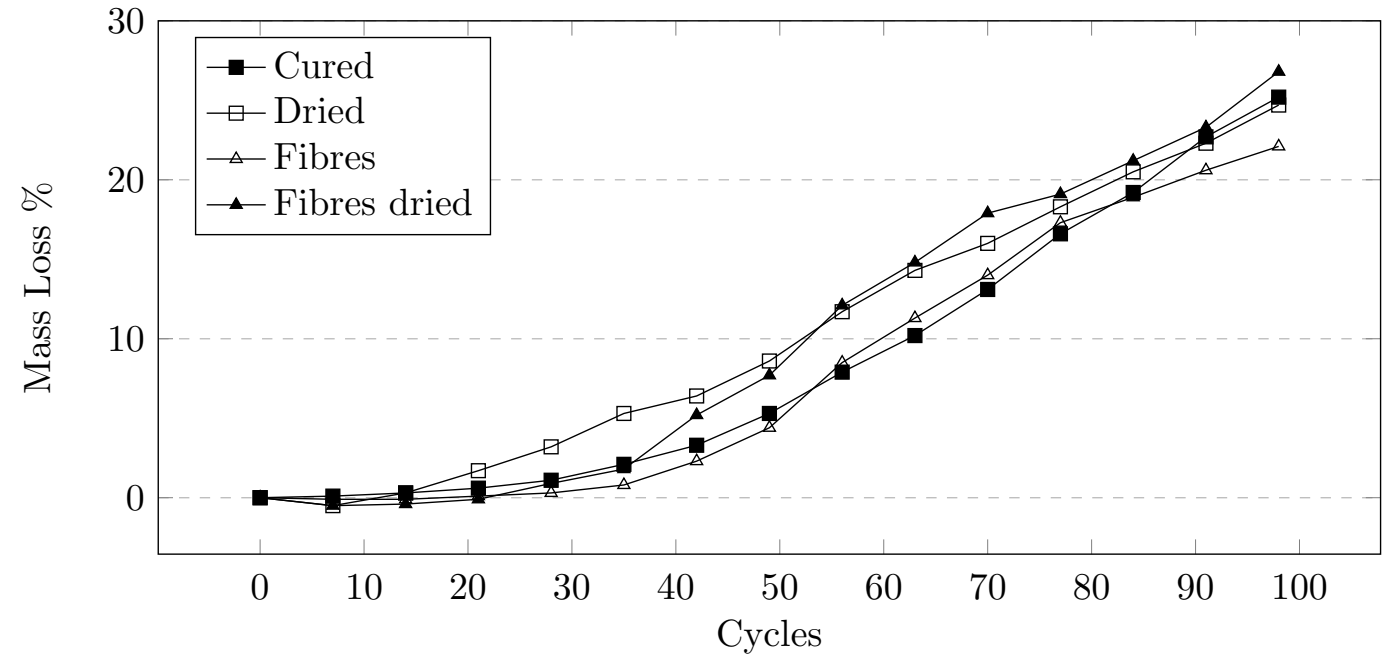

Figure 4.17: Effect of a drying period and the addition of fibres tested using the 24-A-10 method in $\mathrm{CaCl}_{2}$ 


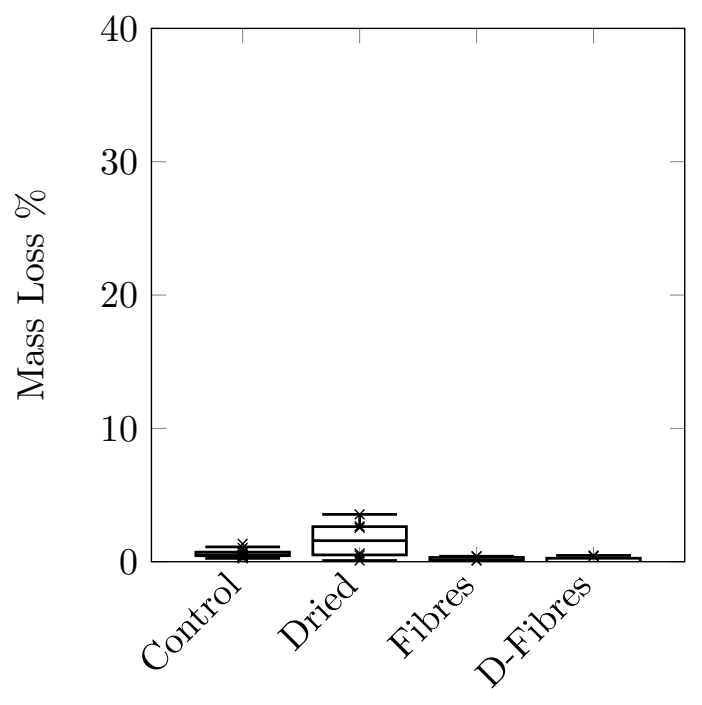

(a) 21 Cycles

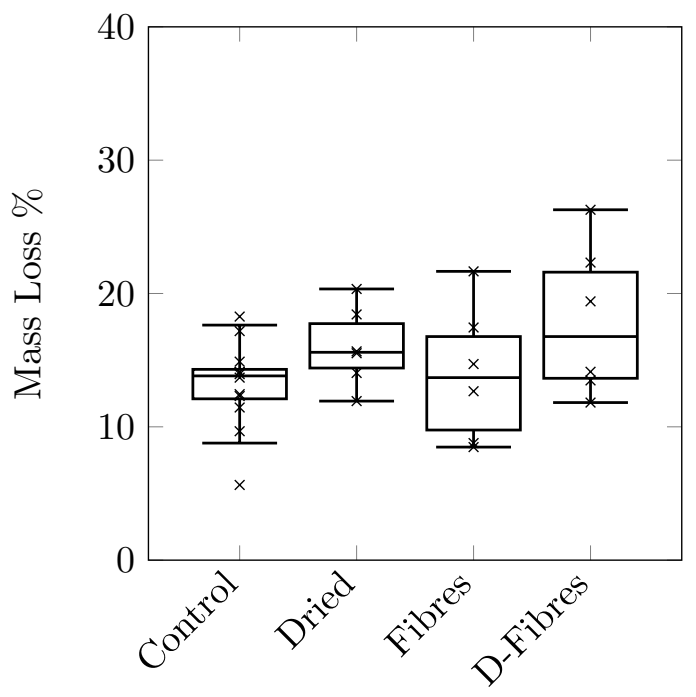

(c) 70 Cycles

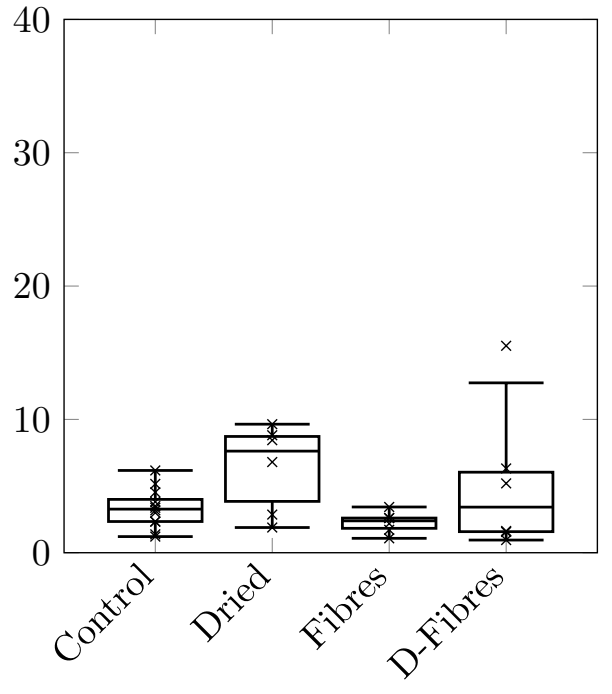

(b) 42 Cycles

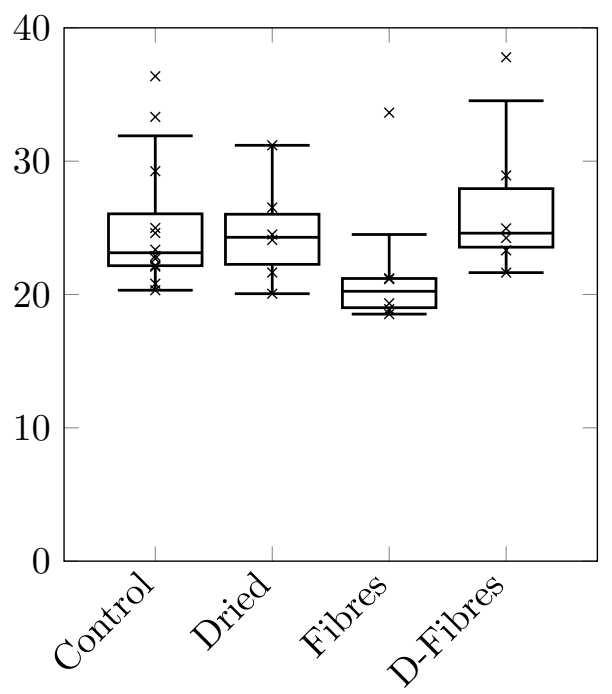

(d) 98 Cycles

Figure 4.18: Mass loss of comparison of samples dried for one week prior to testing and samples with the addition of fibres. 


\subsection{Influence of Deicer type}

\subsubsection{Summary of Effects}

Figure 4.19a shows the average mass loss of samples exposed to different deicers. The graph shows that $\mathrm{CaCl}_{2}, \mathrm{NaCl}$, and urea cause the most damage, while $\mathrm{MgCl}_{2}, \mathrm{~K}$ acetate, $\mathrm{Na}$ acetate, and CMA are not as severe. Although $\mathrm{MgCl}_{2}$ and CMA appear to cause little damage, Figure 4.22 shows that a large degree of variability exists in a number of deicers. In particular, the mass loss of samples exposed to $\mathrm{MgCl}_{2}$ and CMA ranges from no damage to severe damage, leading to fairly inconclusive results regarding their safety as a deicer. Figure 4.19b illustrates the comparison between different deicers using the 24-A-10 method and shows similar trends for the deicers tested albeit at a slower rate. Due to the slower rate, testing was continued for $\mathrm{CaCl}_{2}$ and $\mathrm{NaCl}_{2}$ up to 98 cycles. It is apparent that the damage develops earlier in samples exposed to $\mathrm{NaCl}$, but in the 24-A-10 test, the damage caused by $\mathrm{CaCl}_{2}$ exceeds the damage caused by $\mathrm{NaCl}$ after 70 cycles. Despite the variability, the damage in samples exposed to $\mathrm{CaCl}_{2}, \mathrm{NaCl}$, and urea developed much earlier when compared to the remaining deicers. The mass loss of both K Acetate and Na Acetate were quite consistent and both exhibit around the same levels of moderate mass loss. It is also apparent that very little damage occurred in any of the samples exposed only to freezing and thawing in water. There was an absence of cement flakes at the bottom of the containers holding these samples. This indicates that the damage to pervious concrete even when partially saturated, is not solely from the formation of ice. Samples exposed to $\mathrm{MgCl}_{2}$ and CMA under the 24-A-10 test were saturated in their respective solutions at $38^{\circ} \mathrm{C}$ after 63 freeze thaw cycles.

While the comparisons between $\mathrm{MgCl}_{2}$ and CMA to $\mathrm{K}$ Acetate and Na Acetate are unclear, a general hierarchy of the relative levels of damage of each deicer can be formed:

1. $\mathrm{NaCl}$, Urea, $\mathrm{CaCl}_{2}$ 


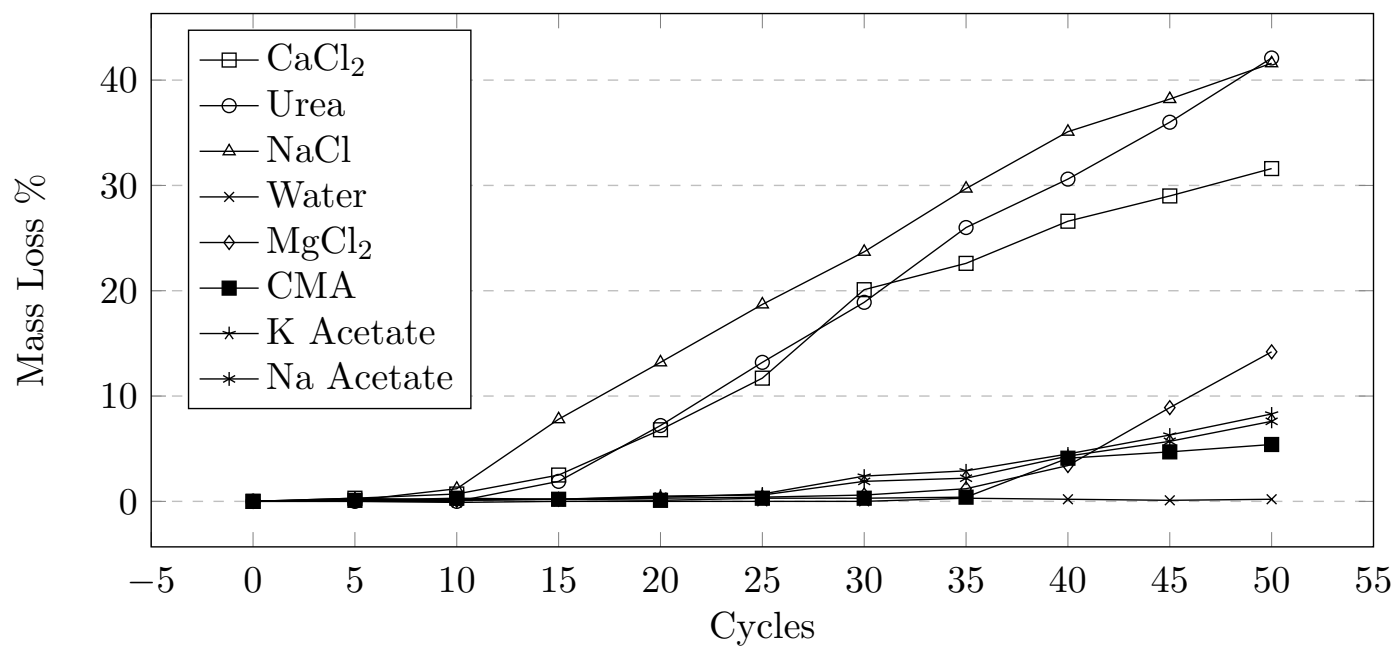

(a)

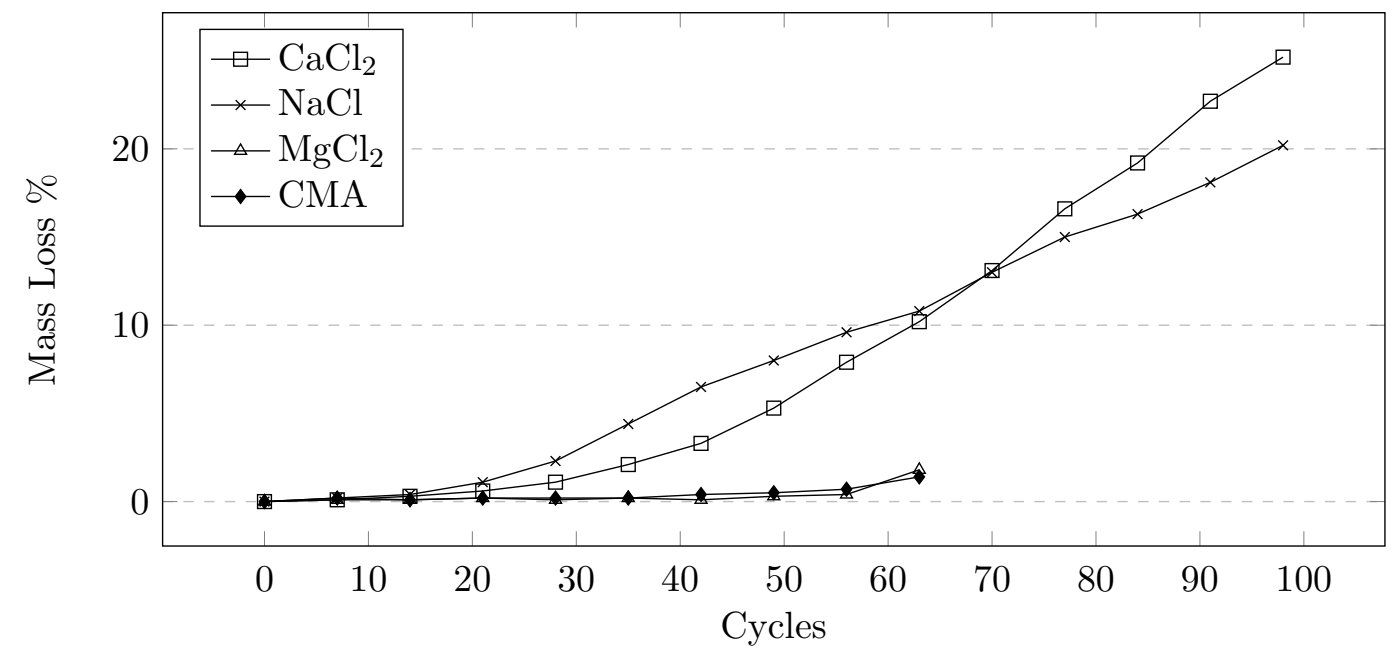

(b)

Figure 4.19: Average mass loss comparison of samples exposed to different deicers under (a) the 24-M-10 method and (b) the 24-A-10 method. 
2. K Acetate, $\mathrm{Na}$ Acetate, $\mathrm{MgCl}_{2}, \mathrm{CMA}$

3. Water

\subsubsection{Progression of Damage}

\section{Cycles}

Referring to Figure 4.22a, it is apparent that damage has developed quite rapidly in samples exposed to $\mathrm{CaCl}_{2}$, urea, and $\mathrm{NaCl}$. At this stage, it appears that on average $\mathrm{NaCl}$ caused more damage than any of the other deicers. The significant difference is illustrated graphically in Figure 4.20. A horizontal overlap of the comparison intervals would indicate that no significant difference exists between the two deicers. Additionally, all deicers have caused a statistically significant amount of mass loss compared to water (Table 4.1).

\section{Cycles}

Figure $4.22 \mathrm{~d}$ much more clearly illustrates the difference between the $\mathrm{CaCl}_{2}$, urea, and $\mathrm{NaCl}$ with the remaining deicers. However, it appears that there is no difference between the $\mathrm{CaCl}_{2}$, urea, and $\mathrm{NaCl}$ (Figure 4.21). At 30 cycles we can also see more damage developing in samples exposed to K Acetate and $\mathrm{Na}$ Acetate.

\section{Cycles}

At 50 cycles, the variability between individual samples of the same set becomes much more apparent (Figure 4.22h). As the initial flat surface of the sample is destroyed, the samples may stand at a crooked angle. The uneven surface may expose a greater area of one sample compared to another. The variability is worsened by the reduced number of samples as some 


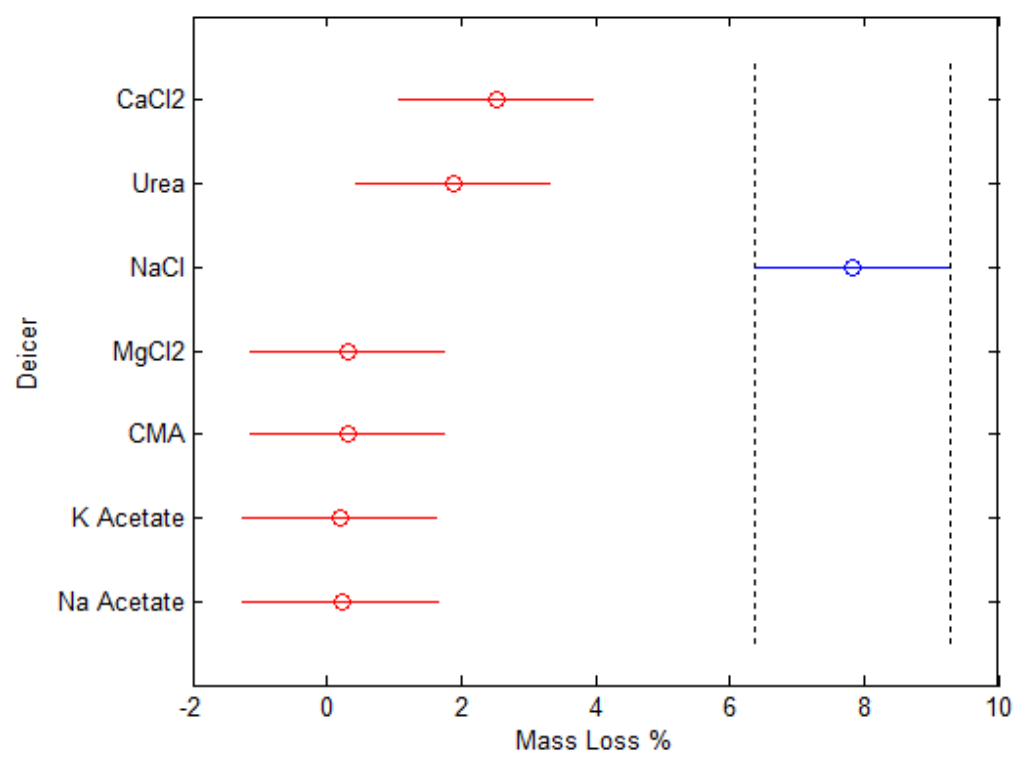

Figure 4.20: Output of Tukey-Kramer analysis generated by MATLAB indicating a significant difference between the average mass loss of $\mathrm{NaCl}$ compared to the other deicers at 15 cycles (24M-10). An overlap of the comparison intervals (horizontal lines) indicates that no significant difference exists between the two deicers.

Table 4.1: T-test of the mass loss of all deicers compared to water after 15 cycles (24-M-10). F-test was first performed to determine if the variance of samples are equal to the variance of water.

\begin{tabular}{llllllllc}
\hline & Mass & & & & & & & \\
Deicer & Loss $(\%)$ & Variance & $\mathrm{F}_{\text {stat }}$ & $\mathrm{F}_{\text {crit }}$ & Variances & $\mathrm{t}_{\text {stat }}$ & $\mathrm{t}_{\text {crit }}$ & Significant \\
\hline Water & -0.04 & 0.018 & - & - & - & - & - & - \\
$\mathrm{CaCl}_{2}$ & 2.52 & 14.933 & 821.59 & 2.82 & Unequal & 2.30 & 2.20 & Yes \\
$\mathrm{Urea}$ & 1.89 & 8.732 & 480.39 & 2.82 & Unequal & 2.26 & 2.20 & Yes \\
$\mathrm{NaCl}$ & 7.84 & 15.262 & 839.65 & 2.82 & Unequal & 6.98 & 2.20 & Yes \\
$\mathrm{MgCl}_{2}$ & 0.17 & 0.043 & 2.38 & 2.62 & Equal & 3.15 & 2.03 & Yes \\
$\mathrm{CMA}_{\mathrm{K} \mathrm{A}}$ & 0.21 & 0.029 & 1.58 & 2.62 & Equal & 4.44 & 2.03 & Yes \\
$\mathrm{Na} \mathrm{A}$ & 0.21 & 0.074 & 4.06 & 2.82 & Unequal & 2.86 & 2.12 & Yes \\
\hline
\end{tabular}




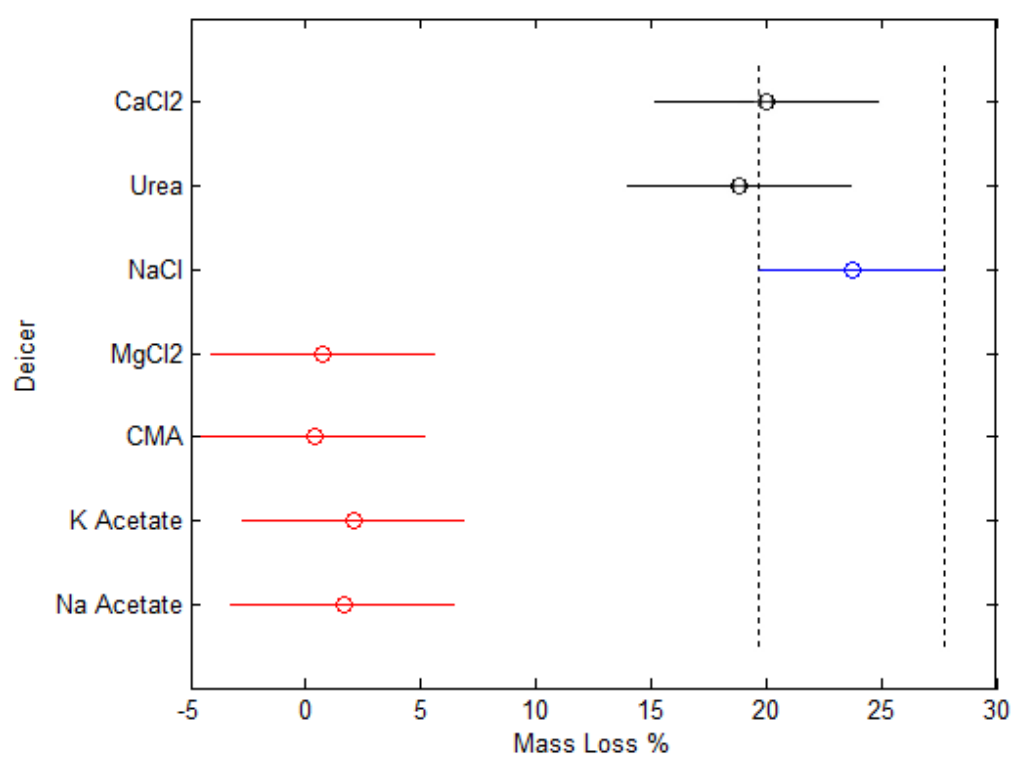

Figure 4.21: Output of Tukey-Kramer analysis generated by MATLAB illustrating the difference between the average mass loss of different deicers at 30 cycles. An overlap indicates that no difference is present.

were used to determine compressive strength. The use of a higher number of cycles would be recommended only if the submerged surface has not suffered much damage.

\subsubsection{Effects at Elevated Temperatures}

Pervious concrete samples were submerged in either a $4 \%$ by weight solution of $\mathrm{MgCl}_{2}$ or $\mathrm{CMA}$ for 4 months. In Figure 4.23 it can be seen that the surface of the sample is no longer flat as the cement paste seems to have expanded relative to the coarse aggregate. 


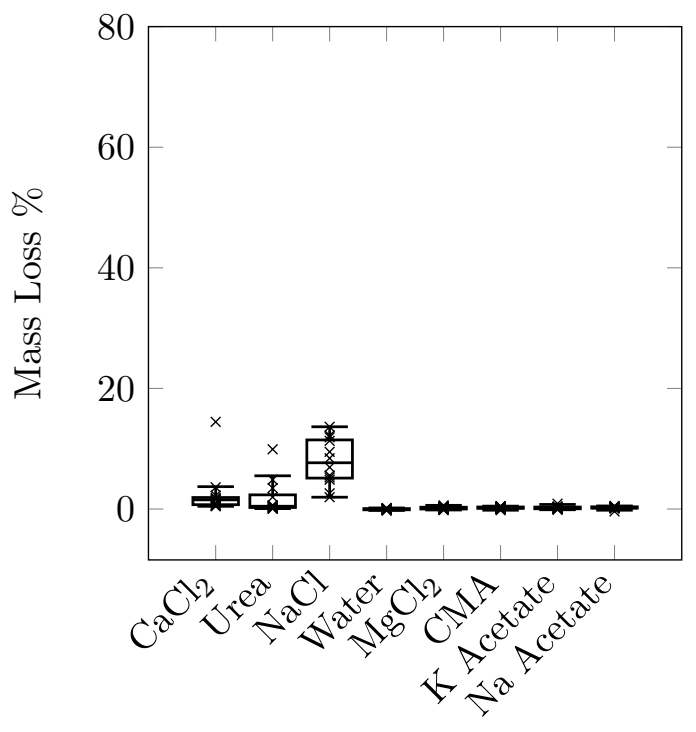

(a) 15 Cycles

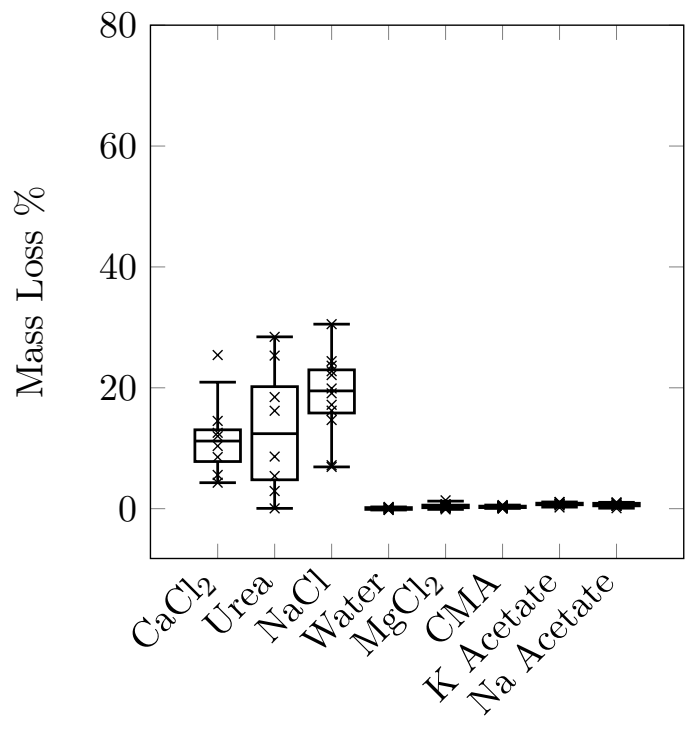

(c) 25 Cycles

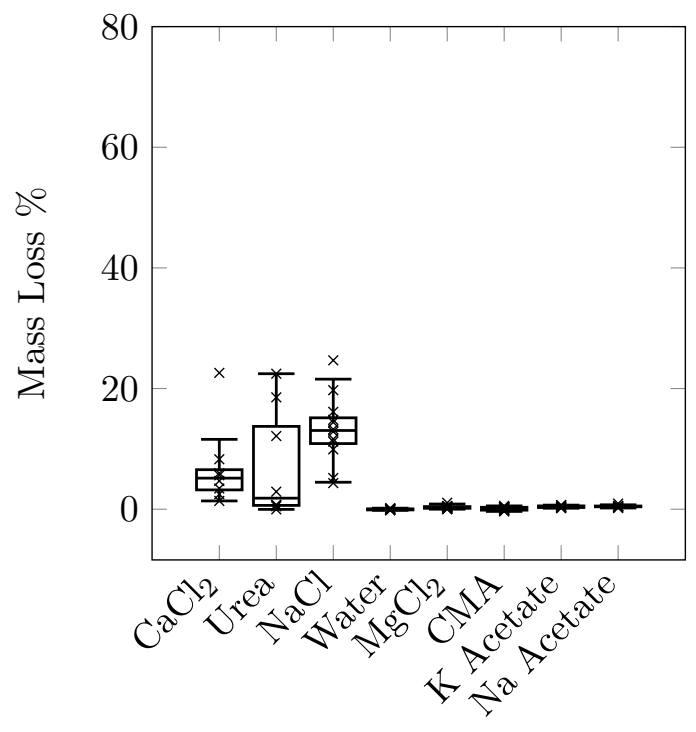

(b) 20 Cycles

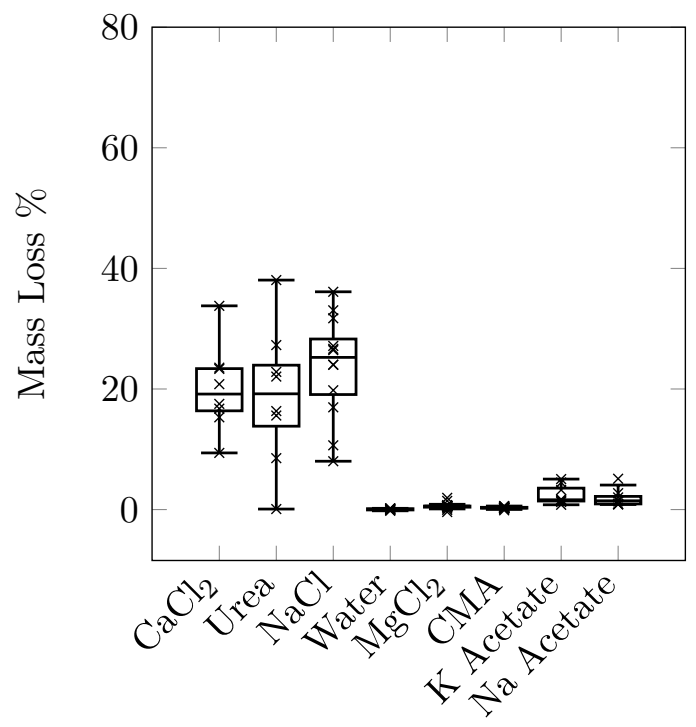

(d) 30 Cycles 


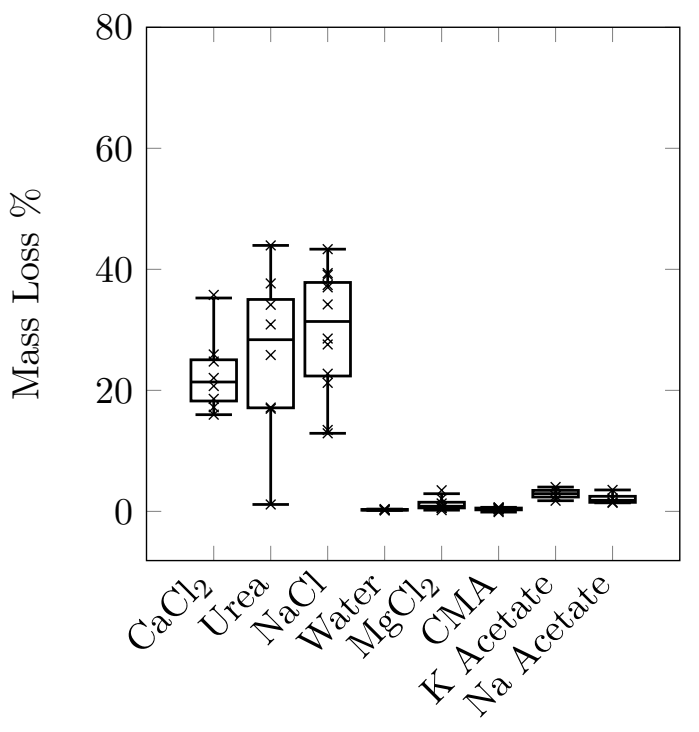

(e) 35 Cycles

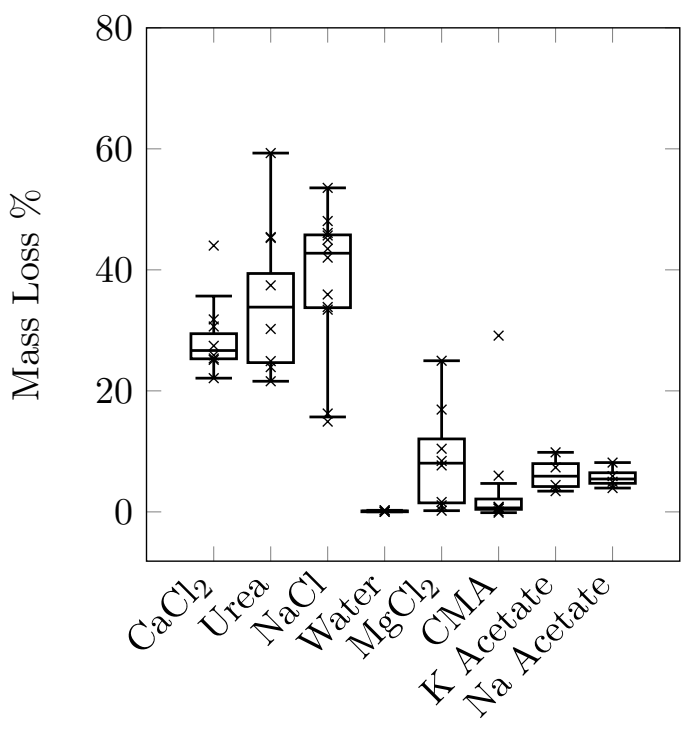

(g) 45 Cycles

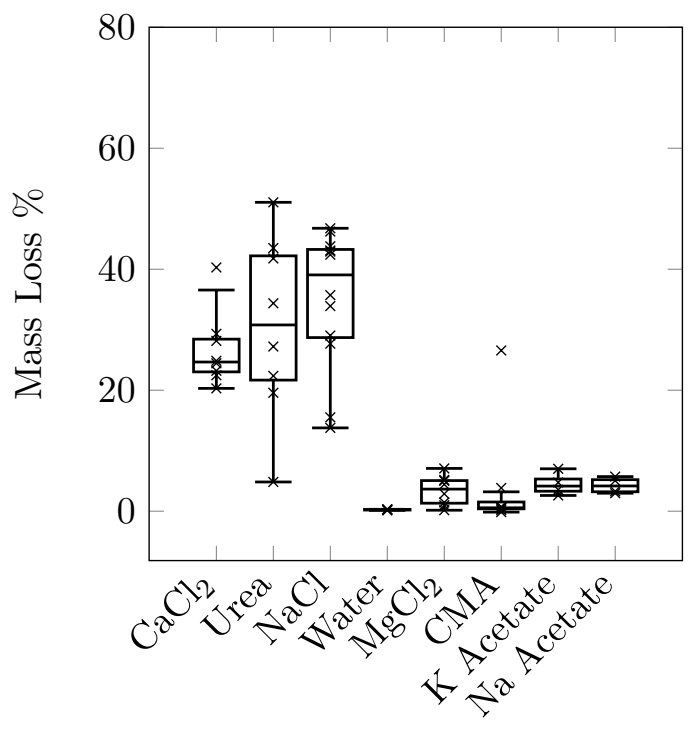

(f) 40 cycles

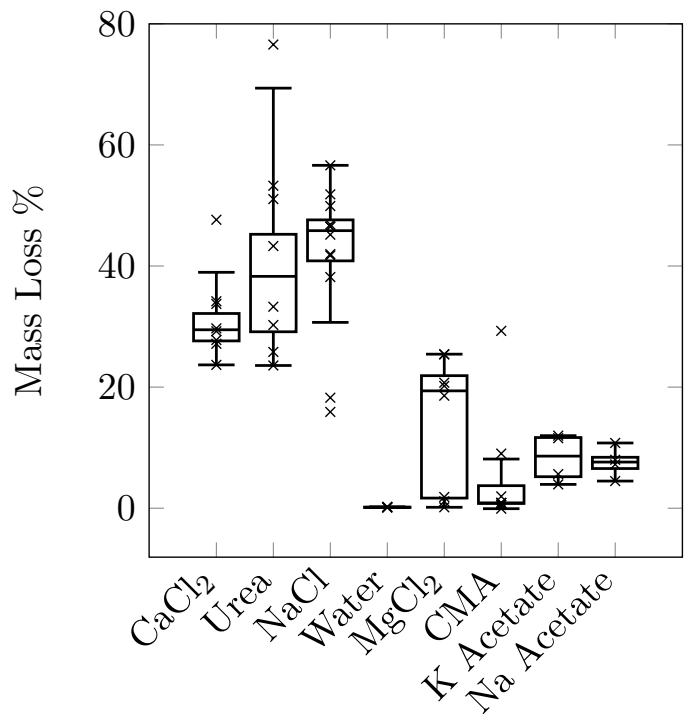

(h) 50 Cycles

Figure 4.22: Box plots comparing the mass loss of samples exposed to different deicers under the 24-M-10 test 


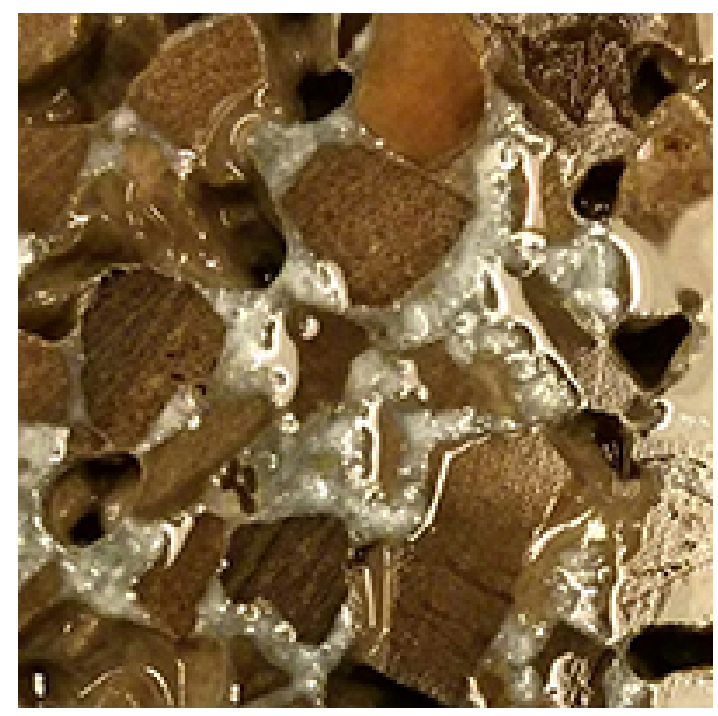

(a) $\mathrm{MgCl}_{2}$

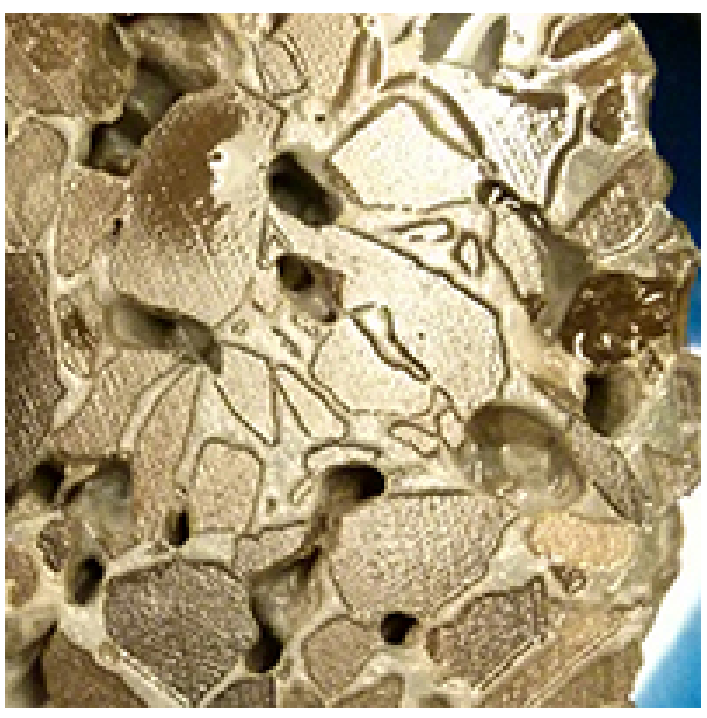

(b) CMA

Figure 4.23: Expansion of the cement paste of pervious concrete after submerging samples in solution for 4 months at $38{ }^{\circ} \mathrm{C}$. 


\section{Chapter 5}

\section{Summary and Discussion}

\subsection{Sample Geometry}

A comparison of the three different sample geometries (100 mm cube, $150 \mathrm{~mm}$ cube, $100 \mathrm{~mm}$ diameter by $150 \mathrm{~mm}$ height cylinders) does not reveal a large difference between variability of samples in terms of mass loss. While the consistency of the compressive strength results of the cylinders was better than the $100 \mathrm{~mm}$ cubes, it was likely due to the method of sample preparation. The $100 \mathrm{~mm}$ cubes were prepared by cutting a large beam into three individual samples and grinding the ends. This potentially results in samples where the two testing surfaces are not parallel or samples with a dimension shorter than $100 \mathrm{~mm}$. However, in the study by Cutler et al. (2010), the use of $100 \mathrm{~mm}$ cubes also resulted in fairly inconsistent compressive strengths. The use of $150 \mathrm{~mm}$ cube samples in the current work did not provide a significant improvement over the cylinders in terms of consistency. As freezer space can be a limiting factor in conducting laboratory experiments, the smaller size of the cylinders will allow more samples to be tested at once. The reduced size also allows for easier casting and handling of the samples. 


\subsection{Depth of Submersion}

For samples that were partially submerged, the damage appeared to be concentrated near the top of the solution; the scaled off cement flakes were lost mainly at this height in the sample. For higher levels of solution this can be problematic as the mass loss will initially appear to be very low, but is followed by significant mass loss as large pieces of concrete break off. A large part of this mass loss would not necessarily be due to salt scaling damage as the much of the cement has not been scaled off. This sudden failure, where large pieces of concrete break off, also occurred in samples in the drained condition (24-M-00 method). A saturation level of $10 \mathrm{~mm}$ seems appropriate for pervious concrete samples made with $14 \mathrm{~mm}$ limestone coarse aggregate. The damage occurs gradually rather than in significant jumps. While a functioning pervious concrete pavement would be expected to be in the drained condition, a drained test, such as the 24-M-00 method used in the present study, can be much more laborious to test in the lab as the samples need to be saturated after every cycle. As the type of damage appears to be the same in either drained or saturated condition (mainly through the loss of cement flakes), it would be reasonable to assume that either condition would be a good indicator of salt scaling resistance.

In conventional concrete the pond of solution on the concrete surface is necessary for salt scaling to occur (Verbeck and Klieger, 1956). Damage still occurred in the drained test in this study, as well as the study by Anderson and Dewoolkar (2015) where mass loss exceeded $15 \%$ in some cases. It is possible that the solution adhering to the cement paste in pervious concrete is sufficient to act as a pond of solution. The thin layer of solution may be sufficient for the glue-spall mechanism to occur as the solution can freeze before draining out of the sample completely. It would be reasonable to assume that the freezing of the thin layer of solution will be much quicker than freezing the large volume of solution used in the 24-M-10 method. It is also possible that the damage is due to an increased degree of saturation of the cement 
paste caused by the deicers, followed by damage due to frost action. Precipitation of salt in the drained method is possible due to the samples being allowed to dry, however, as previously discussed, precipitation of salt is not expected to occur when the samples remain saturated.

\subsection{Automatic and Manual Cycles}

Provided that a sufficiently powerful environmental chamber is used, the rate of cooling of the deicing solution can match that of an industrial freezer. This makes it likely that the rapid mass loss seen in the manual methods can be attributed to the movement of the samples. Frequent movement of the samples will dislodge material and allow for more damage to occur. Since the general trends in mass loss caused by the different deicers appears to be the same in either case, it is difficult to say if one is more representative of field conditions than the other. A programmable environmental chamber would likely result in better consistency and repeatability. While a freezer is normally maintained at $-18{ }^{\circ} \mathrm{C}$, opening the freezer door will cause the temperature to rise rapidly. As different operators will take different lengths of time to place samples in the freezer, the maximum temperature reached will be different. Subsequently, the time to bring the temperature back down to minimum will also be different.

\subsection{Cycle Length}

Extending the freezing period appears to cause more damage. In the case where samples were partially saturated, the extension of the freezing period allowed the solution to reach a lower temperature. The lower temperature would allow more ice to form and also cause the ice to shrink further (particularly important for the glue-spall mechanism). The 12-hour freezing period of the 24-hour cycles was sufficient to bring the temperature of the solution down to the minimum temperature of $-18{ }^{\circ} \mathrm{C}$. The long 12-hour thawing period was required due to the 
washing of the samples. As the entire procedure can take up to four hours, the solution requires enough time to ensure complete thawing by the time the washing procedure begins. Based on these findings, the 24-hour cycle is recommended for testing previous concrete.

\subsection{Effects of Curing, Drying, and the Addition of Fibres}

It should be noted that all samples in this test were cured in laboratory conditions that are likely more ideal than the curing that would occur in field. While drying samples for a week at $50 \% \mathrm{RH}$ and/or the use of fibres did not seem to show any improved resistance to salt scaling, the range of parameters tested was rather narrow. It is possible that drying the samples for a longer period of time or testing the dried samples in the drained condition rather than saturated would show an improvement to the resistance to salt scaling. In the drained condition, it may be more difficult to saturate the sample to the same level as samples that were tested immediately after the curing period. The particular fibres used in this study were PVA fibres with a length of $8 \mathrm{~mm}$ at one specific dosage. The results should not be used to generalized the effects of all fibres in all types of pervious concrete mixes.

\subsection{Different Deicers}

While a conclusive order of the relative levels of damage of each deicer cannot be concluded from the results of this study, a general trend can be formed. $\mathrm{CaCl}_{2}, \mathrm{NaCl}$, and urea appear to be the most damaging, $\mathrm{MgCl}_{2}, \mathrm{~K}$ acetate, $\mathrm{Na}$ acetate, and CMA are less damaging, but all deicers cause more damage than freezing/thawing in water alone. The difference between the various deciers can be due to a number of reasons. It should first be noted that although all the salts are at the same concentration by weight, the molality of each is quite different. It is useful to compare these deicers in terms of molality as this property does not change with the 
temperature. As molality is calculated by dividing the number of moles of the solute by the mass of the solvent it is dissolved in, an equal mass of solute would result in a higher molality for a solute with a lower molecular weight since there would be more moles of that solute at an equal mass. Additionally, the resulting freezing point depression is also different for the different deicers. The molality of both the $\mathrm{NaCl}$ and $\mathrm{MgCl}_{2}$ solutions is higher than $\mathrm{CaCl}_{2}$, while the freezing point of both is lower. However, the results indicate that while $\mathrm{NaCl}$ potentially causes more damage than $\mathrm{CaCl}_{2}, \mathrm{MgCl}_{2}$ does not. If either of these factors alone correlate with the damage, $\mathrm{NaCl}$ and $\mathrm{MgCl}_{2}$ should both cause either more damage or less damage than $\mathrm{CaCl}_{2}$.

From the reported literature, $\mathrm{CaCl}_{2}, \mathrm{MgCl}_{2}$, and CMA often cause more severe damage than $\mathrm{NaCl}$ through chemical deterioration after long term exposure (Darwin et al., 2008). For a number of deicers in this test, the damage was apparent as early as ten cycles. Additionally, the use of supplementary cementing materials often helps mitigate the chemical deterioration from these deicers due to the consumption of $\mathrm{Ca}(\mathrm{OH})_{2}$. As shown in the literature review, the use of blast furnace slag or fly ash results in a reduced resistance to salt scaling. This makes it unlikely for the damage due to salt scaling to be caused by chemical deterioration.

While the results of the study by Cutler et al. (2010), showed that $\mathrm{CaCl}_{2}$ caused more damage than $\mathrm{NaCl}$, the concentration of each deicer was at $9 \%$. Therefore it cannot be said that the results of the present study contradicts the results presented by Cutler et al. (2010). In conventional concrete, at the pessimum concentration, it has been shown that $\mathrm{NaCl}$ causes more damage than $\mathrm{CaCl}_{2}$ (Verbeck and Klieger, 1956). While at higher concentrations, Wang et al. (2006) found that $\mathrm{CaCl}_{2}$ causes more salt scaling damage than $\mathrm{NaCl}$, similar to $\mathrm{Cutler}$ et al. (2010).

As the literature on salt scaling of pervious concrete is limited compared to conventional concrete, it is difficult to say if the mechanism that affects both is the same. For example, Anderson and Dewoolkar (2015) found that fly ash was beneficial to the resistance of pervious concrete 
to salt scaling, which contradicts what was found in the literature for conventional concrete.

A convincing theory is the glue-spall mechanism, in it the difference between deicers can be attributed to the strength of the brine ice. The strength and other characteristics of the ice may be different depending on the deicer used. Valenza and Scherer (2007b) discuss the need for the ice to crack in order for the damage to occur under the glue-spall mechanism. In order for this mechanism to hold true, for all deicers, the ice must begin to crack only once the concentration has increased to approximately 4\% (the pessimum concentration). Additionally, the strength of the brine ice should be different for the different deicers at this concentration; strong ice should produce more salt scaling damage. This was discussed by Valenza and Scherer (2007b) as it was noted that at higher concentrations, the brine ice does not develop enough strength. The stress-strain relationship of brine ice formed from different concentrations of $\mathrm{NaCl}$ and $\mathrm{CaCl}_{2}$ was studied by $\mathrm{Li}$ and $\mathrm{Zhou} \mathrm{(2012).} \mathrm{It} \mathrm{was} \mathrm{shown} \mathrm{that} \mathrm{at} \mathrm{the} \mathrm{same} \mathrm{concentration,} \mathrm{the}$ elastic modulus of $\mathrm{NaCl}$ was higher than that of $\mathrm{CaCl}_{2}$. This could explain the result of $\mathrm{NaCl}$ causing more damage than $\mathrm{CaCl}_{2}$ in salt scaling that is seen in this study as well as in some of the literature (Verbeck and Klieger, 1956). Similar studies should be performed on brine ice of other deicers to determine if this trend holds true in order to better understand the mechanism of salt scaling.

Increasing the degree of saturation of the paste will increase freeze-thaw damage in pervious concrete (Yang et al., 2006). As increasing the deicer content will also increase the degree of saturation (MacInnis and Whiting, 1979), it is possible that this mechanism is responsible for salt scaling in pervious concrete. The difference between deicers would then be due to the extent to which each deicer influences the degree of saturation and also its effect on the freezing point. Since it was argued that the opposing effects (increased degree of saturation and reduction of freezing point) is the reason for the pessimum concentration, it can be difficult to test both of these parameters in conjunction with one another. For example, if "deicer A" increases the degree of saturation much more than "deicer B", but "deicer A" also depresses the freezing 
point much more than "deicer B" (resulting in the less ice forming), it would be difficult to predict which deicer will cause more damage without performing an actual salt scaling test.

\subsection{Failure Criteria}

Based on a visual inspection of the remaining flat surface area of each sample compared to its mass loss, a cutoff point can be determined. For a cylinder sample with a diameter of 100 $\mathrm{mm}$ and a height of $150 \mathrm{~mm}$, a mass loss in the range of 3-5\% would be reasonable based the remaining area of the initial cut surface (Figure 5.1). Most samples are still able to stand upright in this range, however, it is apparent that severe damage has occurred. This is important as the area exposed to the deicing solution changes as more damage occurs. This could help to explain some of the variability seen between samples within the same set.

Using this criteria, $\mathrm{CaCl}_{2}$, urea, and $\mathrm{NaCl}$ exceeded $3-5 \%$ mass loss within 30 cycles. The exact number of cycles is difficult to determine as the mass was taken only once every 5 cycles. Additionally, this occurs at different times for different samples of the same set. It is suggested that the use of the average or the median mass loss within each set of samples be used to determine the number of cycles to failure. Due to the variability present, the use of a median mass loss may be more appropriate. Using this, samples exposed to solutions of $\mathrm{CaCl}_{2}$, urea, and $\mathrm{NaCl}$ failed after 20, 25, and 15 cycles respectively. While samples exposed to solutions of $\mathrm{MgCl}_{2}, \mathrm{~K}$ acetate, and $\mathrm{Na}$ acetate would all be considered to have failed at either 40 or 45 cycles, depending on whether the upper or lower end of the criteria is selected. Samples exposed only to water and CMA did not fail even after 50 cycles. Although the use of the median value indicates that CMA will not cause sample failure even after 50 cycles, a number of individual samples did suffer particularly high levels of mass loss. It is possible that continued long term use of CMA will eventually lead to severe deterioration. Field trials should be conducted to better correlate the test results to in field performance. 


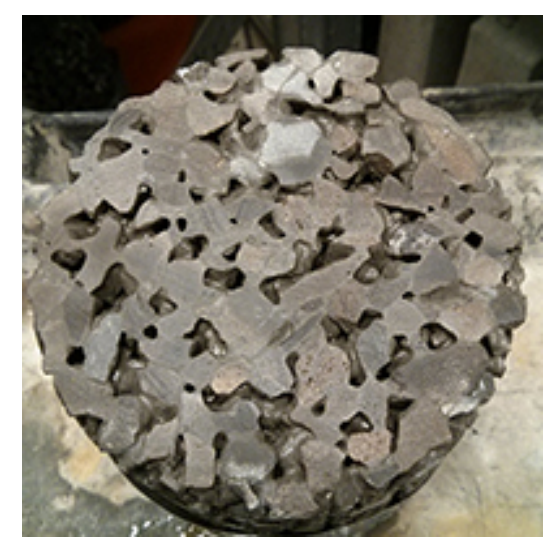

(a) $0 \%$

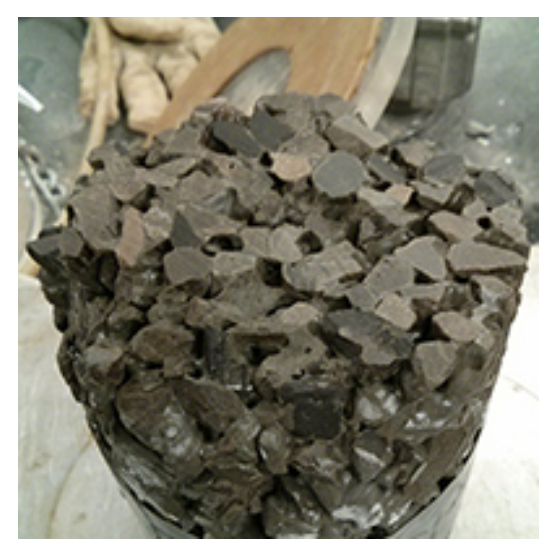

(c) $2.5 \%$

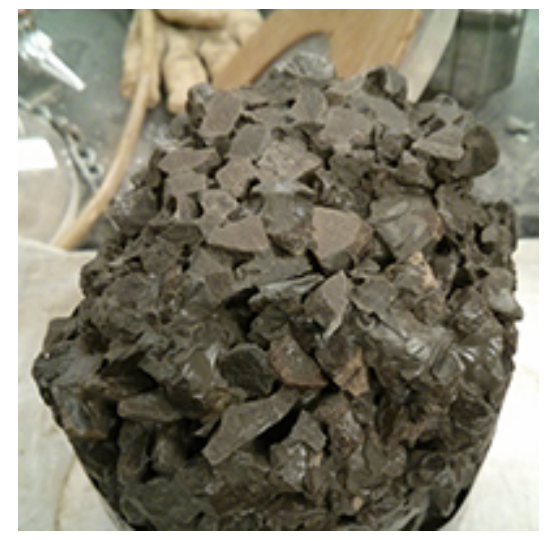

(e) $6.0 \%$

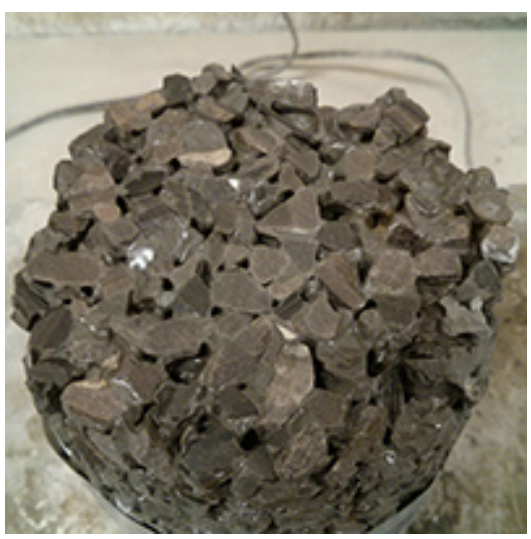

(b) $1.0 \%$

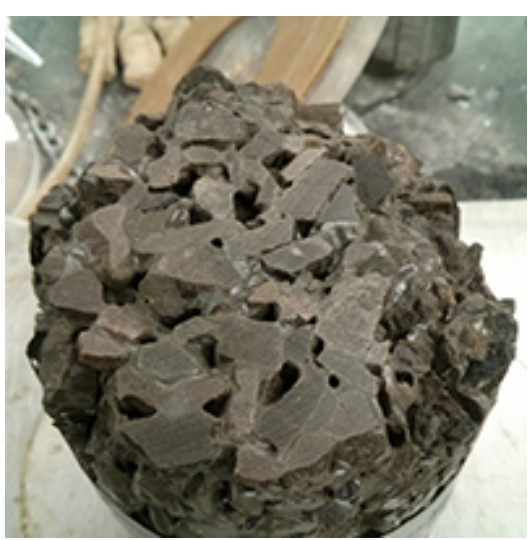

(d) $4.7 \%$

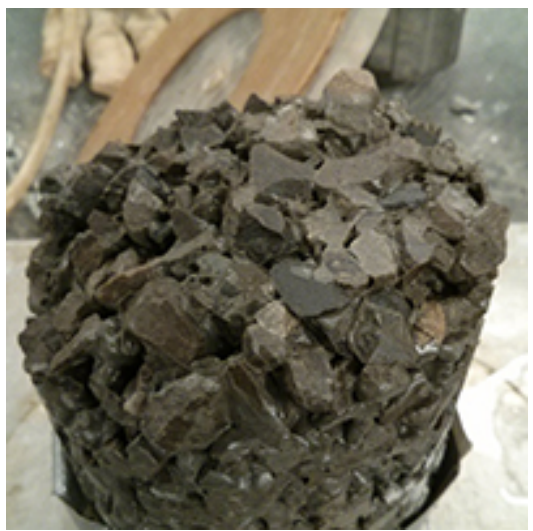

(f) $8.3 \%$

Figure 5.1: Various levels of mass loss of different samples 


\section{Chapter 6}

\section{Conclusion}

Based on the results of this research, a number of conclusions can be drawn:

- The ease of casting and reduced sample mass of the pervious concrete cylinders makes it more convenient and practical to test than larger cubes. If necessary, the compressive strength of the cylinders can be tested and provide consistent results if the testing surface has not been visibly damaged. Compressive strength was found to be particularly effective in comparing samples with little or no mass loss.

- A cycle length of 24 hours with a freezing period of 12 hours allows the temperature of the solution (at a $10 \mathrm{~mm}$ saturation level) to reach the minimum freezing temperature of $-18{ }^{\circ} \mathrm{C}$. The 12 hour thawing period also allows for sufficient thawing to occur before the samples are washed to dried to determine mass loss.

- A saturation level of $10 \mathrm{~mm}$ is suggested to cause gradual but significant mass loss. It is also more convenient than submerging samples in $50 \mathrm{~mm}$ of solution as a smaller volume of solution needs to be prepared. The lower volume of solution will also help ensure that the solution reaches a lower temperature. 
- At an equal concentration by weight (4\%), the most severe salt scaling damage was caused by $\mathrm{CaCl}_{2}, \mathrm{NaCl}$, and urea. $\mathrm{MgCl}_{2}, \mathrm{~K}$ acetate, $\mathrm{Na}$ acetate, and $\mathrm{CMA}$ did not cause as much damage, and all deicers caused more damage than freezing and thawing in water alone.

- While $\mathrm{MgCl}_{2}$ and CMA appear relatively safer in terms of salt scaling at 50 cycles, pervious concrete samples exposed to these deicers showed signs of expansion of the cement paste despite the low $\mathrm{w} / \mathrm{c}$ ratio and the $15 \%$ slag replacement.

- The use of an environmental chamber resulted in less damage compared to moving samples in and out of a freezer manually. The general trend of the relative levels of damage of the different deicers remained the same in either than manual or automatic method. For $\mathrm{CaCl}_{2}$ and $\mathrm{NaCl}$, despite the damage in the automatic method being less than in the manual method, it was still quite severe. This makes the automated method suitable for salt scaling testing if it is available.

- For cylinder samples with a diameter of $100 \mathrm{~mm}$ and a height of $150 \mathrm{~mm}$, a failure criteria of $3-5 \%$ is suggested. In this range, notable damage has occurred on the bottom surface, but most samples in this range are able to stand upright. This is important as the variability that occurs between samples of the same set in later stages is likely due to the unevenness of the samples. As large variability can exist, a set should contain 12 samples with failure being defined once the median mass loss has exceed 3-5\%. 


\section{Appendix A}

\section{Salt Scaling Photos}

The figures in this appendix show the mass loss of a typical sample at different cycles. 


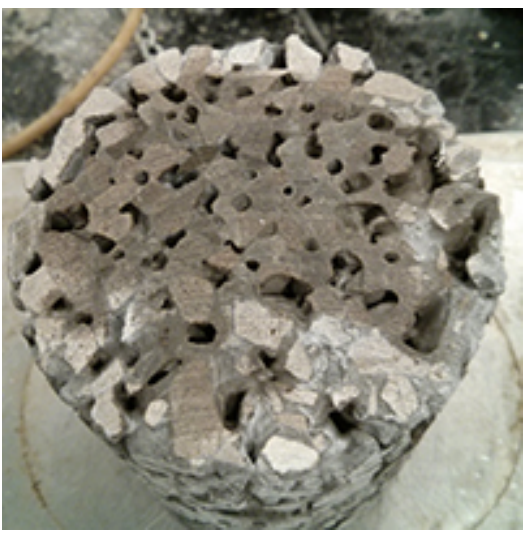

(a) 0 cycles

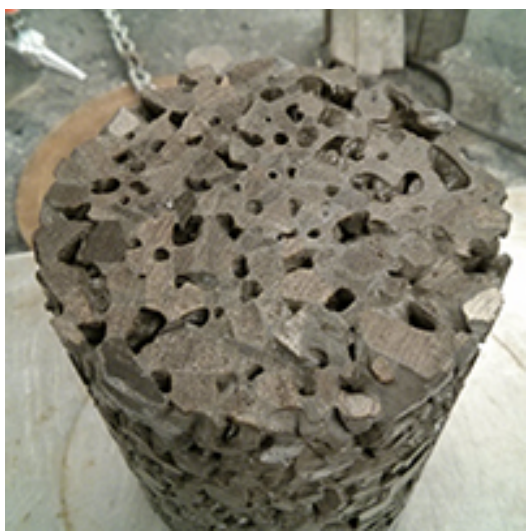

(c) 20 cycles

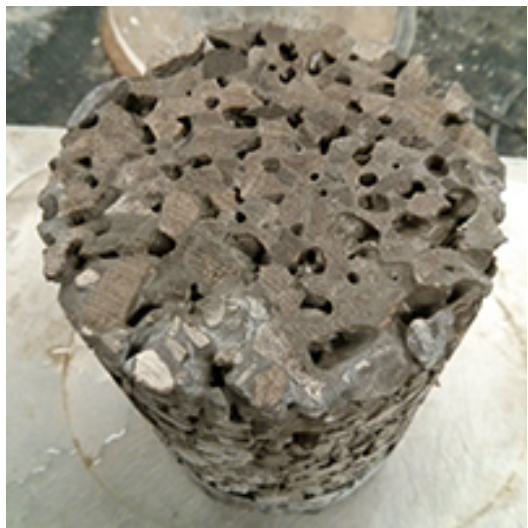

(e) 40 cycles

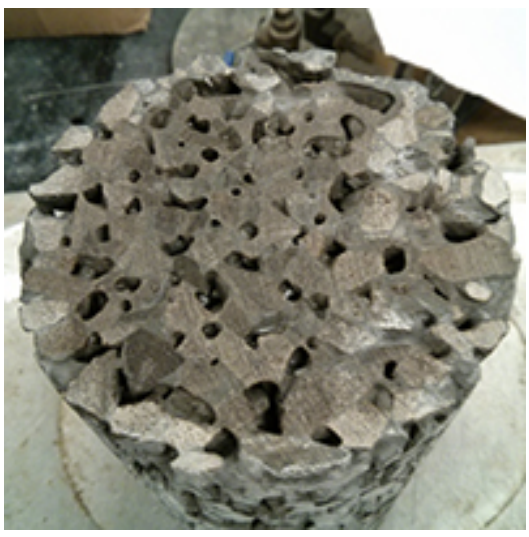

(b) 10 cycles

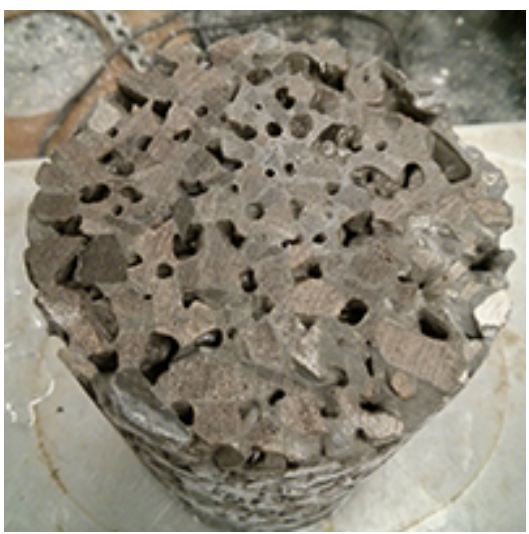

(d) 30 cycles

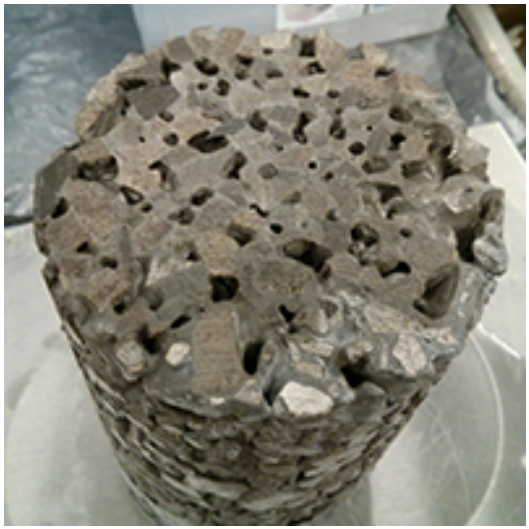

(f) 50 cycles

Figure A.1: 24-M-10 test method in water. 


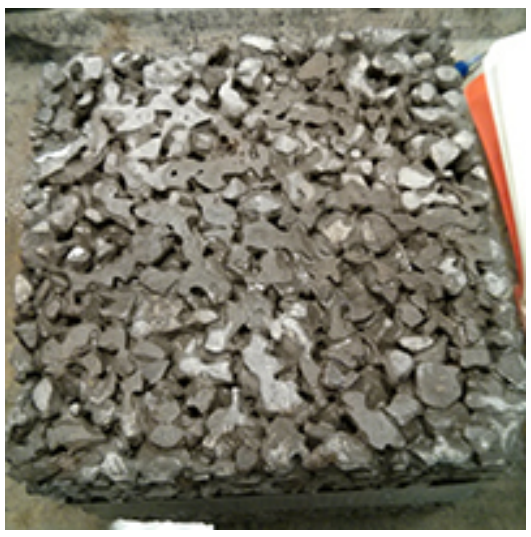

(a) 0 cycles

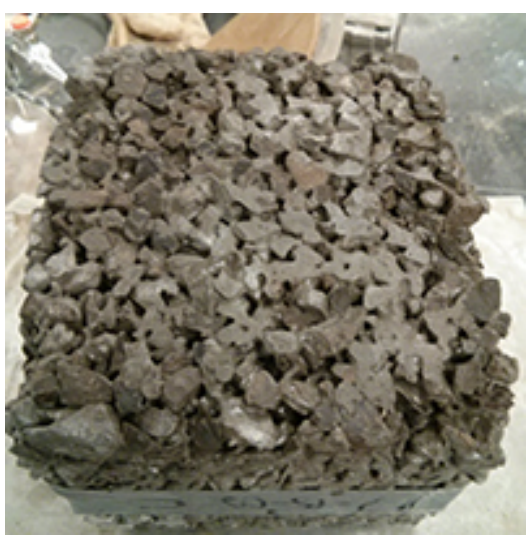

(c) 20 cycles

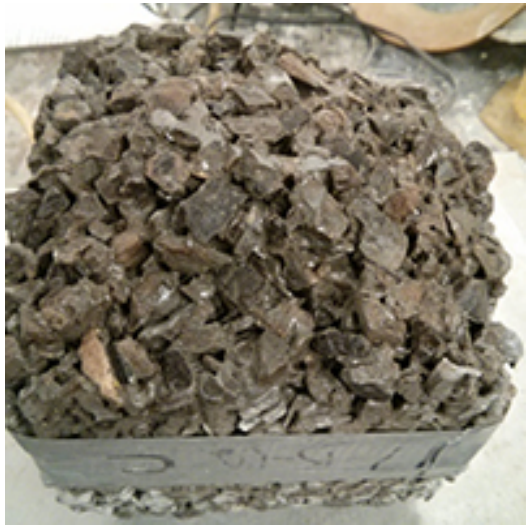

(e) 40 cycles

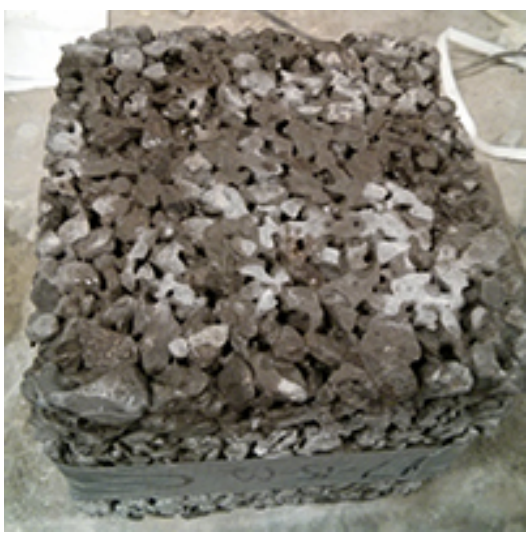

(b) 10 cycles

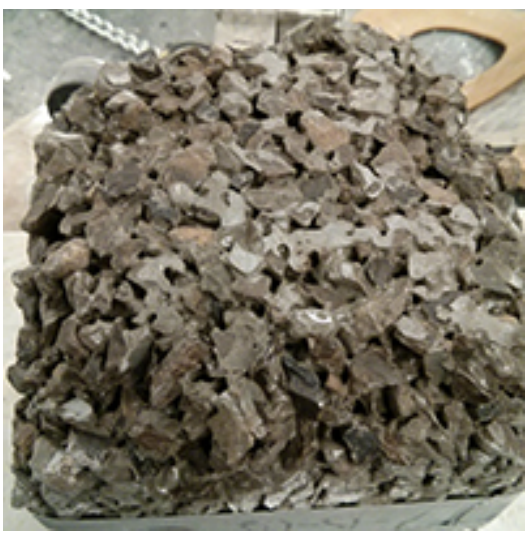

(d) 30 cycles

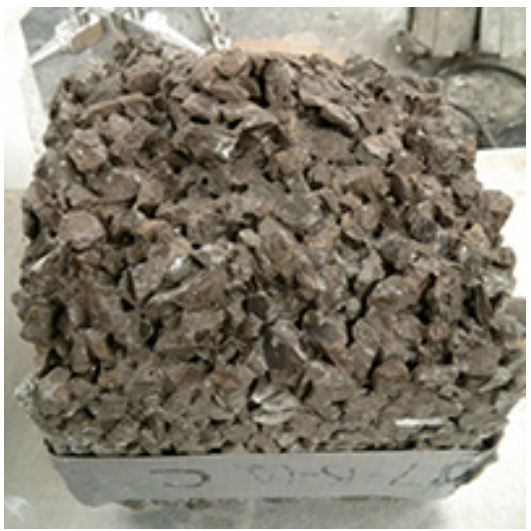

(f) 50 cycles

Figure A.2: 24-M-10 test method in $\mathrm{CaCl}_{2}$ with $150 \mathrm{~mm}$ cube samples. 


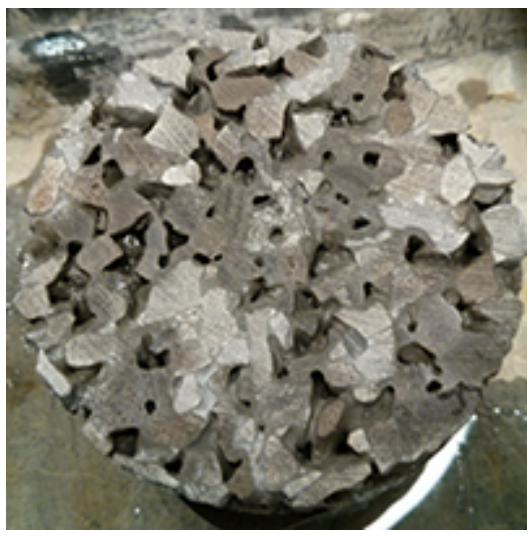

(a) 0 cycles

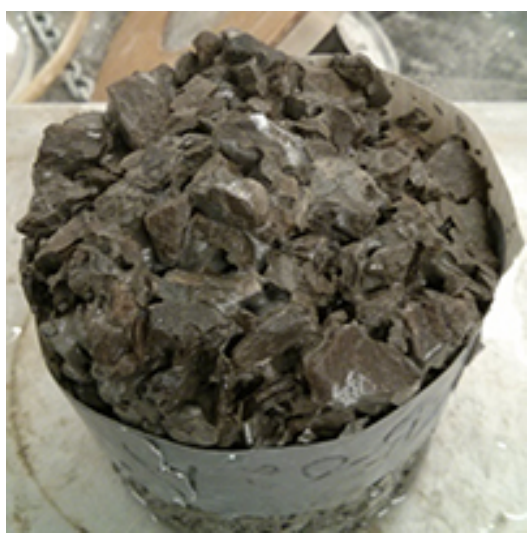

(c) 20 cycles

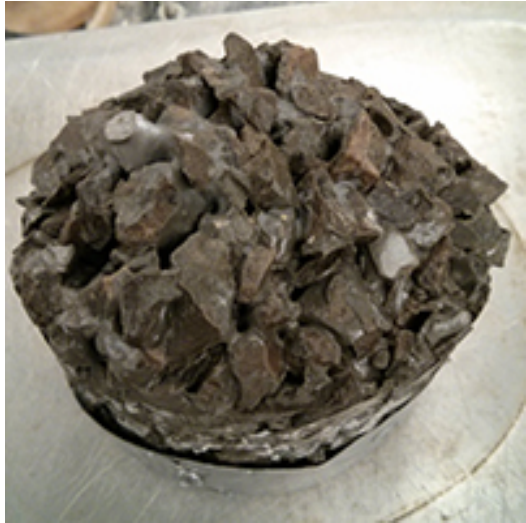

(e) 40 cycles

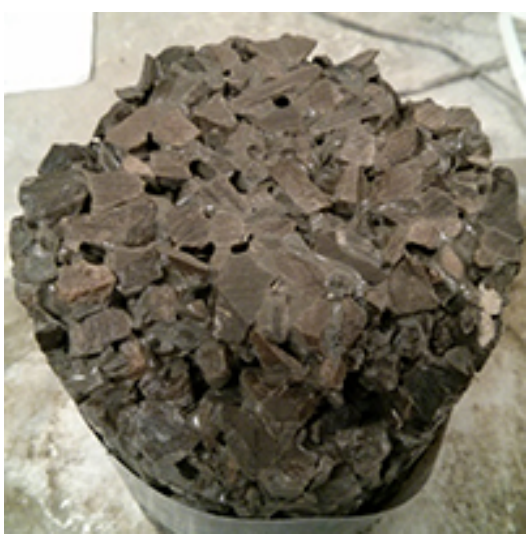

(b) 10 cycles

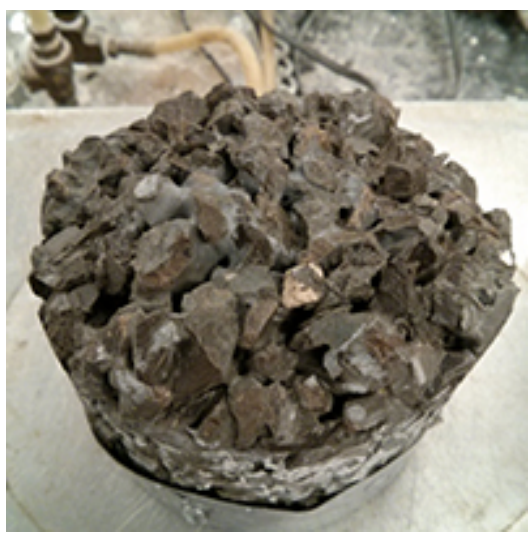

(d) 30 cycles

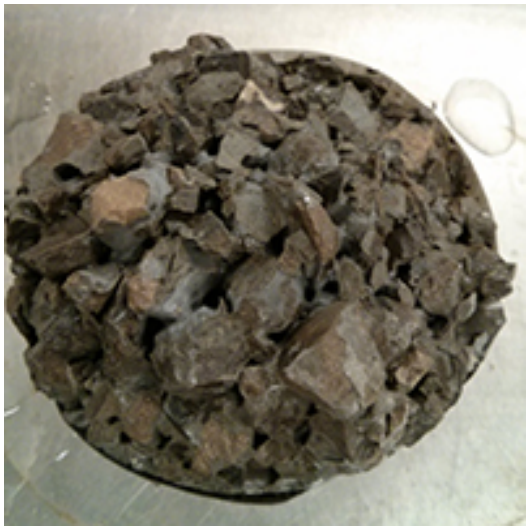

(f) 50 cycles

Figure A.3: 24-M-10 test method in $\mathrm{CaCl}_{2}$ with cylinder samples 


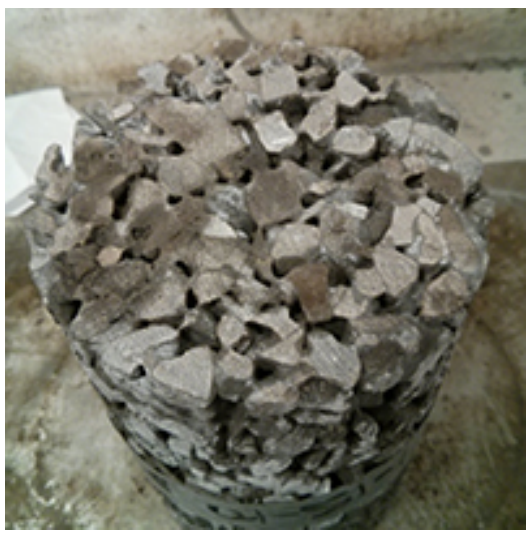

(a) 0 cycles

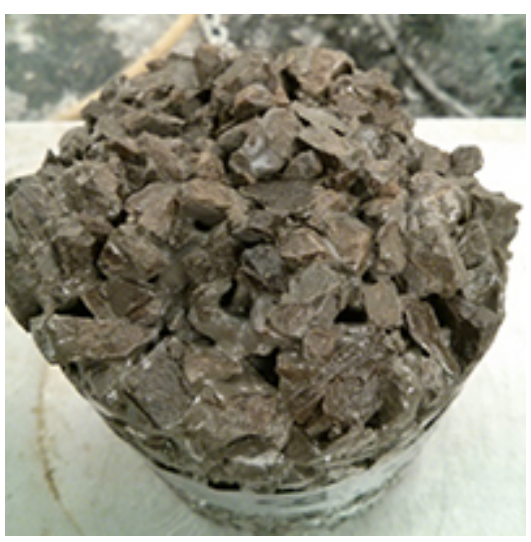

(c) 20 cycles

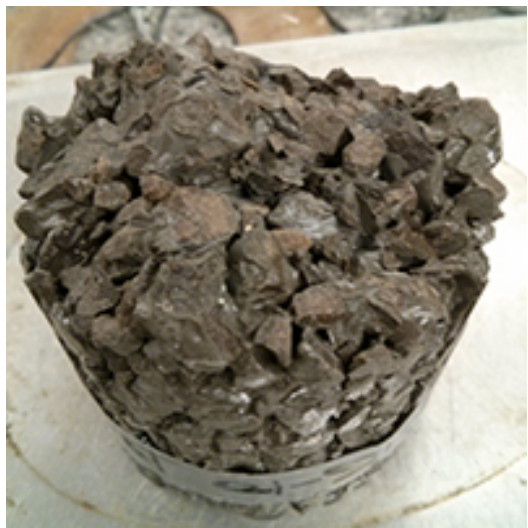

(e) 40 cycles

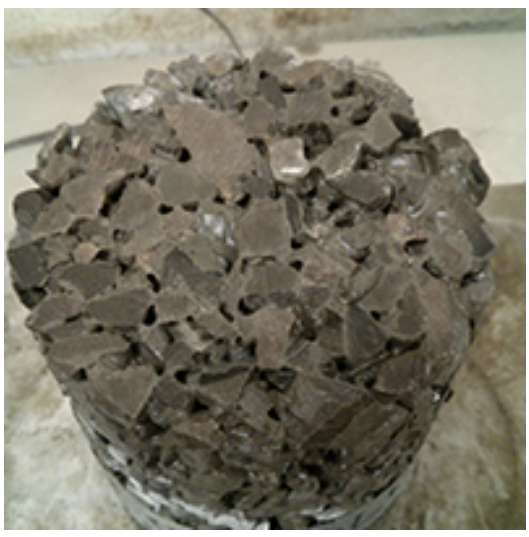

(b) 10 cycles

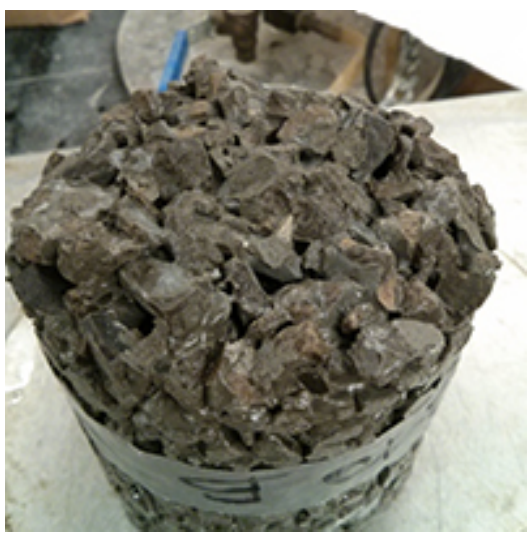

(d) 30 cycles

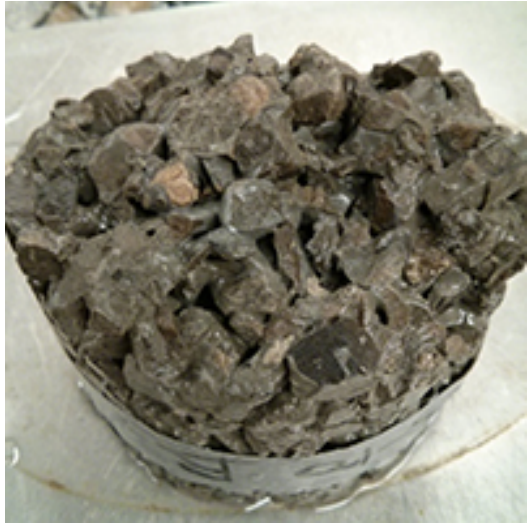

(f) 50 cycles

Figure A.4: 24-M-10 test method in urea. 


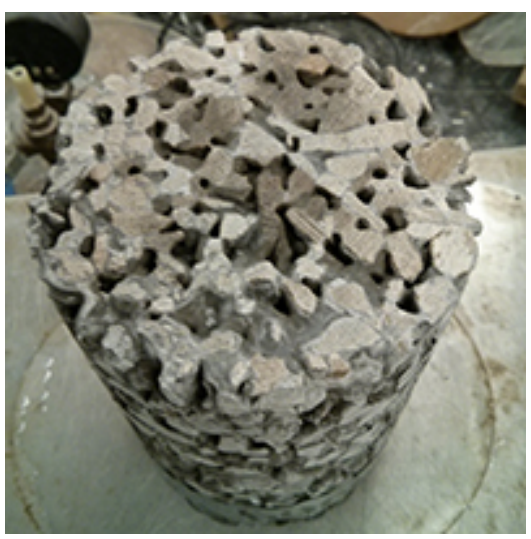

(a) 0 cycles

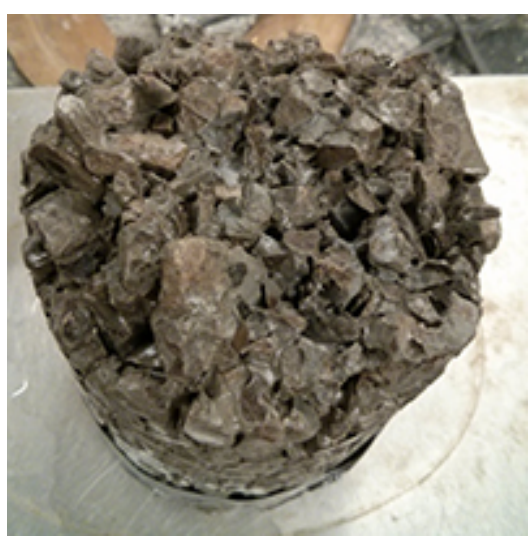

(c) 20 cycles

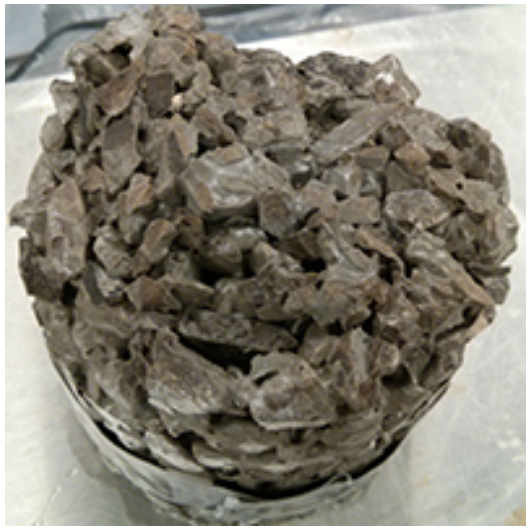

(e) 40 cycles

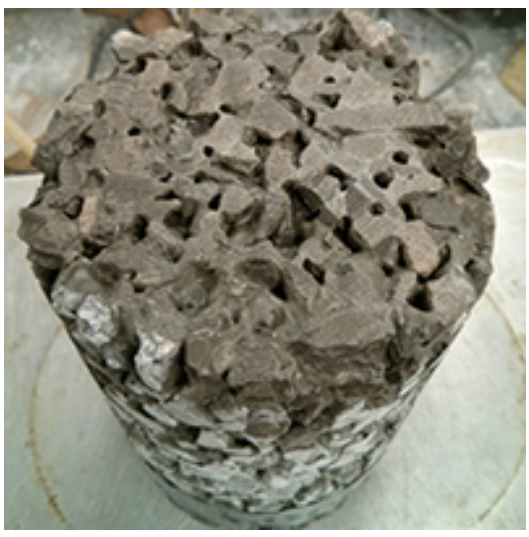

(b) 10 cycles

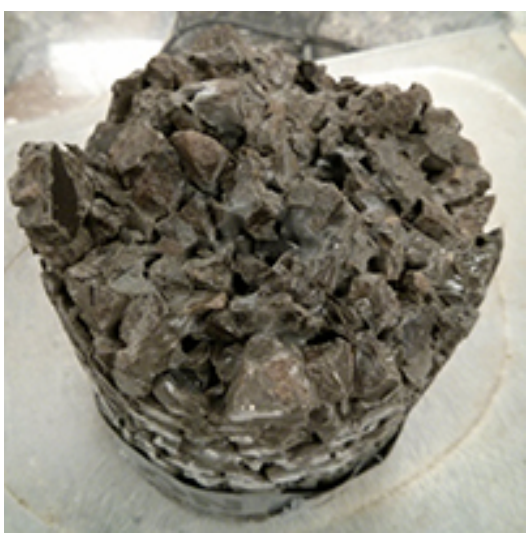

(d) 30 cycles

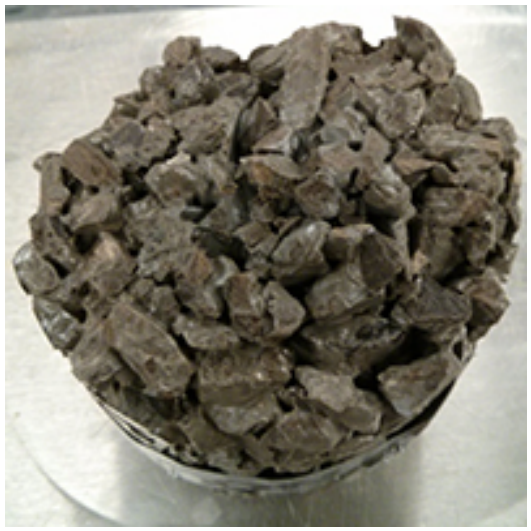

(f) 50 cycles

Figure A.5: 24-M-10 method in NaCl. 


\section{Appendix B}

\section{Statistical Analysis}

This section contains the statistical analysis to determine if any significant reduction in compressive strength exists when compared to samples that have not been subjected to any freeze-thaw cycles. An F-test was first used to determine if the sample variances are the same. 
Table B.1: F-Test for $100 \mathrm{~mm}$ cubes using the 12-A-00 method.

\begin{tabular}{lllll}
\hline & \multicolumn{4}{c}{ Cycles } \\
\cline { 2 - 5 } F-test & 0 & 16 & 32 & 52 \\
\hline Mean & 14.246 & 15.436 & 14.450 & 13.898 \\
Variance & 1.248 & 7.156 & 7.857 & 4.528 \\
Observations & 3 & 6 & 6 & 6 \\
$\mathrm{df}$ & 2 & 5 & 5 & 5 \\
$\mathrm{~F}$ & - & 5.735 & 6.297 & 3.629 \\
$\mathrm{P}(\mathrm{F} \leq \mathrm{f})$ one-tail & - & 0.155 & 0.143 & 0.230 \\
$\mathrm{~F}_{\text {crit }}$ one-tail & - & 19.296 & 19.296 & 19.296 \\
Variances & - & Equal & Equal & Equal \\
\hline
\end{tabular}

Table B.2: t-Test for $100 \mathrm{~mm}$ cubes using the 12-A-00 method.

\begin{tabular}{llll}
\hline & \multicolumn{3}{c}{ Cycles } \\
\cline { 2 - 4 } t-test & 16 & 32 & 52 \\
\hline Pooled Variance & 5.468 & 5.969 & 3.591 \\
$\mathrm{df}$ & 7 & 7 & 7 \\
$\mathrm{t}$ statistic & 0.720 & 0.118 & 0.260 \\
$\mathrm{P}(\mathrm{T} \leq \mathrm{t})$ one-tail & 0.247 & 0.455 & 0.401 \\
$\mathrm{t}_{\text {crit }}$ one-tail & 1.895 & 1.895 & 1.895 \\
Difference & $\mathrm{No}$ & $\mathrm{No}$ & $\mathrm{No}$ \\
\hline
\end{tabular}


Table B.3: F-Test for cylinders using the 12-A-00 method.

\begin{tabular}{lllll}
\hline & \multicolumn{4}{c}{ Cycles } \\
\cline { 2 - 5 } F-test & 0 & 16 & 32 & 52 \\
\hline Mean & 17.988 & 16.402 & 17.393 & 16.488 \\
Variance & 0.202 & 2.247 & 1.028 & 0.102 \\
Observations & 3 & 3 & 3 & 3 \\
df & 2 & 2 & 2 & 2 \\
$\mathrm{~F}$ & - & 11.118 & 5.087 & 1.992 \\
$\mathrm{P}(\mathrm{F} \leq \mathrm{f})$ one-tail & - & 0.0825 & 0.164 & 0.334 \\
$\mathrm{~F}_{\text {crit }}$ one-tail & - & 19 & 19 & 19 \\
Variances & - & Equal & Equal & Equal \\
\hline
\end{tabular}

Table B.4: t-Test for cylinders using the 12-A-00 method.

\begin{tabular}{llll}
\hline & \multicolumn{3}{c}{ Cycles } \\
\cline { 2 - 4 } t-test & 16 & 32 & 52 \\
\hline Pooled Variance & 1.225 & 0.615 & 0.152 \\
$\mathrm{df}$ & 4 & 4 & 4 \\
$\mathrm{t}$ statistic & 1.755 & 0.930 & 4.717 \\
$\mathrm{P}(\mathrm{T} \leq \mathrm{t})$ one-tail & 0.077 & 0.203 & 0.005 \\
$\mathrm{t}_{\text {crit } \text { one-tail }}$ & 2.13 & 2.13 & 2.13 \\
Difference & $\mathrm{No}$ & $\mathrm{No}$ & Yes \\
\hline
\end{tabular}


Table B.5: F-Test for cylinders under 12-A-50.

\begin{tabular}{lllll}
\hline & \multicolumn{4}{c}{ Cycles } \\
\cline { 2 - 5 } F-test & 0 & 16 & 32 & 52 \\
\hline Mean & 17.864 & 21.273 & 22.401 & 20.202 \\
Variance & 13.691 & 3.891 & 3.363 & 2.553 \\
Observations & 3 & 3 & 3 & 3 \\
df & 2 & 2 & 2 & 2 \\
$\mathrm{~F}$ & - & 3.519 & 4.071 & 5.364 \\
$\mathrm{P}(\mathrm{F} \leq \mathrm{f})$ one-tail & - & 0.221 & 0.197 & 0.157 \\
$\mathrm{~F}_{\text {crit }}$ one-tail & - & 19.000 & 19.000 & 19.000 \\
Variances & - & Equal & Equal & Equal \\
\hline
\end{tabular}

Table B.6: t-Test for cylinders using the 12-A-50 method.

\begin{tabular}{llll}
\hline & \multicolumn{3}{c}{ Cycles } \\
\cline { 2 - 4 } t-test & 16 & 32 & 52 \\
\hline Pooled Variance & 8.791 & 8.527 & 8.122 \\
$\mathrm{df}$ & 4 & 4 & 4 \\
$\mathrm{t}$ statistic & 1.408 & 1.903 & 1.004 \\
$\mathrm{P}(\mathrm{T} \leq \mathrm{t})$ one-tail & 0.116 & 0.065 & 0.186 \\
$\mathrm{t}_{\text {crit }}$ one-tail & 2.132 & 2.132 & 2.132 \\
Difference & $\mathrm{No}$ & $\mathrm{No}$ & $\mathrm{No}$ \\
\hline
\end{tabular}


Table B.7: F-Test for cylinders using the 15-A-75 method.

\begin{tabular}{llll}
\hline & \multicolumn{3}{c}{ Cycles } \\
\cline { 2 - 4 } F-test & 0 & 18 & 36 \\
\hline Mean & 17.023 & 18.407 & 13.585 \\
Variance & 0.936 & 4.511 & 3.703 \\
Observations & 3 & 3 & 3 \\
df & 2 & 2 & 2 \\
$\mathrm{~F}$ & - & 4.820 & 3.958 \\
$\mathrm{P}(\mathrm{F} \leq \mathrm{f})$ one-tail & - & 0.172 & 0.202 \\
$\mathrm{~F}$ crit one-tail & - & 19.000 & 19.000 \\
Variances & - & Equal & Equal \\
\hline
\end{tabular}

Table B.8: t-Test for cylinders using the 16-A-75 method.

\begin{tabular}{lll}
\hline \multirow{2}{*}{ t-test } & \multicolumn{2}{c}{ Cycles } \\
\cline { 2 - 3 } & 18 & 36 \\
\hline Pooled Variance & 2.723 & 2.320 \\
$\mathrm{df}$ & 4 & 4 \\
$\mathrm{t}$ statistic & 1.027 & 2.765 \\
$\mathrm{P}(\mathrm{T} \leq \mathrm{t})$ one-tail & 0.181 & 0.025 \\
$\mathrm{t}_{\text {crit }}$ one-tail & 2.132 & 2.132 \\
Difference & No & Yes \\
\hline
\end{tabular}




\section{References}

ACI Committee 522, March 2010. Report on pervious concrete.

Afrani, I., Rogers, C., 1994. The effects of different cementing materials and curing on concrete scaling. Cement, Concrete, and Aggregates, CCAGPD 16 (2).

Ahani, R. M., Nokken, M. R., 2012. Salt scaling resistance the effect of curing and presaturation. Construction and Building Materials 26 (1), 558-564.

Anderson, I., Dewoolkar, M. M., Sep 2015. Laboratory freezing-and-thawing durability of fly ash pervious concrete in a simulated field environment. ACI Materials Journal 112 (5), 603-611.

Anderson, I. A., Dewoolkar, M. M., Suozzo, M., August 2013. Laboratory and field evaluations of pervious concrete. Tech. rep.

Basheer, L., Cleland, D. J., 2006. Freeze thaw resistance of concretes treated with pore liners. Construction and Building Materials 20 (10), 990-998.

Bouzoubaa, N., Bilodeau, A., Fournier, B., Hooton, R. D., Gagne, R., Jolin, M., 2008. Deicing salt scaling resistance of concrete incorporating supplementary cementing materials: laboratory and field test data. Canadian Journal of Civil Engineering 35 (11), 1261-1261.

Bouzoubaa, N., Bilodeau, A., Fournier, B., Hooton, R. D., Gagne, R., Jolin, M., 2011. Deicing salt scaling resistance of concrete incorporating fly ash and (or) silica fume: laboratory and field sidewalk test data. Canadian Journal of Civil Engineering 38 (4), 373-382. 
Boyd, A. J., Hooton, R. D., 2007. Long-term scaling performance of concretes containing supplementary cementing materials. Journal of Materials in Civil Engineering 19 (10), 820-825.

Chang, C.-F., Chen, J.-W., 2006. The experimental investigation of concrete carbonation depth. Cement and Concrete Research 36 (9), 1760-1767.

Chidiac, S. E., Panesar, D. K., 2008. Evolution of mechanical properties of concrete containing ground granulated blast furnace slag and effects on the scaling resistance test at 28 days. Cement and Concrete Composites 30 (2), 63-71.

Clark, J., 2005. Solid-liquid phase diagrams: salt solution. URL http://www.chemguide.co.uk/physical/phaseeqia/saltsoln.html

Cruz Jr., C., 2008. Microscopic observations of internal frost damage and salt scaling.

Cutler, H. E., Wang, K., Schaefer, V. R., Kevern, J. T., 2010. Resistance of portland cement pervious concrete to deicing chemicals. Transportation Research Record: Journal of the Transportation Research Board 2164 (1), 98-104.

Dam, T. V., Hooton, D., Julio-Betancourt, G., Peterson, K., Smith, K., Sutter, L., 2008. The deleterious chemical effects of concentrated deicing solutions on portland cement concrete. Technical Report SD2002-01-X, Michigan Tech Transportation Institute.

Darwin, D., Browning, J., Gong, L., Hughes, S. R., 2008. Effects of deicers on concrete deterioration. ACI Materials Journal 105 (6), 622.

Dias, W. P. S., 2000. Reduction of concrete sorptivity with age through carbonation. Cement and Concrete Research 30 (8), 1255-1261.

Duos, C., Eggers, J., 1999. Evaluation of grade 120 granulated ground blast furnace slag.

Eguez Alava, H., De Belie, N., De Schutter, G., 2014. The influence of carbonation on deicer scaling resistance of blast furnace slag concrete (bfsc). In: XIII International Conference on Durability of Building Materials and Components (XIII DBMC). pp. 138-146. 
Fagerlund, G., 1973. Critical degrees of saturation at freezing of porous and brittle materials. Ph.D. thesis, Lund University.

Fagerlund, G., 1993. The critical spacing factor: preliminary version. Report TVBM (Intern 7000-rapport).

Folagbade, S. O., 2012. Effect of fly ash and silica fume on the sorptivity of concrete. International Journal of Engineering Science and Technology 4 (9), 4238-4243.

Fournier, B., Bérubé, M., Vézina, D., 1987. Condition survey of concrete structures built with potentially alkali-reactive limestone aggregates from the québec city area (québec, canada). Special Publication 100, 1343-1364.

Gagné, R., Houehanou, E., Jolin, M., Escaffit, P., 2011. Study of the relationship between scaling resistance and sorptivity of concrete. Canadian Journal of Civil Engineering 38 (11), $1238-1248$.

Giebson, C., Seyfarth, K., Stark, J., 2010. Influence of acetate and formate-based deicers on asr in airfield concrete pavements. Cement and Concrete Research 40 (4), 537-545.

Gruyaert, E., Van den Heede, P., De Belie, N., 2013. Carbonation of slag concrete: Effect of the cement replacement level and curing on the carbonation coefficient effect of carbonation on the pore structure. Cement and Concrete Composites 35 (1), 39-48.

Gulati, S. T., Hagy, H. E., 1982. Analysis and measurement of glue-spall stresses in glass-epoxy bonds. Journal of the American Ceramic Society 65 (1), 1-5.

Harnik, A., Meier, U., Rösli, A., 1980. Combined influence of freezing and deicing salt on concretephysical aspects. In: Durability of building materials and components. ASTM International.

He, Z.-m., Long, G.-c., Xie, Y.-j., 2012. Influence of subsequent curing on water sorptivity and 
pore structure of steam-cured concrete. Journal of Central South University 19 (4), 11551162.

Jacobsen, S., Sther, D. H., Sellevold, E. J., 1997. Frost testing of high strength concrete: Frost/salt scaling at different cooling rates. Materials and Structures 30 (1), 33-42.

Kevern, J. T., Wang, K., Schaefer, V. R., 2008. Pervious concrete in severe exposures. Concrete international 30 (07), 43-49.

Klieger, P., 1957. Curing requirements for scale resistance of concrete. Highway Research Board Bulletin (150).

Knöfel, D. K., Hoffmann, D., Snethlage, R., 1987. Physico-chemical weathering reactions as a formulary for time-lapsing ageing tests. Materials and Structures 20 (2), 127-145.

Leung, H., Kim, J., Nadeem, A., Jaganathan, J., Anwar, M., 2016. Sorptivity of self-compacting concrete containing fly ash and silica fume. Construction and Building Materials 113, 369375 .

Li, Q., Zhou, Z. Y., 2012. Research on the effect of concentration and type of de-icing salt on concrete salt-scaling. In: Advanced Materials Research. Vol. 450. Trans Tech Publ, pp. $14-20$.

Li, W., Pour-Ghaz, M., Castro, J., Weiss, J., 2012. Water absorption and critical degree of saturation relating to freeze-thaw damage in concrete pavement joints. Journal of Materials in Civil Engineering 24 (3), 299-307.

Lindmark, S., 1998. Mechanisms of salt frost scaling of portland cement-bound materials: Studies and hypothesis. Lund Inst. Tech., Lund, Sweden.

Liu, Z., Hansen, W., 2015. Freezing characteristics of air-entrained concrete in the presence of deicing salt. Cement and Concrete Research 74, 10-18. 
Liu, Z., Hansen, W., 2016. Effect of hydrophobic surface treatment on freeze-thaw durability of concrete. Cement and Concrete Composites 69, 49-60.

MacInnis, C., Whiting, J. D., 1979. The frost resistance of concrete subjected to a deicing agent. Cement and Concrete Research 9 (3), 325-336.

Mata, L., 2008. Sedimentation of pervious concrete pavement systems. a dissertation. Civil Engineering, Raleigh, North Carolina.

Mata, L. A., Leming, M. L., 2012. Vertical distribution of sediments in pervious concrete pavement systems. ACI materials Journal 109 (2).

Meininger, R. C., Association, N. R. M. C., et al., 1988. No-fines pervious concrete for paving. National Ready Mixed Concrete Association.

Mwaluwinga, S., Ayano, T., Sakata, K., 1997. Influence of urea in concrete. Cement and Concrete Research 27 (5), 733-745.

Nili, M., Zaheri, M., 2011. Deicer salt-scaling resistance of non-air-entrained roller-compacted concrete pavements. Construction and Building Materials 25 (4), 1671-1676.

Nmai, C. K., 2006. Freezing and thawing. In: Significance of Tests and Properties of Concrete and Concrete-Making Materials. ASTM International.

Pigeon, M., Gagne, R., Foy, C., 1987. Critical air-void spacing factors for low water-cement ratio concretes with and without condensed silica fume. Cement and Concrete Research 17 (6), 896-906.

Pigeon, M., Marchand, J., Pleau, R., 1996. Frost resistant concrete. Construction and Building Materials 10 (5), 339-348.

Powers, T., 1945. A working hypothesis for furthr studies of frost resistance of concrete/tc power. Proc. ACI (41), 245-272. 
Sadegzadeh, M., Page, C., Vassie, P., 1993. Effects of urea on durability of reinforced concrete. Magazine of concrete research 45 (164), 179-186.

Santagata, M. C., Collepardi, M., 2000. The effect of cma deicers on concrete properties. Cement and Concrete Research 30 (9), 1389-1394.

Seo, T., Jung, Y., Kim, J., Na, O., 2016. Durability of steam-cured concrete with slag under the combined deterioration of freezing-thawing cycles and deicing chemicals. Structural Concrete.

Shi, X., Akin, M., Pan, T., Fay, L., Liu, Y., Yang, Z., 2009. Deicer impacts on pavement materials: Introduction and recent developments. The Open Civil Engineering Journal 3 (1), $16-27$.

Shi, X., Fay, L., Peterson, M. M., Berry, M., Mooney, M., 2011. A fesem/edx investigation into how continuous deicer exposure affects the chemistry of portland cement concrete. Construction and Building Materials 25 (2), 957-966.

Silva, J. M., Cramer, S. M., Anderson, M. A., Tejedor, M. I., Muñoz, J. F., 2014. Concrete microstructural responses to the interaction of natural microfines and potassium acetate based deicer. Cement and Concrete Research 55, 69-78.

Sun, Z., Scherer, G. W., 2010. Effect of air voids on salt scaling and internal freezing. Cement and Concrete Research 40 (2), 260-270.

Sutter, L., Dam, T., Peterson, K., Johnston, D., 2006a. Long-term effects of magnesium chloride and other concentrated salt solutions on pavement and structural portland cement concrete: Phase i results. Transportation Research Record 1979 (1), 60-68.

Sutter, L., Peterson, K., Touton, S., Van Dam, T., Johnston, D., 2006b. Petrographic evidence of calcium oxychloride formation in mortars exposed to magnesium chloride solution. Cement and Concrete Research 36 (8), 1533-1541. 
Turk, K., Karatas, M., Gonen, T., 2013. Effect of fly ash and silica fume on compressive strength, sorptivity and carbonation of scc. KSCE Journal of Civil Engineering 17 (1), 202-209.

Utgenannt, P., 2002. Influence of carbonation on the scaling resistance of opc concrete. In: Proc. of the Intl. Workshop on Frost Damage in Concrete, Minneapolis, MN, RILEM, Paris, France (June 1999). pp. 103-113.

Valenza, J. J., Scherer, G. W., 2007a. A review of salt scaling: I. phenomenology. Cement and Concrete Research 37 (7), 1007-1021.

Valenza, J. J., Scherer, G. W., 2007b. A review of salt scaling: Ii. mechanisms. Cement and Concrete Research 37 (7), 1022-1034.

Vancura, M., MacDonald, K., Khazanovich, L., 2011. Microscopic analysis of paste and aggregate distresses in pervious concrete in a wet, hard freeze climate. Cement and Concrete Composites 33 (10), 1080-1085.

Verbeck, G., Klieger, P., 1956. Studies of 'salt' Scaling of Concrete. Bulletin (Portland Cement Association. Research and Development Laboratories. Research Department). Portland Cement Association.

Wang, K., Nelsen, D. E., Nixon, W. A., 2006. Damaging effects of deicing chemicals on concrete materials. Cement and Concrete Composites 28 (2), 173-188.

Yang, J., Jiang, G., 2003. Experimental study on properties of pervious concrete pavement materials. Cement and Concrete Research 33 (3), 381-386.

Yang, Q., Yang, Q., Zhu, P., 2003. Scaling and corrosion resistance of steam-cured concrete. Cement and concrete research 33 (7), 1057-1061.

Yang, Z., 2011. Freezing-and-thawing durability of pervious concrete under simulated field conditions. ACI Materials Journal 108 (2). 
Yang, Z., Brown, H., Cheney, A., 2006. Influence of moisture conditions on freeze and thaw durability of portland cement pervious concrete. In: Concrete Technology Forum: Focus on Pervious Concrete. Citeseer, pp. 24-25.

Yener, E., 2015. A new frost salt scaling mechanism for concrete pavements based on brine rejection from ice layer adhered to concrete surface. Road Materials and Pavement Design $16(1), 89-100$. 